\title{
Impact of palm oil sustainability certification on village well-being and poverty in Indonesia
}

\section{Authors}

Truly Santika ${ }^{1,2,3}$, Kerrie A. Wilson ${ }^{3,4}$, Elizabeth A. Law ${ }^{3,5}$, Freya A.V. St. John ${ }^{6}$, Kimberly M. Carlson ${ }^{7,8}$, Holly Gibbs ${ }^{9}$, Courtney L. Morgans ${ }^{2,3}$, Marc Ancrenaz ${ }^{10,11}$, Erik Meijaard ${ }^{2,3,11}$ \& Matthew J. Struebig ${ }^{2}$

\section{Author affiliations}

1 Natural Resources Institute (NRI), University of Greenwich, Chatham Maritime, ME4 4TB, UK

2 Durrell Institute of Conservation and Ecology (DICE), School of Anthropology and Conservation, University of Kent, Canterbury, CT2 7NR, UK

3 Centre of Excellence for Environmental Decisions (CEED), The University of Queensland, Brisbane, Australia

4 Institute for Future Environments, Queensland University of Technology, Brisbane, Australia

5 Norwegian Institute for Nature Research (NINA), Trondheim, Norway

6 School of Natural Resources, Bangor University, Bangor, UK

7 Department of Natural Resources and Environmental Management, University of Hawaii, Honolulu, USA

8 Department of Environmental Studies, New York University, New York, USA

9 Department of Geography and Nelson Institute for Environmental Studies, University of WisconsinMadison, Madison, Wisconsin, USA

10 Kinabatangan Orang-utan Conservation Programme, Sandakan, Sabah, Malaysia

11 Borneo Futures, Brunei Darussalam 


\section{Abstract}

The Roundtable on Sustainable Palm Oil (RSPO) has emerged as the leading sustainability certification system to tackle socio-environmental issues associated with the oil palm industry. To date, the effectiveness of RSPO certification for achieving its socioeconomic objectives remains uncertain. We evaluate the impact of certification on village-level well-being across Indonesia by applying counterfactual analysis to multi-dimensional government poverty data. We compare poverty across 36,311 villages between 2000 and 2018, tracking changes from before oil palm plantations were first established to several years after plantations were certified. Certification was associated with reduced poverty in villages with primarily market-based livelihoods, but not with those in which subsistence livelihoods were dominant before switching to oil palm. We highlight the importance of baseline village livelihood systems in shaping local impacts of agricultural certification, and assert that oil palm certification in certain village contexts may require additional resources to ensure socioeconomic objectives are realised.

Oil palm cultivation has expanded tremendously in response to global demand for oils and fats over the last three decades. In 2018, the crop covers around 19 million hectares of land across the tropics, and a further 10-14 million hectares is likely needed in this region to satisfy projected global demand in $2050^{1}$. In the same year, Indonesia was the world's largest palm oil producer, supplying more than 40 million tonnes of crude palm oil, or $56 \%$ of global production ${ }^{2}$. The country's oil palm plantation area has tripled since 2000 and now covers 14 million hectares, greater than the area of $\mathrm{Java}^{2}$. Unlike other key agricultural commodities in Indonesia where farms are largely managed by smallholders, the ownership of Indonesian oil palm plantations is mostly through private corporations ${ }^{2}$ (Extended Data Figure 1).

The continuing expansion of oil palm across tropical countries has prompted fierce national and international debate ${ }^{3,4}$. While governments, industry lobbies, and companies have pointed to regional economic development and rural poverty alleviation to justify expansion of the oil palm sector ${ }^{4-6}$, numerous social and environmental costs of the industry have also been reported. These include land conflicts ${ }^{7-9}$, loss of forest ${ }^{10}$, biodiversity ${ }^{1}$ and traditional livelihoods and culture ${ }^{8,11}$, water scarcity and pollution ${ }^{12-14}$, increased flooding ${ }^{15}$, and heightened risk of fire and concomitant emissions, especially due to expansion of plantations on peatland ${ }^{16-19}$. In response to these sustainability concerns, the Roundtable on Sustainable Palm Oil (RSPO) was formed in 2004 as a multi-stakeholder participatory body that promotes more sustainable production, in part by offering a sustainability certification system ${ }^{20}$. In 2019, around 4 million hectares of oil palm plantations had been certified, equating to $20 \%$ of the global area cultivated ${ }^{21}$. Certified plantations are predominantly managed by companies $\left(90 \%{ }^{21}\right)$, although there has been pressure on the RSPO to enable greater smallholder participation ${ }^{22}$.

Despite 15 years of promoting more sustainable production practices, the effectiveness of RSPO certification in delivering social and environmental benefits to local communities in producing areas remains uncertain $^{23,24}$. Mixed impacts of certification have been reported by several studies based on counterfactual evidence comparing the performance of certified and similar non-certified concessions ${ }^{25-29}$. Few if any such 
robust evaluations have addressed social aspects beyond basic financial measures, mainly because of a lack of systematic socioeconomic data availability over large spatial and temporal scales. In addition, past social evaluations have not fully accounted for the substantial heterogeneity in baseline village conditions, such as socioeconomic and sociocultural characteristics, which may result in misleading assessments of certification outcomes ${ }^{30,31}$. Indeed, numerous sociology and development studies provide evidence for the widespread failures of development programmes based on modernization approaches and technologies applied to agriculture without adequately considering resource barriers to local communities, institutional and infrastructural constraints, and cultural values ${ }^{32,33}$ (see Supplementary Methods 1 for further discussion).

Here we evaluate the impact of RSPO certification on village well-being across the main oil palm producing regions of Indonesia: Sumatra (land area of $470,000 \mathrm{~km}^{2}$; comprising 24,259 villages or Desa), Kalimantan $\left(540,000 \mathrm{~km}^{2} ; 7,095\right.$ villages), and Papua $\left(420,000 \mathrm{~km}^{2} ; 4,957\right.$ villages) (Figure 1). Of the total 36,311 villages sampled across the three islands, we identified 2,602 villages with large-scale non-certified industrial oil palm plantations (i.e. those with at least $10 \%$ of the land area allocated to non-certified industrial plantations - the median amount across the whole region) and 794 villages with large-scale RSPO-certified plantations (i.e. $\geq 10 \%$ of the village land area allocated to RSPO-certified plantations). We define villagelevel well-being in line with the Sustainable Livelihood Approach $^{34-35}$ in terms of the socioeconomic (i.e., living conditions, infrastructure, and income support) and socioecological (i.e., security, social equity, and natural hazard prevention) capabilities of people to function in society (Supplementary Table 1 and Supplementary Methods 2). Poverty arises when these capabilities break down ${ }^{36}$. We applied rigorous counterfactual analysis based on statistical matching methods to address three research questions: (1) How have oil palm and RSPO certification expanded in Indonesia in the context of ongoing rural development and agrarian transition?; (2) What have been the impacts of oil palm and subsequent RSPO certification on village-level well-being?; and (3) What lessons can be learned from how these impacts have been generated in relation to changing land-use, livelihoods, and community composition?

To answer these questions, we tracked changes in 18 socioeconomic and socioecological well-being indicators throughout the certification process, starting before plantations were first established to several years after plantations were certified. We derived these well-being indicators together with information on primary livelihood sectors from a large longitudinal dataset of village-level censuses - Potensi Desa (PODES) or 'Village Potential' - collected by Indonesia's Bureau of Statistics (BPS) roughly every three years between 2000 and $2018^{37}$. By incorporating the latest census in 2018, we evaluated poverty change in 587 villages 511 years after the development of industrial oil palm plantations and 500 villages 5-11 years after the issuance of RSPO oil palm certificates, thereby providing insights on how impacts manifest as land is first converted to oil palm and then later certified. This nuanced assessment of how the characteristics of the oil palm industry evolve over time in a particular location is rarely addressed in other studies.

\section{Regional variation in oil palm and RSPO certification}

The pace of development in Indonesia's oil palm industry has been unevenly distributed. Most development has occurred in Sumatra (now 81,200 $\mathrm{km}^{2}$ ) (Figure 1a and Extended Data Figure 2), with the island being the oldest centre of oil palm production. The industry then expanded eastward across the major regions of 
Kalimantan $\left(53,300 \mathrm{~km}^{2}\right)$ (Figure $1 \mathrm{~b}$ and Extended Data Figure 3) and more recently Papua $\left(2,100 \mathrm{~km}^{2}\right)$ (Figure $1 \mathrm{c}$ and Extended Data Figure 4). In Sumatra, the extent of oil palm plantations nearly doubled since 2000, while Kalimantan and Papua experienced a near-fourfold increase in production area over the same period (Figure 1 and Extended Data Figures 2-4). The three regions can be viewed as being at advanced, intermediate, and early stages of oil palm development, respectively. These distinct development stages are broadly reflective of the expansion of the crop pan-tropically. For example, Malaysia and Thailand are also at an advanced stage of oil palm development, while the industry is still in its infancy across Latin America ${ }^{1}$.

The developmental context in Sumatra, Kalimantan, and Papua is also reflected in patterns of plantation ownership. In Indonesia, cultivation of more than 25 hectares of croplands by a single farmer or entity requires a concession permit (Izin Usaha Perkebunan or IUP), issued by the head of a regency, mayor, or governor (Ministerial Decree No. 98/Permentan/2013). In Sumatra, between 2000 and 2018, oil palm plantations (i.e. planted oil palm) are largely dominated by non-concession holders (64\% for NCONC), which mostly represent smallholders $(68 \%)$ and medium to large-scale industrial plantations with unknown concession status (32\%, Supplementary Figure 1). There, the rate of plantation expansion outside of known concession boundaries (NCONC) has exceeded that within large-scale concessions, i.e., non-certified industrial oil palm plantations (CONC) and RSPO-certified industrial plantations (CERT) (Figure 1a and Extended Data Figure 2). Conversely, over the same period, large-scale industrial plantations have dominated oil palm expansion in Kalimantan and Papua (66\% for CONC and CERT combined in Kalimantan and $69 \%$ for CONC in Papua) (Figures 1b-c and Extended Data Figures 3-4).

Analysis of the primary land-use or cover in villages between 2000 and 2018 indicates that those with $\geq 10 \%$ of village land area under industrial oil palm plantation in 2018 but $<10 \%$ of area in industrial oil palm in 2000 experienced a typical sequence of land-use prior to oil palm development (Figure $2 \mathrm{a}$ and Extended Data Figure 5). In 2000, 23\% of these villages were primarily forested, and timber was frequently commercially harvested ${ }^{38}$ resulting in degraded forest stands. These villages were then transformed to agricultural lands, mixed plantations and shrubs, then to (non-certified) industrial oil palm plantations. Some of the existing (non-certified) oil palm plantations were later granted RSPO certification. Conversion from forest to certified plantations had rarely occurred (Extended Data Figure 5).

Each of these land-uses is associated with specific livelihood systems and community composition (i.e. ethnicity) within village boundaries defined in the PODES census. Based on data from 2000, 2005, 2011 and 2018 across villages in Sumatra, Kalimantan, and Papua, those villages with high natural forest cover were typically dominated by subsistence-based communities (i.e. subsistence farming, fishing, and forest product gathering, in complex agroforestry systems and with weak exposure to the market economy) and comprised a high proportion of people belonging to ethnic groups native to the island (Figure 3). Villages with agricultural lands, mixed plantations and shrubs as the primary land-use or cover typically had a larger proportion of agricultural plantation communities, mainly polyculture smallholders (with some exposure to the market system ${ }^{30,31}$ ), and larger proportions of ethnic groups from other islands who are likely recent migrants (Figure 3). Villages with non-certified oil palm plantations as the primary land-use had substantially larger proportions of their community working in plantation agriculture, where monoculture oil palm was the norm (with stronger market-driven orientation ${ }^{30,31}$ ), and large proportions of migrants (Figure 3). In villages dominated by the RSPO-certified plantations, monoculture oil palm plantation communities and migrants 
were also prominent (Figure 3). Thus, primary land-use transition is likely to have significant social implications for village communities through changes in livelihood systems and social structure (Figure 2b). These transitions are not necessarily unidirectional; for example, if oil palm fails, the system can return to mixed plantations and shrubs. We do not consider such transitions away from oil palm here.

Rural development has traditionally been, and often still is, pushed by governments to achieve development targets measured mostly through economic material attainment (i.e. large industry and manufacturing, and the market-based economy), rather than on improving underlying human-capital (i.e. capability and adaptation of technology within local culture, knowledge, and outlook) ${ }^{39}$. Relying heavily on industry and market-driven systems to meet development targets can result in immense social costs to rural communities because doing so allows little opportunity and time for people to adapt ${ }^{40}$. Kalimantan exemplifies this type of rapid development over the last two decades, as evident from the high prevalence $(52 \%)$ of villages experiencing drastic change in dominant land-use from high natural forest cover to primarily oil palm monoculture (41\%) and from forest to certified plantations (11\%) between 2000 and 2018 (Figure 4a). Comparatively, in Sumatra and Papua $88 \%$ of villages with industrial oil palm plantations or certified plantations as the primary land-use in 2018 were already dominated by industrial monoculture plantations in 2000 (Figure 4a).

Land-use changes in villages shifting to industrial oil palm plantations (Figure 4a) reflect an underlying pattern of oil palm development and expansion in Indonesia. Papua represents an early stage of the oil palm industry, where plantation development is mainly confined within former or current transmigration villages and operated mostly by large oil palm companies ${ }^{41}$ (Figure 4a and Extended Data Figure 4). Kalimantan represents the intermediate stage of industrial oil palm development, where company plantations have expanded rapidly into villages in forested landscapes that are dominated by subsistence-based communities (Figure 4a and Extended Data Figure 3). These expansions lead to an influx of workers and stimulate spontaneous migrations to the newly opened oil palm areas ${ }^{42}$. At this intermediate stage, oil palm smallholdings also expand, but the expansion rate is slower than the industrial-scale plantations (Extended Data Figure 3). Sumatra represents the advanced stage of oil palm development, where the number of smallholders, who either migrated in the preceding intermediate stage or more recently, continues to grow and expand exceeding the rate of expansion of the company plantations (Figure 4a and Extended Data Figure 2). This in turn creates a complex company and smallholder relationship ${ }^{43,44}$. The intermediate stage of oil palm development that occurred over the last two decades in Kalimantan (Figure 4b) generated swift radical transformation in village life systems in many parts of the island which often led to conflict ${ }^{30,31}$. Based on the PODES data, during this transformation period, social conflicts were $22 \%$ more prevalent in villages with industrial oil palm plantation development compared to those without, and such conflicts were more prevalent in Kalimantan than in Sumatra and Papua (Supplementary Figure 2).

\section{Impacts of oil palm and certification on well-being}

We assessed the impact of RSPO certification on village well-being by comparing the change in equallyweighted indicators in villages with plantations certified for 5-11 years to those with non-certified plantations over the same time interval, while ensuring similar baseline characteristics in both types of villages 
(Supplementary Table 2). Results aggregated across the three Indonesian islands indicate that the impact of certification varied by baseline village primary livelihood sector prior to certification. Compared to similar villages with non-certified plantations, those with certified plantations experienced an overall reduction in well-being. Combined measures of socioeconomic and socioecological well-being declined by $11 \%$ on average in communities that relied on subsistence-based livelihoods prior to certification compared to noncertified villages (Figure $5 b$ ). This decline was driven mainly by the fall in socioecological indicators, predominantly via a significant increase in the prevalence of conflicts, low wage agricultural labourers, and water and air pollution (Extended Data Figure 6). Conversely, the overall well-being marginally improved by $4 \%$ in communities that relied on market-based livelihoods before certification (i.e. polyculture plantations or monoculture non-certified oil palm plantations) (Figure $5 b$ ).

We found that expansion of oil palm into new areas resulted in similar well-being change patterns as certification (Figure 5). Villages that relied on subsistence livelihoods prior to oil palm development experienced an overall reduction in well-being by $16 \%$ on average after $5-11$ years compared to the counterfactual of no oil palm development across all three islands (Figure 5a). The reduction in overall wellbeing was driven by the decline in both socioeconomic and socioecological components, primarily the reduction in electricity access, adequate sanitation and cooking energy, and secondary schools, as well as the increased prevalence of conflicts, low wage agricultural labourers, water pollution, and floods (Extended Data Figure 7). Villages with oil palm plantations where the majority of communities had relied on marketbased livelihoods before oil palm development (i.e. polyculture plantations outside concessions) also experienced reduced overall well-being by $9 \%$ compared to the counterfactual, but the impact on socioeconomic well-being was marginally positive (improved by $3 \%$ on average) (Figure $5 a$ ). Thus, the immediate impact of oil palm development in the production villages with market-based livelihoods appears to be better than that observed in villages dominated by subsistence-based livelihoods; socioecological losses appear to be partially compensated by socioeconomic gains.

Because in Kalimantan certification has taken place disproportionately in areas where village communities were still dependent on subsistence-based livelihoods (Figure 4a), the impact of certification on well-being in this region has been negative overall (Extended Data Figure 8b). On the other hand, the impact of certification in Sumatra has been positive overall (albeit marginal) (Extended Data Figure 8b), mitigating negative impacts on socioecological well-being indicators associated with non-certified oil palm. Unlike in Kalimantan, a higher proportion of plantations in Sumatra has been certified in villages where market-based communities are more dominant (Figure 4a). This demonstrates that failing to account for the influence of baseline livelihoods on the potential benefit flows of certification could lead to misplaced inferences from the impact evaluation.

\section{Well-being change through oil palm and certification processes}

Trends in the change of village well-being through the process of oil palm expansion and certification provide a more comprehensive picture of the underlying mechanisms driving the impact (Figure 6). In villages with subsistence livelihoods, socioeconomic improvements in oil palm villages were slightly slower to accumulate than those in non-oil palm villages, but this trend improved marginally following RSPO certification. 
Socioecological well-being in these subsistence-based villages worsened following oil palm development, a trend that continued after certification (Figure 6a). This pattern was widespread in Kalimantan (Extended Data Figure 8b), particularly in lowland peatland areas near the coast, which have experienced most certification efforts to date. Conversely, improvements to socioeconomic well-being experienced in Indonesia were greater where oil palm, and later certification, was established in villages with market-based livelihoods. Measures of socioecological well-being in these market-based villages deteriorated following expansion of the oil palm sector, but later improved following certification, albeit marginally (Figure 6b). Thus, socioecological well-being in market-based villages with certification at the current state is indeed worse than without oil palm development two decades ago, but slightly better than the counterfactual of no certification a decade ago. This pattern is prevalent in Sumatra (Extended Data Figure 8b). Thus, focusing merely on the immediate effect of certification could lead to missed crucial information and insights about what happened in village communities before certification even existed.

The overall negative association between certification in subsistence-based villages and outcome variables (compared to a counterfactual of non-certified plantations) reflects not an adverse outcome from certification itself, but the overwhelming social impact of large-scale industrial oil palm plantations on the well-being of communities who still depend on forest and associated natural capital, which indeed may be difficult to compensate even within a sound regulatory certification framework. In Indonesia, the size of individual RSPO-certified plantations is significantly larger than non-certified industrial plantations (i.e. median plantations area of 8,000 and 2,500 ha for certified and non-certified plantations, respectively, based on data from Sumatra and Kalimantan) (Extended Data Figure 9a). A certified plantation company typically manages $10 \%$ of village land areas across three adjoining villages (Extended Data Figure $9 \mathrm{~b}$ ). Comparatively, one non-certified industrial plantation company typically manages only $3 \%$ of a village land area (Extended Data Figure 9b). These differences are likely related to the high costs and technical capacities required for the RSPO membership participation and further for certification, which only large companies can bear ${ }^{45}$. This implies that there is likely an immense pressure being placed on the environment (i.e. soil, air, and water quality and quantity) by certified plantations and the associated mills relative to non-certified ones simply due to the total plantation size and production scale across broader landscapes comprising several neighbouring villages ${ }^{29,46,47}$. Further, the scale of certified plantations compared to the non-certified ones indicates that the certified companies tend to have a much larger influence over village land-use, environment, and economy compared to those managing non-certified plantations. This could create more unbalanced social power structures in certified plantations in which traditional communities and their local governance have a relatively limited say over what happens on their land ${ }^{40}$. Thus, although here we have carefully controlled for the total size of all industrial plantations at village-level in order to fairly compare certified versus non-certified plantation villages (Supplementary Table 2), the effect observed in certified plantation villages is likely to be masked by the overall plantation impact over larger jurisdictional scales. This suggests that the amount of land under cultivation by a single entity has significant implications for the extent to which the perceived benefits of certification translate to improvements in community well-being. Our findings for the subsistence villages also imply that similar negative implications for community well-being recorded for certified plantations will likely occur for similarly extensive non-certified plantations. 


\section{Conclusion}

The effectiveness of RSPO certification in upholding social and environmental standards within the oil palm industry has been called into question ${ }^{23,24}$. Using a comprehensive counterfactual assessment of longitudinal census data from Indonesia, the world's leading palm oil producing country, we show that the association between RSPO certification and village-level well-being varies by location and baseline village livelihood conditions before certification was initiated. While marginal positive impacts were observed in villages where most communities relied on market-based livelihoods prior to certification, RSPO certification was associated with largely negative outcomes in rural villages oriented toward subsistence agriculture. The latter was likely because certified plantations under single companies tend to be substantially larger than non-certified plantations and cover several neighbouring villages, therefore the social and environmental externalities are difficult to remediate.

A potential caveat to these findings is that our analysis specifically focuses on the direct impact of certification and oil palm development on villages with oil palm production. We did not assess the possibility that impacts of oil palm or certification may be spatially autocorrelated or could lead to spillover effects ${ }^{29}$ over a broader extent beyond the production areas, e.g. in neighbouring villages without the oil palm industry. If this kind of spill-over mechanism exists, the oil palm industry could even generate a wider welfare gap among villages at broader jurisdictional scales (e.g. regency level) by accruing socioeconomic and socioecological costs to rural subsistence-based villages with the oil palm industry while accumulating most of welfare benefits to suburban market-based villages. We also did not assess how different categories of oil palm production (i.e. different types of smallholders such as independent versus tied smallholders, and noncertified plantations) within villages classified as certified may have contributed to well-being, since data are not currently resolved to these levels. Our evaluation focuses on localised impacts collectively over large spatial scales but does not incorporate national-level socioeconomic benefits obtained through taxation of palm oil production. Additional indirect impacts of the RSPO on government sustainability policies and practices for oil palm, such as the development of the national Indonesian Sustainable Palm Oil (ISPO) certification standard, are also so far immeasurable. These potential caveats notwithstanding, our appraisal has established important baseline information for further impacts to be monitored as the RSPO standard develops.

Our finding that oil palm development has failed to improve well-being in rural subsistence villages calls for careful consideration by key decision-makers of unintended indirect impacts of pushing large-scale industrial oil palm into frontier forest areas where local communities still rely heavily on environmental services. We feel that it is important for governments in oil palm producing countries to consider limiting the extent of industrial-scale plantations that can be developed until more positive impacts on community wellbeing can be guaranteed. This not only applies to existing rural areas in Indonesia, but also to other world regions such as Central and West Africa and Latin America where the oil palm industry is expanding. RSPO's recent commitment to zero-deforestation and avoidance of peatlands ${ }^{20}$ as well as Indonesia's moratorium on concession allocation in primary forests and on peatlands should help steer the industry towards already developed agricultural lands with primarily market-based livelihoods. 
Given that challenges associated with the oil palm industry vary by village baseline primary livelihoods, specific targeting of these livelihoods in certification criteria, as well as ensuring compliance with existing criteria with respect to livelihoods and communities, is recommended. In rural subsistence villages where industrial plantations have been established, we recommend further scrutiny by certification assessors on stringent compliance of social and environmental measures by companies - not only on zero deforestation, but also on preventing and mitigating pollution and water scarcity, and the avoidance of plantation expansion without Free, Prior and Informed Consent, as defined in the RSPO Principles and Criteria. In market-based villages, in addition to the aforementioned activities, the RSPO should continue focusing on supporting smallholder participation and encouraging company-smallholder cooperation. The RSPO jurisdictional approach to certification ${ }^{22}$ has recently been piloted in several former transmigration villages, e.g. in Seruyan Regency in Central Kalimantan, and holds great promise for these market-based villages in supporting "shared responsibilities" and cooperation across multiple stakeholders to work together towards improving sustainability at village jurisdictional levels.

\section{Methods}

\section{Data}

\section{Oil palm plantations and certification and land cover}

Throughout, the term 'plantation' refers to the area planted with oil palm, and 'concession' the area where a land permit has been granted to develop oil palm, but where the land has not necessarily been planted. Therefore, a concession owned by a company can either cover a larger area than the plantation if the concession is not fully developed, or cover roughly the same area as the plantation if the concession is entirely planted with palm. A plantation can also be developed outside a company concession, either as a smallholding or illegally ${ }^{43}$.

We used plantation maps of every three years between 1997 and 2014, described in Santika et al. ${ }^{30,31}$, but extended to 2018 and to cover Sumatra and Papua. These include medium and large-scale industrial plantations (25-100 ha and >100 ha, respectively) and smallholder plots ( $<25 \mathrm{ha}$ ). We also used spatial data on oil palm concessions and RSPO member plantations (certified and non-certified) across Indonesia described in Carlson et al. ${ }^{26}$. The data contain concessions certified by 2015 , which we updated to include those certified or proposed for certification between 2015 and 2018 through web searching of records of RSPO-certified mills and supply estates. Annual forest cover 2001-2018 was estimated by overlaying the extent of natural forest (primary and secondary) across Indonesia in 2000 provided by Margono et al. ${ }^{48}$ and the locations of annual deforestation derived from the Global Forest Change (GFC) website $^{49}$.

Combining information on forest cover, plantations, concession boundaries, and RSPO member plantations (certified and non-certified), we estimated the distributions of natural forest and three plantation ownership types (Figure 1): (1) RSPO-certified industrial plantations (CERT); (2) non-certified plantations within concession boundaries (which mainly includes the non-certified RSPO-member plantations and non- 
RSPO industrial-scale plantations) (CONC); (3) non-certified plantations outside concessions (largely includes independent smallholders ( $<25 \mathrm{ha}$ ) and small proportion of medium to large plantations ( $\geq 25 \mathrm{ha}$ ) with unknown concession permit) (NCONC) (Supplementary Figure 1). Areas outside natural forest and oil palm plantations mainly comprise agricultural lands, mixed plantations (e.g. rubber, coffee), shrubs, settlements, and infrastructure (Figure 1). Our impact evaluation focussed specifically on oil palm plantations within concession boundaries (CONC) and RSPO-certified plantations (CERT), and excluded those outside known concession permits (NCONC). Detailed methodologies for generating these spatial data are provided in Supplementary Methods 3.

\section{Village primary livelihoods}

Primary livelihood sectors across the villages in Sumatra, Kalimantan and Papua were derived from the Potensi Desa (PODES) census, collected from village heads by the Central Bureau of Statistics (BPS) of Indonesia roughly every three years between 2000 and $2018^{37}$. These data contain information on the socioeconomic and development status for each village administrative boundary. Three major livelihoods were identified via PODES: (1) subsistence production including small-scale farming for staple foods, fishing, and the collection of forest products, (2) agricultural plantations including both polyculture and monoculture plantations, and (3) other sectors including horticulture, aquaculture, livestock, agricultural services, and nonagricultural activities (Figure 3a). In the analysis, market-based livelihoods includes agricultural plantations (polyculture and monoculture) and other sectors ${ }^{30,31}$.

\section{Indicators of well-being}

Village-level PODES data from 2000, 2003, 2005, 2008, 2011, 2014, and 2018 were used as proxy indicators for two aspects of village well-being, i.e. socioeconomic and socioecological (Santika et al. 2019a,b; Supplementary Table 1). The socioeconomic aspect includes living conditions, infrastructure, and income support, and the socioecological aspect includes security, social equity, and natural hazard prevention ${ }^{50,51}$. PODES provides the most comprehensive public information on land-use, population demographics, and village infrastructure available in Indonesia, and has been used extensively to inform government policy and development studies ${ }^{52,53}$. The choice of indicators and directionality of the effects on well-being listed in Supplementary Table 1 correspond to existing methodologies used to assess poverty and livelihoods ${ }^{30,31}$, such as the Sustainable Livelihood Approach $\left(S\left\llcorner A^{34}\right)\right.$, the Multidimensional Poverty Index $\left(\mathrm{MPI}^{54}\right)$, and the Nested Spheres of Poverty $\left(\mathrm{NESP}^{55}\right)$. Our categorization of indicators closely follows that advocated by the SLA ${ }^{34,35}$, in which the socioeconomic grouping encapsulates the human (basic), physical, and financial dimensions of well-being, and the socioecological encapsulates social and natural dimensions (Supplementary Methods 2).

\section{Analysis of land-use and livelihood change at village level}

To capture the patterns of transition in primary land-use towards RSPO-certified plantations at village level, we classified each village into one of four categories based on the dominant land cover: (1) natural forest; (2) agricultural lands, mixed plantations and shrubs; (3) non-certified industrial oil palm plantations; and (4) 
RSPO-certified industrial oil palm plantations. Following a classification tree (Supplementary Figure 3), we first sorted villages based on the percentage of natural forest cover (primary and secondary forest): (1) villages with $\geq 50 \%$ of the land area allocated to natural forest (hereafter termed as 'villages with primarily natural forest'); and (2) the remaining villages ( $>50 \%$ of the land areas allocated to agriculture, plantations, shrubs and other land-uses). We then divided the second category based on the extent of industrial-scale plantations: (1) villages with $\geq 10 \%$ of the land area allocated to planted industrial oil palm concession (hereafter termed as 'oil palm plantation villages'); and (2) those otherwise (hereafter termed as 'villages with primarily agricultural lands, mixed plantations, and shrubs'). Finally, we divided the 'oil palm villages' based on the extent of certified plantations: (1) villages with $\geq 10 \%$ of the land area allocated to planted certified oil palm concession (hereafter termed as 'RSPO-certified plantation villages'); and (2) those otherwise (hereafter termed as 'Non-certified plantation villages'). We used the $10 \%$ threshold for defining the oil palm plantation villages based on the median proportion of village land area allocated to industrial oil palm plantations across Sumatra, Kalimantan and Papua (Supplementary Figure 4c, left plot). We also used the $10 \%$ threshold for defining RSPO-certified plantation villages for the same reason across Sumatra and Kalimantan, noting there were insufficient certified plantations in Papua to evaluate impact there (Supplementary Figure 4d).

We tracked the change in village primary land-use that leads to predominantly industrial-scale oil palm plantations and RSPO certification between 2000 and 2018 across villages in Sumatra, Kalimantan and Papua (see Supplementary Table 3 for the number of villages for assessed). To obtain an approximation of the latent structure of land-use change, we used the observed village primary land-use in 2000, 2005, 2011, and 2018 (Supplementary Figure 3).

To determine the livelihood dynamics associated with land-use change, we quantified the likelihood of a village falling within the three livelihood classes (i.e. subsistence livelihoods; agricultural plantations; and other sectors) for each primary land-use category (i.e. natural forest; agricultural lands, mixed plantations and shrubs; non-certified industrial oil palm plantations; and RSPO-certified industrial oil palm plantations) in 2000, 2005, 2011 and 2018 (Figure 3a). To provide a nuanced understanding of the scale of plantations (either small to medium landholders, or large-scale industrial plantations) associated with each livelihood class, we calculated the average proportion of village plantations located within the boundaries of oil palm concession. Larger proportions indicate a higher likelihood of the primary livelihood sector and economy in a village being driven by large-scale monoculture oil palm plantations compared to small and medium-scale plantations (Figure 3a). To assess the change in community composition and migration in the village, we also quantified the likelihood of each village falling within three broad ethnic identities or classes (i.e. all people identify as belonging to ethnic groups native to the island in question; majority belong to ethnic groups native to the island; or majority belong to ethnic groups from outside the island) for each village primary land-use category over the same period (Figure $3 b$ ).

\section{Analysis of impact evaluation}

\section{Spatial and temporal unit of analysis}


We conducted two separate impact evaluation analyses on poverty: $(A)$ the impact of industrial oil palm plantations, and (B) impact of RSPO certification. For both analyses, we used the village administrative boundary as the spatial unit of analysis, which was defined in the BPS census in $2014^{56}$. The impact of oil palm on the change in village well-being (analysis A) was determined 5-11 years after plantation development to allow for time delays in the accrual of well-being benefits, e.g. profits from harvesting ${ }^{57}$ and infrastructure development ${ }^{58}$, as well as manifestation of social and environmental impacts, e.g. conflicts ${ }^{7-9}$, influx of workers ${ }^{5}$, and pollution ${ }^{12}$. The impact of certification on the change in village well-being (analysis B) was also determined 5-11 years after certification. To do so, we compared the change in indicators between paired PODES censuses, i.e. 2000 and 2005 (5 years), 2000 and 2008 (8 years), 2000 and 2011 (11 years). The oil palm impact analysis covered 11 paired census data, and the analysis of certification impact covered three (Supplementary Table 4).

\section{Units for treatment and counterfactual (control)}

When evaluating the impact of industrial oil palm plantation development (analysis A), the units receiving treatment were villages with $\geq 10 \%$ of their land area allocated to industrial oil palm plantation over the full study periods, but not within the previous five years. We used the $10 \%$ threshold based on the approximate median proportion of village land area allocated to industrial oil palm plantations across Sumatra, Kalimantan and Papua (Supplementary Figure 4c, left plot). As the unit for counterfactuals or controls, we used villages where none of the land areas were allocated to industrial oil palm plantations over the range of the analysis period, nor in the five years prior to that (see conceptual diagram outlining the definitions in Supplementary Figure 5).

For the certification impact analysis (analysis B), the units receiving treatment were oil palm villages (i.e. villages with $\geq 10 \%$ of the land areas allocated to industrial oil palm plantations) where $\geq 10 \%$ of the land area were assigned to certified plantations over the full analysis periods, but no certified plantations were detected within the previous three years. Again the $10 \%$ threshold for certification was based on the approximate median proportion of village land area allocated to certified plantations across Sumatra and Kalimantan (excluding Papua as few plantations were certified) (Supplementary Figure 4d). For the counterfactual, we used oil palm villages with the same proportion of their areas allocated to industrial oil palm plantations as that in the treated villages and where none of the plantations were certified over the analysis period, nor in the previous three years (Supplementary Figure 6).

\section{Analytical framework}

For each of two impact evaluations (oil palm and certification, separately) we followed four steps. First, for each island and time period (or paired PODES censuses) we generated the propensity score or likelihood for the spatial assignment of industrial oil palm plantations or certification based on a given set of biophysical and socioeconomic variables. Second, we applied a binary matching method for each island and time period to select control villages with similar baseline characteristics as those in the treated villages through nearest neighbour matching or search of propensity score and exact matching of key categorical variables. Third, we applied difference-in-difference regression to the matched dataset. Fourth, we conducted diagnostic tests 
and sensitivity analyses to verify the robustness of our estimates against modelling specification and approach. Detailed steps for conducting each impact evaluation are provided in Supplementary Methods 4.

\section{Step 1: Generating propensity scores}

We generated the propensity scores for each island (i.e. Sumatra, Kalimantan and Papua for analysis A; Sumatra and Kalimantan for analysis B) and time period by employing a non-parametric generalized boosted regression model (GBM) for binary outcomes implemented in the R-package gbm $^{59}$. The GBM model allows flexibility in fitting non-linear response curves for predicting treatment assignment and can incorporate a large number of covariates without negatively affecting model prediction. We controlled for potentially confounding variables in each impact assessment in terms of both selections of villages for treatment and the outcome being measured (Supplementary Table 2). To achieve this, we included variables representing: (a) socio-political factors, (b) accessibility, (c) agricultural productivity, and (d) baseline village socioeconomic conditions. This selection is based on previous analyses of oil palm expansion without certification in Kalimantan ${ }^{30,31}$.

\section{Step 2: Applying the matching method}

For analysis A, we employed a binary matching method $^{60}$ to select a set of control villages in which oil palm plantations had not been developed and that exhibited the same baseline characteristics as villages where plantations had been established. For analysis B, we applied the matching to select a set of control oil palm villages without certification and which exhibited the same baseline characteristics as oil palm villages where certification had been granted. Both analyses $A$ and $B$ were performed based on nearest-neighbour matching of propensity scores using all variables described in Supplementary Table 2 and exact matching of the categorical baseline variables (i.e. KBPT, LZON, FORB, SOIL, and $L V H D$ ). We applied a 0.25 calliper width of each propensity score standard deviation in the nearest neighbour approach, as this width was previously shown to be optimal ${ }^{61}$. Matching algorithms were implemented separately for each of the 18 indicators of well-being (Supplementary Table 1) in the R-package Matching ${ }^{62}$.

For analysis A, the matching method was applied for each of the indicators (Supplementary Table 1), three islands (Sumatra, Kalimantan, and Papua), and 11 time periods (Supplementary Table 4), separately. We observed substantial improvement in the extent of overlapping areas of all continuous variables (ELEV, SLOP, CITY, POPB, SDRY, SWET, TRNS, and VILA) between villages with and without industrial oil palm plantation development in the matched dataset compared to the original (unmatched) dataset (Supplementary Figure 7 and Supplementary Table 5; aggregated across 18 indicators of well-being, three islands, and 11 time periods). For analysis $B$, the matching method was applied for each indicator (Supplementary Table 1), two islands (Sumatra and Kalimantan), and three time periods (Supplementary Table 4), separately. Again, we observed substantial improvement in the extent of overlapping areas of all continuous variables (ELEV, SLOP, CITY, POPB, SDRY, SWET, TRNS, VILA, and OPV) in the oil palm villages with and without certification after matching was performed (Supplementary Figure 8 and Supplementary Table 6; aggregated across 18 indicators of well-being, two islands, and three time periods).

\section{Step 3: Difference-in-difference regression}


For each indicator of well-being $k$, we first calculated the change or difference over 5-11 years (i.e. between two PODES censuses), and then multiplied the change by $w_{k}$ (Supplementary Table 1 ). The value of $w_{k}$ represents the directional effect of the change in indicator $k$ that defines improvement in well-being, i.e. $w_{k}=1$ if positive change (or an increase) in indicator $k$ represents improvement in well-being (e.g. proportion of household with electricity) and $w_{k}=-1$ if negative change (or a reduction) in indicator $k$ represents improvement in well-being (e.g. prevalence of malnutrition, frequency of conflicts). We then divided the value by the maximum of the absolute change of well-being across all villages and time periods within each island. Thus, we obtained values that ranged roughly between -1 and 1 , where -1 and 1 denote the largest reduction and improvement in the well-being indicator across all study villages in each island, respectively, and 0 denotes no change in the well-being indicator after 5-11 years. We applied this transformation approach mainly to preserve information about the directionality of change in well-being (i.e. relative improvement or reduction) over time, and to allow comparable measures across different indicators.

The impact of industrial oil palm plantations (analysis A) on village-level well-being was estimated by comparing the change in well-being indicators in villages with oil palm plantation development with the change in control villages without plantations, i.e. the difference in the differences in well-being indicators between two PODES censuses between oil palm and non oil palm villages, for each island and village livelihood type. The impact of oil palm certification (analysis B) on village-level well-being was estimated by comparing the change in well-being indicators in oil palm villages with certified plantations with the change in control oil palm villages without certification, i.e. the difference in the differences in well-being indicators between two PODES censuses between certified and non certified oil palm villages, for each island and village livelihood type. The number of villages assessed for both analyses is shown in Supplementary Table 3. The overall effect (and confidence interval) of industrial oil palm plantations or RSPO certification on improving each aspect of well-being for each island and livelihood type was obtained by pooling estimates across all indicators belonging to the same group of well-being aspect (Supplementary Table 1).

\section{Step 4: Diagnostic tests and sensitivity analyses}

To assess the quality of our matched dataset we examined the change in the distributions of variables potentially affecting the assignments of industrial oil palm plantation villages (for analysis A) or certified plantation villages (for analysis $B$ ) before and after matching procedure. We achieved bias reduction of 92.998.6\% for covariates matched in analysis A (Supplementary Table 5), and 81.7-98.3\% for analysis B (Supplementary Table 6), indicating that samples were strongly matched in both assessments.

We conducted a series of sensitivity analyses to verify the robustness of our estimates against modelling specification and approach. This included: (1) generating propensity scores separately within island, time period, and livelihood type, in contrast to our main approach of generating the scores within island and time period; and (2) applying different categorization of well-being indicators by shifting indicators security and social equity from socioecological to socioeconomic aspects. The alternative method for generating the propensity scores yielded similar conclusions about the impact of oil palm development (analysis A) and certification (analysis B) on well-being as those generated by the main approach (Supplementary Figure 9). The alternative grouping of indicators under the socioeconomic and socioecological aspects resulted in worsened performance of industrial oil palm development (analysis A) 
and certification (analysis B) on village well-being than those obtained from the main approach (Supplementary Figure 10). This is because the negative impact of oil palm development or certification on key indicators of social well-being (i.e. prevalence of conflicts and low wage agricultural labourers) tended to be less pronounced than the negative impact on natural hazard prevalence, but worse than the impact on living conditions, infrastructure provision, and income support (Extended Data Figures 6-7).

\section{Acknowledgements}

We thank three anonymous reviewers for valuable feedback, and the Roundtable on Sustainable Palm Oil for sharing concession data. This study was supported by the Arcus Foundation, the Australian Research Council Centre of Excellence for Environmental Decisions Discovery program, the Darwin Initiative, and University of Kent Global Challenges Impact Fund. M. Struebig was supported by a Leverhulme Trust Research Leadership Award. K. Carlson acknowledges funding from the NASA New (Early Career) Investigator Program in Earth Science (NNX16AI20G) and the US Department of Agriculture's National Institute of Food and Agriculture, including Hatch Project HAW01136-H and McIntire Stennis Project HAW01146-M, managed by the College of Tropical Agriculture and Human Resources. St. John has received funding from the European Research Council (ERC) under the European Union's Horizon 2020 grant agreement No. 755956 (CONHUB).

\section{Competing interests}

The authors declare no competing interest for this work.

\section{Author contributions}

T.S., M.J.S., E.M. and K.A.W. conceived the idea. T.S. designed the study, processed the socioeconomic and environmental data, and performed the analyses. M.J.S. coordinated the project, and obtained funding with E.M. and K.A.W. K.M.C. and H.G. provided the concessions data. E.A.L., F.A.V.S.J., C.L.M. and M.A. assisted with the socioeconomic and environmental datasets. T.S. and M.J.S. led the manuscript, which was critically reviewed and edited by the other authors. All authors contributed to the interpretation of analyses and gave final approval for publication.

\section{Data availability}

Key datasets used to conduct our analysis are publicly available from the cited references (forest cover data available from https://glad.umd.edu/dataset/primary-forest-cover-loss-indonesia-2000-2012 and https://earthenginepartners.appspot.com/science-2013-global-forest/download_v1.5.html and socioeconomic data from https://mikrodata.bps.go.id/mikrodata/index.php/catalog/PODES). 


\section{References}

1. Meijaard, E., Garcia-Ulloa, J., Sheil, D., Carlson, K., Wich, S.A. et al. (2018) Oil Palm and Biodiversity - A Situation Analysis. IUCN Oil Palm Task Force, Gland, Switzerland.

2. Directorate General of Estate Crops Indonesia (2019) Tree Crop Estate Statistics of Indonesia 20172019. Jakarta.

3. Sayer, J., Ghazoul, J., Nelson, P. \& Boedhihartono, A.K. (2012) Oil palm expansion transforms tropical landscapes and livelihoods. Global Food Security 1, 114-119.

4. Susanti, A. \& Maryudi, A. (2016) Development narratives, notions of forest crisis, and boom of oil palm plantations in Indonesia. Forest Policy and Economics 73, 130-139.

5. Potter, L. (2012) New transmigration 'paradigm' in Indonesia: Examples from Kalimantan. Asia Pacific Viewpoint 53, 272-287.

6. Pye, O. (2019) Commodifying sustainability: Development, nature and politics in the palm oil industry. World Development 121, 218-228.

7. McCarthy, J.F. (2010) Processes of inclusion and adverse incorporation: oil palm and agrarian change in Sumatra, Indonesia. The Journal of Peasant Studies 37, 821-850.

8. Colchester, M. (2011) Palm Oil and Indigenous Peoples in South East Asia. Forest Peoples Programme.

9. Li, T.M. (2017) Intergenerational displacement in Indonesia's oil palm plantation zone. The Journal of Peasant Studies 44, 1158-1176.

10. Gaveau, D.L., Locatelli, B., Salim, M.A., Yaen, H., Pacheco, P. et al. (2019) Rise and fall of forest loss and industrial plantations in Borneo (2000-2017). Conservation Letters 12, e12622.

11. White, B.N.F. (2012) Gendered experiences of dispossession: Oil palm expansion in a Dayak Hibun community in West Kalimantan. The Journal of Peasant Studies 39, 995-1016.

12. Carlson, K.M., Curran, L.M., Ponette-González, A.G., Ratnasari, D., Lisnawati, N. et al. (2014) Influence of watershed-climate interactions on stream temperature, sediment yield, and metabolism along a land use intensity gradient in Indonesian Borneo. Journal of Geophysical Research: Biogeosciences 119, 1110-1128.

13. Merten, J., Röll, A., Guillaume, T., Meijide, A., Tarigan, S. et al. (2016) Water scarcity and oil palm expansion: social views and environmental processes. Ecology and Society 21, 5.

14. Luke, S.H., Barclay, H., Bidin, K., Chey, V.K., Ewers, R.M. et al. (2017) The effects of catchment and riparian forest quality on stream environmental conditions across a tropical rainforest and oil palm landscape in Malaysian Borneo. Ecohydrology 10, e1827.

15. Wells, J.A., Wilson, K.A., Abram, N.K., Nunn, M., Gaveau, D.L.A. et al. (2016) Rising floodwaters: mapping impacts and perceptions of flooding in Borneo. Environmental Research Letters 11, 064016.

16. Carlson, K.M., Curran, L.M., Asner, G.P., Pittman, A.M., Trigg, S.N. et al. (2013) Carbon emissions from forest conversion by Kalimantan oil palm plantations. Nature Climate Change 3, 283.

17. Marlier, M.E., DeFries, R.S., Kim, P.S., Koplitz, S.N., Jacob, D.J. et al. (2015) Fire emissions and regional air quality impacts from fires in oil palm, timber, and logging concessions in Indonesia. Environmental Research Letters 10, 085005.

18. Tan-Soo, J.S. \& Pattanayak, S.K. (2019) Seeking natural capital projects: Forest fires, haze, and earlylife exposure in Indonesia. Proceedings of the National Academy of Sciences 116, 5239-5245. 
19. Santika, T., Budiharta, S., Law, E.A., Dennis, R.A., Dohong, A. et al. (2020) Interannual climate variation, land type and village livelihood effects on fires in Kalimantan, Indonesia. Global Environmental Change 64, 102129.

20. RSPO (2018) RSPO Principles \& Criteria Certification For the Production of Sustainable Palm Oil. Roundtable on Sustainable Palm Oil, Kuala Lumpur, Malaysia.

21. RSPO (2019a) Impact Report. Available at: https://rspo.org/about/impacts. Accessed 4 October 2019.

22. RSPO (2019b) RSPO Jurisdictional Approach.

23. Ruysschaert, D. \& Salles, D. (2014) Towards global voluntary standards: Questioning the effectiveness in attaining conservation goals: The case of the Roundtable on Sustainable Palm Oil (RSPO). Ecological Economics 107, 438-446.

24. De Man, R. \& German, L. (2017) Certifying the sustainability of biofuels: Promise and reality. Energy Policy 109, 871-883.

25. Cattau, M.E., Marlier, M.E. \& DeFries, R. (2016) Effectiveness of Roundtable on Sustainable Palm Oil (RSPO) for reducing fires on oil palm concessions in Indonesia from 2012 to 2015 . Environmental Research Letters 11, 105007.

26. Carlson, K.M., Heilmayr, R., Gibbs, H.K., Noojipady, P., Burns, D.N. et al. (2018) Effect of oil palm sustainability certification on deforestation and fire in Indonesia. Proceedings of the National Academy of Sciences 115, 121-126.

27. Morgans, C.L., Meijaard, E., Santika, T., Law, E., Budiharta, S. et al. (2018) Evaluating the effectiveness of palm oil certification in delivering multiple sustainability objectives. Environmental Research Letters 13, 064032.

28. Furumo, P.R., Rueda, X., Rodríguez, J.S. \& Ramos, I.K.P. (2019) Field evidence for positive certification outcomes on oil palm smallholder management practices in Colombia. Journal of Cleaner Production 245, 118891.

29. Heilmayr, R., Carlson, K.M. \& Benedict, J.J. (2020) Deforestation spillovers from oil palm sustainability certification. Environmental Research Letters 15, 075002.

30. Santika, T., Wilson, K.A., Budiharta, S., Law, E.A., Poh, T.M. et al. (2019a) Does oil palm agriculture help alleviate poverty? A multidimensional counterfactual assessment of oil palm development in Indonesia. World Development 120, 105-117.

31. Santika, T., Wilson, K.A., Meijaard, E., Budiharta, S., Law, E.A. et al. (2019b) Changing landscapes, livelihoods and village welfare in the context of oil palm development. Land Use Policy 87, 104073.

32. Jerneck, A. \& Olsson, L. (2013) More than trees! Understanding the agroforestry adoption gap in subsistence agriculture: Insights from narrative walks in Kenya. Journal of Rural Studies 32, 114-125.

33. Chan, K.M., Goldstein, J., Satterfield, T., Hannahs, N., Kikiloi, K. et al. (2011) Cultural services and non-use values. In: Natural Capital: Theory and Practice of Mapping Ecosystem Services, pp. 206228.

34. Scoones, I. (1998) Sustainable Rural Livelihoods: A Framework for Analysis. IDS Working Paper 72. Sussex: Brighton Institute of Development Studies, University of Sussex.

35. Liu, Y. \& Xu, Y. (2016) A geographic identification of multidimensional poverty in rural China under the framework of sustainable livelihoods analysis. Applied Geography 73, 62-76.

36. Sen, A. (2006) Conceptualizing and measuring poverty. In: Poverty and Inequality, pp. 30-46. 
37. Bureau of Statistic (BPS) Indonesia (2019) Village Potential Statistics (PODES) 2000, 2003, 2005, 2008, 2014, and 2018. Jakarta, Indonesia.

38. Setiawan, E.N., Maryudi, A., Purwanto, R.H. \& Lele, G. (2016) Opposing interests in the legalization of non-procedural forest conversion to oil palm in Central Kalimantan, Indonesia. Land Use Policy 58, 472-481.

39. Gupta, J., Pouw, N.R. \& Ros-Tonen, M.A. (2015) Towards an elaborated theory of inclusive development. The European Journal of Development Research 27, 541-559.

40. Dauvergne, P. \& Neville, K.J. (2010) Forests, food, and fuel in the tropics: the uneven social and ecological consequences of the emerging political economy of biofuels. The Journal of Peasant Studies 37, 631-660.

41. Budidarsono, S., Susanti, A. \& Zoomers, A. (2013) Oil palm plantations in Indonesia: The implications for migration, settlement/resettlement and local economic development. In: Biofuels - Economy, Environment and Sustainability. Intech, Rijeka (Croatia), pp. 173-193.

42. Schoneveld, G.C., van der Haar, S., Ekowati, D., Andrianto, A., Komarudin, H. et al. (2019) Certification, good agricultural practice and smallholder heterogeneity: Differentiated pathways for resolving compliance gaps in the Indonesian oil palm sector. Global Environmental Change 57, 101933.

43. Gaveau, D.L.A., Pirard, R., Salim, M.A., Tonoto, P., Yaen, H. et al. (2017) Overlapping land claims limit the use of satellites to monitor no-deforestation commitments and no-burning compliance. Conservation Letters 10, 257-264.

44. Jelsma, I., Schoneveld, G.C., Zoomers, A. \& Van Westen, A.C.M. (2017) Unpacking Indonesia's independent oil palm smallholders: An actor-disaggregated approach to identifying environmental and social performance challenges. Land Use Policy 69, 281-297.

45. Waldman, K.B. \& Kerr, J.M. (2014) Limitations of certification and supply chain standards for environmental protection in commodity crop production. Annual Review of Resource Economics 6 , 429-449.

46. Klasen, S., Meyer, K.M., Dislich, C., Euler, M., Faust, H. et al. (2016) Economic and ecological tradeoffs of agricultural specialization at different spatial scales. Ecological Economics 122, 111-120.

47. Dislich, C., Keyel, A.C., Salecker, J., Kisel, Y., Meyer, K.M. et al. (2017) A review of the ecosystem functions in oil palm plantations, using forests as a reference system. Biological Reviews 92, 15391569 .

48. Margono, B.A., Potapov, P.V., Turubanova, S., Stolle, F. \& Hansen, M.C. (2014) Primary forest cover loss in Indonesia over 2000-2012. Nature Climate Change 4, 730.

49. Hansen, M.C., Potapov, P.V., Moore, R., Hancher, M., Turubanova, S. et al. (2013) High-resolution global maps of 21st-century forest cover change. Science $342,850-853$.

50. Bergamini, N., Blasiak, R., Eyzaguirre, P., Ichikawa, K., Mijatovic, D. et al. (2013) Indicators of Resilience in Socio-ecological Production Landscapes (SEPLs). United Nations University Institute of Advanced Studies (UNU-IAS).

51. Dale, V.H., Efroymson, R.A., Kline, K.L., Langholtz, M.H., Leiby, P.N. et al. (2013) Indicators for assessing socioeconomic sustainability of bioenergy systems: a short list of practical measures. Ecological Indicators 26, 87-102. 
52. Miteva, D.A., Loucks, C.J. \& Pattanayak, S.K. (2015) Social and environmental impacts of forest management certification in Indonesia. PLoS One 10, e0129675.

53. Lee, J.S.H., Miteva, D.A., Carlson, K.M., Heilmayr, R. \& Saif, O. (2020) Does the oil palm certification create trade-offs between environment and development in Indonesia? SocArXiv. DOI: 10.31219/osf.io/zrwpd

54. Alkire, S., Chatterjee, M., Conconi, A., Seth, S., \& Vaz, A. (2014) Global Multidimensional Poverty Index 2014. OPHI Briefing 21. Oxford: University of Oxford.

55. Gönner, C., Haug, M., Cahyat, A., Wollenberg, E., DeJong, W. et al. (2007) Capturing Nested Spheres of Poverty: A Model for Multidimensional Poverty Analysis and Monitoring. CIFOR Occasional Paper No. 46. Bogor, Indonesia: Center for International Forestry Research.

56. Bureau of Statistic (BPS) Indonesia (2014) Digital Map of Local Statistical Area 2014. Jakarta, Indonesia.

57. Lee, J.S.H., Ghazoul, J., Obidzinski, K., \& Koh, L.P. (2014) Oil palm smallholder yields and incomes constrained by harvesting practices and type of smallholder management in Indonesia. Agronomy for Sustainable Development 34, 501-513.

58. Gatto, M., Wollni, M., Asnawi, R. \& Qaim, M. (2017) Oil palm boom, contract farming, and rural economic development: Village-level evidence from Indonesia. World Development 95, 127-140.

59. Ridgeway, G. (2017) gbm: Generalized Boosted Regression Models. R Package Version 2.1.1. 2015.

60. Dehejia, R.H. \& Wahba, S. (2002) Propensity score-matching methods for nonexperimental causal studies. Review of Economics and Statistics 84, 151-161.

61. Austin, P.C. (2011) Optimal caliper widths for propensity - score matching when estimating differences in means and differences in proportions in observational studies. Pharmaceutical Statistics 10, 150161.

62. Sekhon, J.S. (2015) Multivariate and Propensity Score Matching With Balance Optimization. R Package Version 4.9-2. 


\section{Figures}
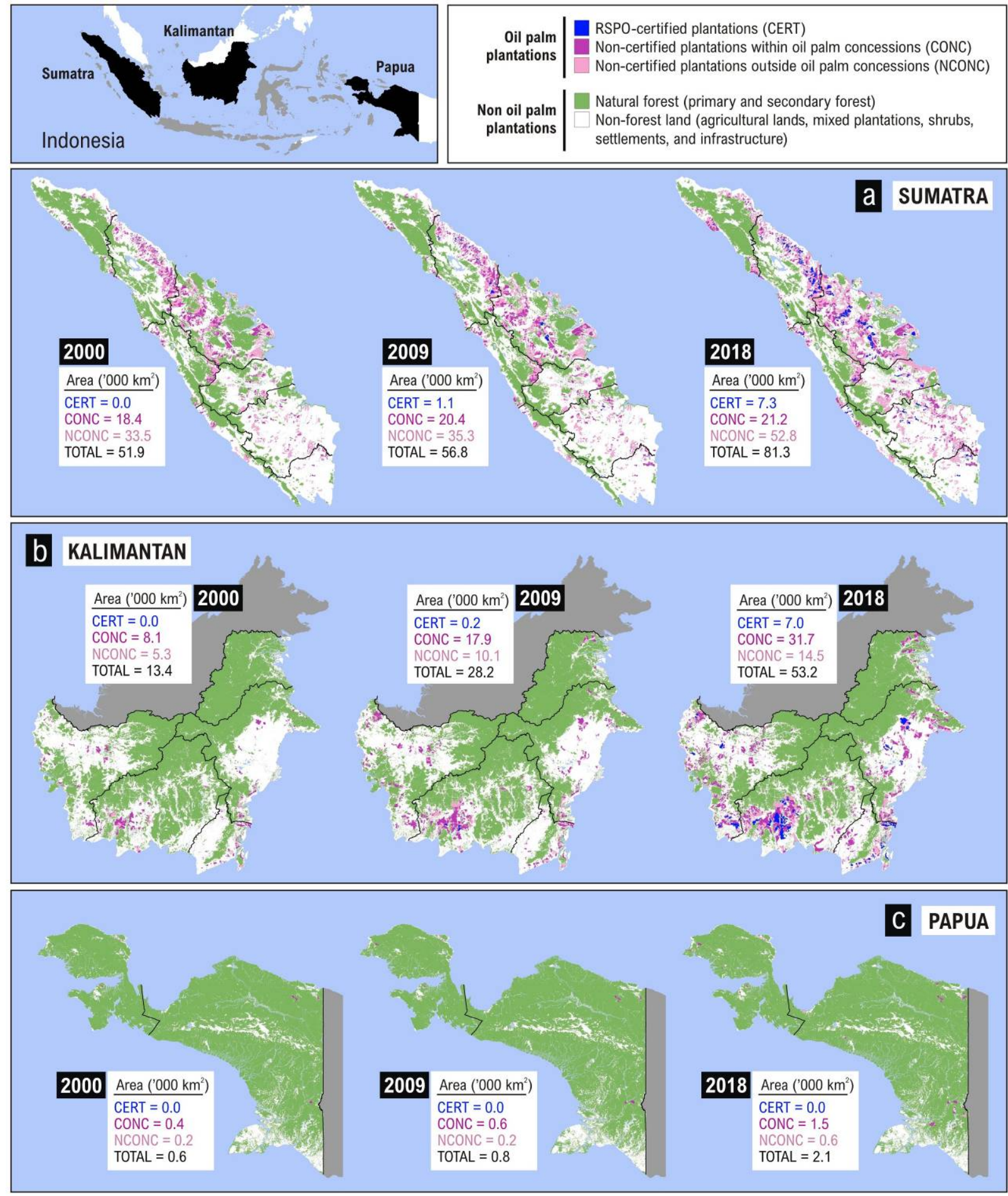

Figure 1. Change in distribution of forest and oil palm plantations in Sumatra, Kalimantan and Papua. The change in the distribution of forest and oil palm plantations every 9 years between 2000 and 2018 across three major Indonesian islands: (a) Sumatra, (b) Kalimantan, and (c) Papua. Oil palm plantations are grouped into three categories: (1) RSPO-certified plantations, i.e. certified large-scale industrial plantations (CERT), (2) non-certified plantations within oil palm concessions, i.e. non RSPO-certified large-scale industrial plantations (CONC), and (3) non-certified plantations outside known oil palm concessions, i.e. mainly independent small-scale landholders and medium to large-scale plantations with unknown concession status (NCONC) (see Methods). Detailed maps for portions of each island are provided in Extended Data Figures 2-4. 


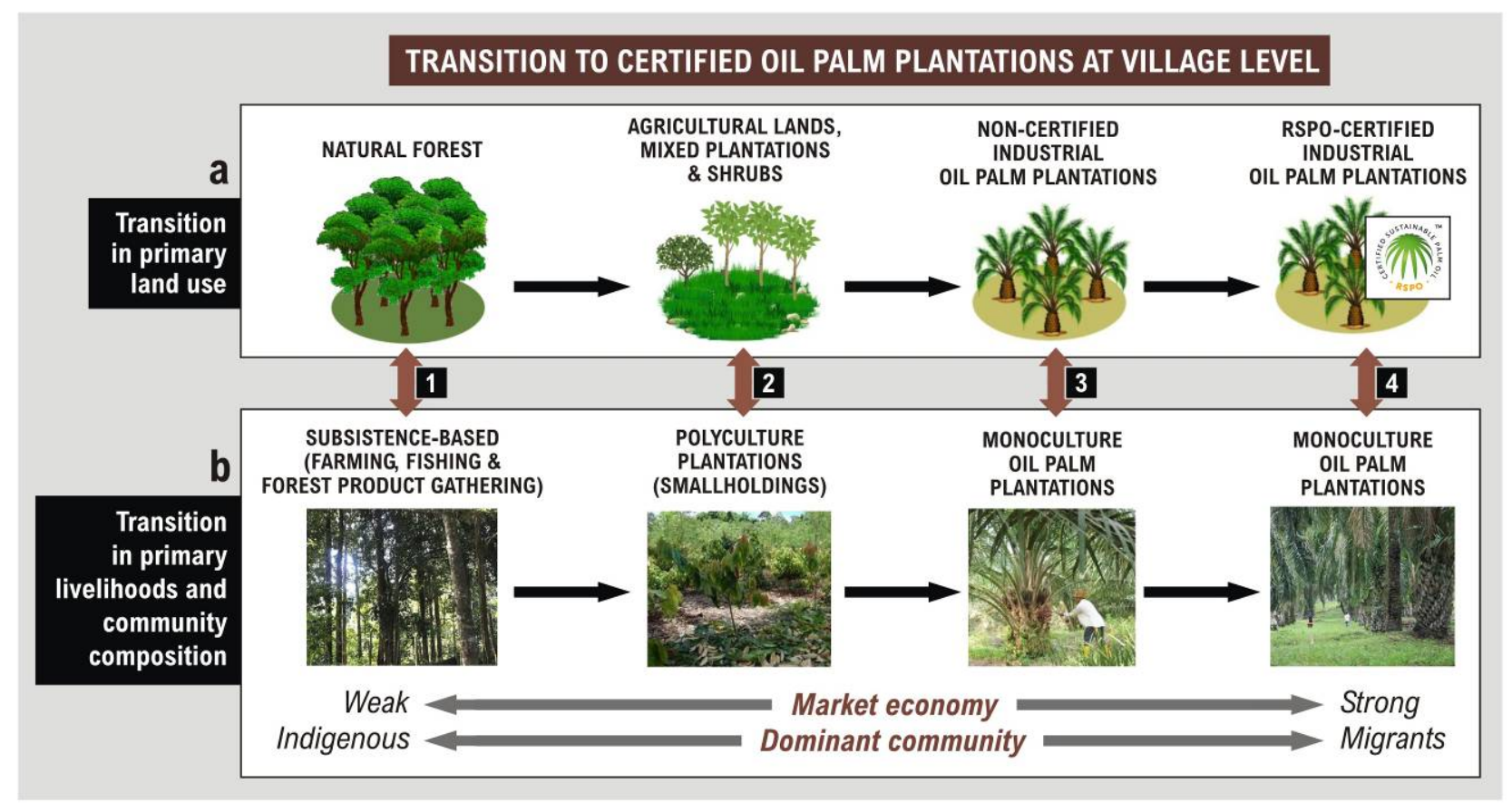

Figure 2. Village land-use (and associated livelihood) pathways to oil palm certification. (a) The change in village primary land-use, from (1) high natural forest cover to (2) agricultural lands, mixed plantations and shrubs, followed by (3) industrial oil palm plantations (non-certified), then finally becoming (4) RSPO-certified industrial plantations. (b) The change in village primary livelihoods and community composition most likely associated with the change in village primary land-use, from (1) subsistence-based livelihoods in complex agroforestry systems (weak market exposure) dominated by indigenous communities, to (2) polyculture plantation (smallholding) livelihoods (moderate market exposure) dominated by indigenous communities and a higher proportion of migrants, then finally becoming (3) monoculture oil palm plantation livelihoods (stronger market-driven) with a high proportion of migrants. 

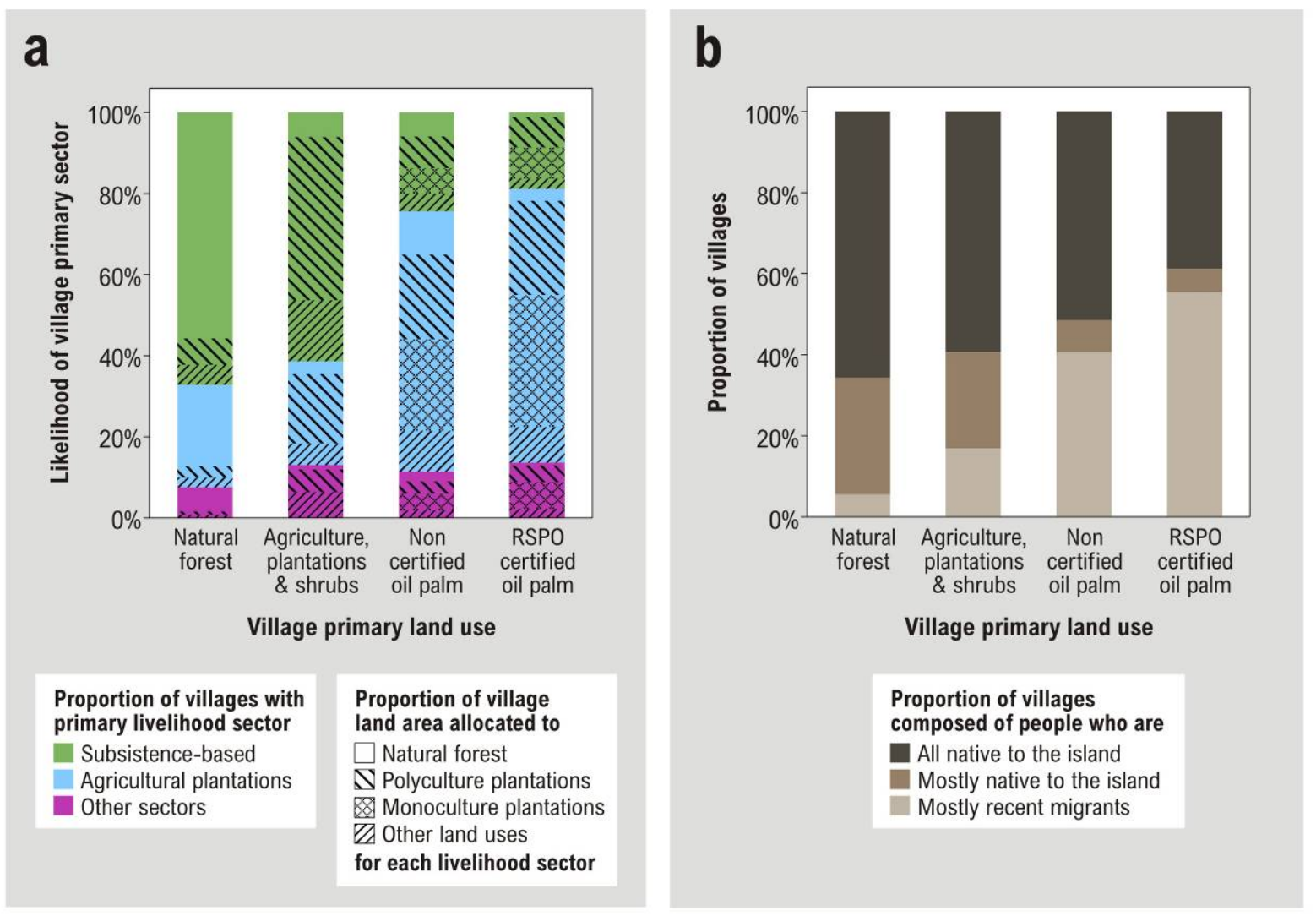

Figure 3. Village primary livelihoods and ethnic features or identities by village primary land-use. (a) Proportion of villages with primary livelihoods subsistence-based, agricultural plantations, and other sectors, and proportion of village land area allocated to natural forest, polyculture plantations, monoculture plantations, and other land-uses for each livelihood class, by village primary land-use (natural forest; agricultural lands, plantations, and shrubs; non-certified industrial oil palm plantations; and RSPO-certified industrial oil palm plantations), averaged across 2000, 2005, 2011 and 2018 data. (b) Proportion of villages within each land-use type that are composed of people who all, or mostly identify themselves belonging to ethnic groups native, versus non-native, to the island. 


\section{a}

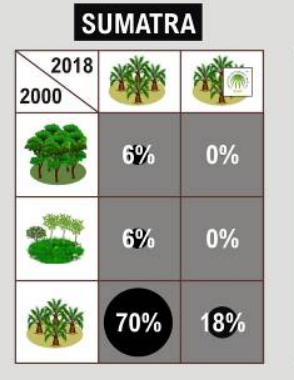

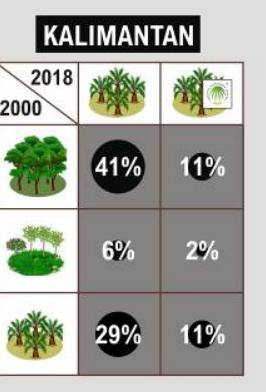

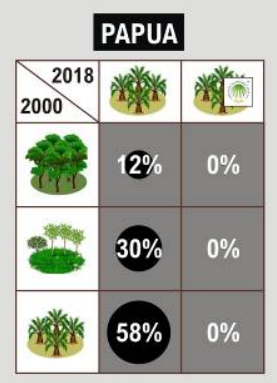

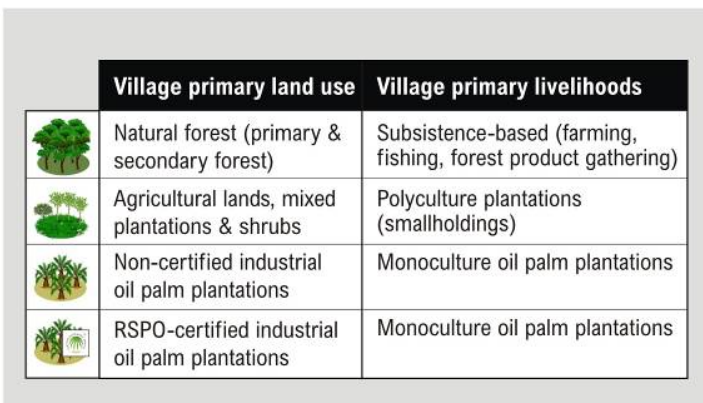

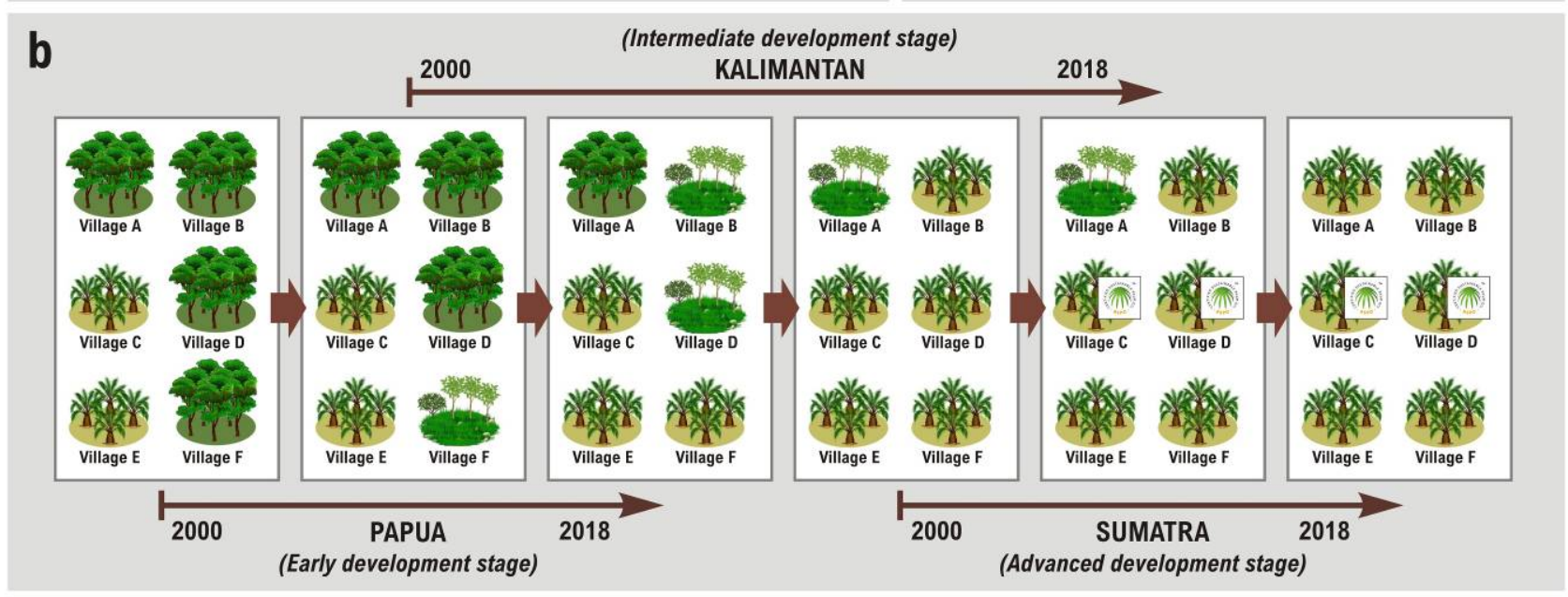

Figure 4. Village land-use (and the associated livelihood) change matrix to oil palm plantation and certification. (a) Change in village primary land-use (and the associated primary livelihoods) between 2000 and 2018, from natural forest; agricultural lands, mixed plantations and shrubs; and non-certified industrial oil palm plantations in 2000; to non-certified industrial oil palm plantations and RSPO-certified plantations in 2018, in Sumatra, Kalimantan, and Papua. (b) Schematic diagram of transition of village primary land-use (and the associated livelihoods) between 2000 and 2018 from left to right, representing different development stages of the industrial oil palm plantations for Papua, Kalimantan, and Sumatra, i.e. early, intermediate, and advanced stage, respectively. The boxes in Figure $4 \mathrm{~b}$ represent the development stage of the island, not necessarily the parts where oil palm expanded. We used 6 villages in each box to best resemble the matrix described in Figure 4a. 

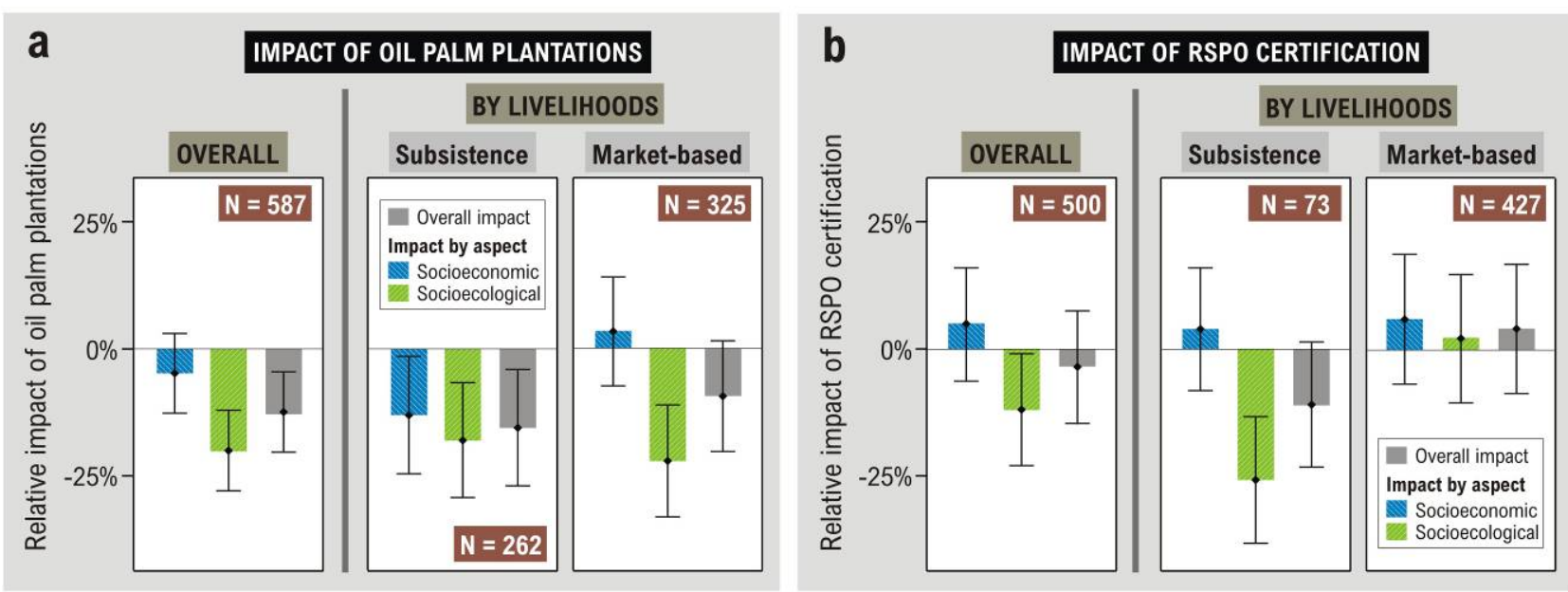

Figure 5. Impact of oil palm plantation development and certification on well-being in oil palm-

growing villages. (a) Impact of oil palm plantations on village-level well-being, evaluated by comparing the change in well-being indicators in villages with oil palm after 5-11 years of plantation development against the change in well-being in villages without oil palm across Sumatra, Kalimantan and Papua. (b) Impact of RSPO certification on village-level well-being, evaluated by comparing the change in well-being indicators in villages with certified plantation after 5-11 years of certification against the change in well-being in villages with non-certified oil palm plantations across Sumatra and Kalimantan. In both analyses comparisons are made between village types with similar baseline characteristics appropriate to the datasets analysed. $\mathrm{N}$ represents the number of villages assessed in each panel. Error bars represent $95 \%$ confidence intervals of combination of all indicators in the groups. 


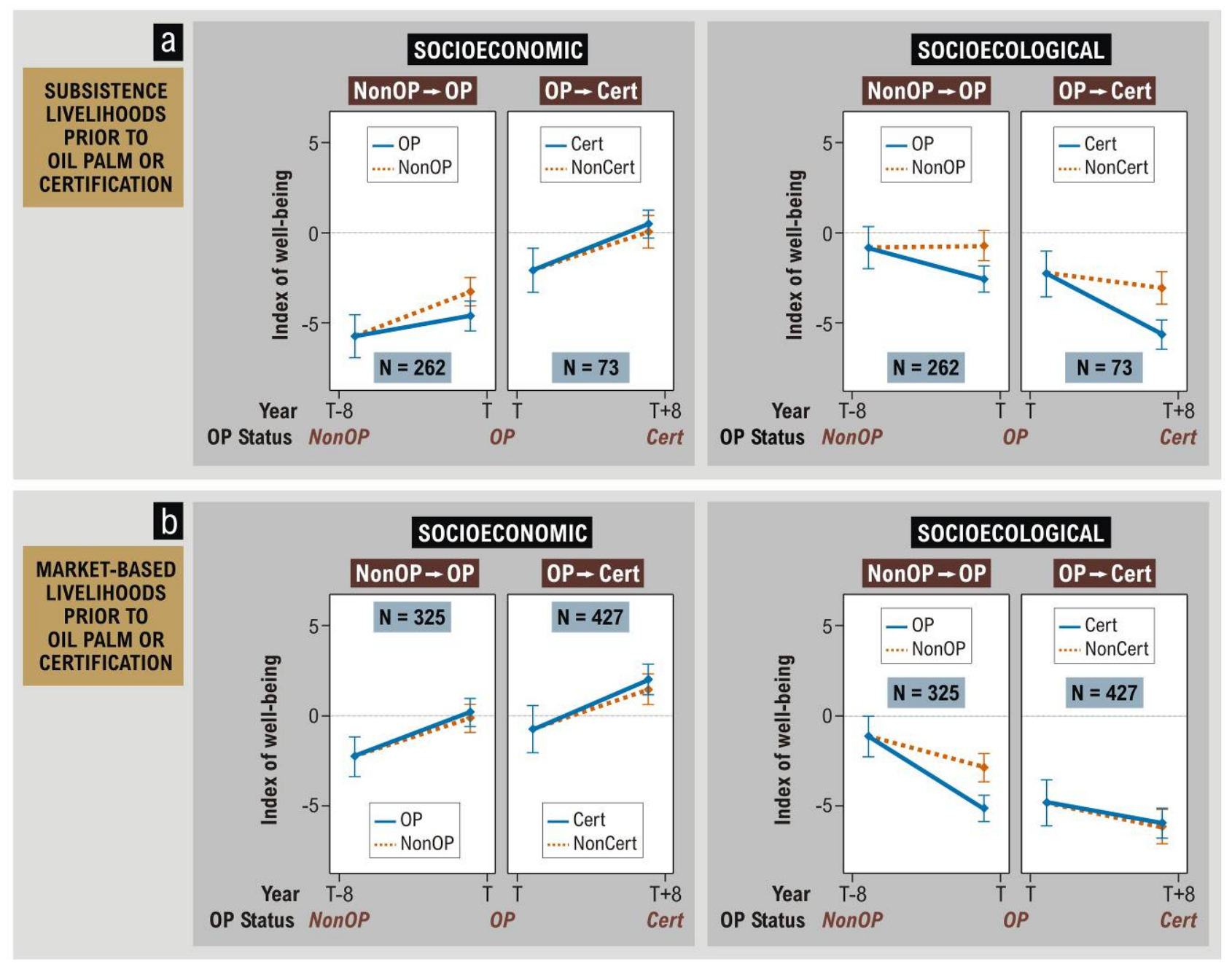

Figure 6. Trends in the change of village well-being through the oil palm and certification processes. Trends in the change of socioeconomic and socioecological well-being indices within 5-11 years (median 8 years) before and after oil palm development, and within 5-11 years (median 8 years) after oil palm certification. Villages are partitioned by their baseline primary livelihoods (a) subsistence-based livelihoods typical of the majority of plantations in Kalimantan, or (b) market-based livelihoods typical of most villages with oil palm in Sumatra and Papua. $\mathrm{N}$ represents the number of villages assessed in each panel. Error bars represent $95 \%$ confidence intervals. It is worth noting that the baseline characteristics of samples for generating the left (Non-OP $\rightarrow$ OP) and right (OP $\rightarrow$ Cert) panels are different, thus the counterfactual comparisons should only be made within panels. The estimates in T-8 time period are the same between the treated and control villages because the samples were matched. 


\section{Extended Data}
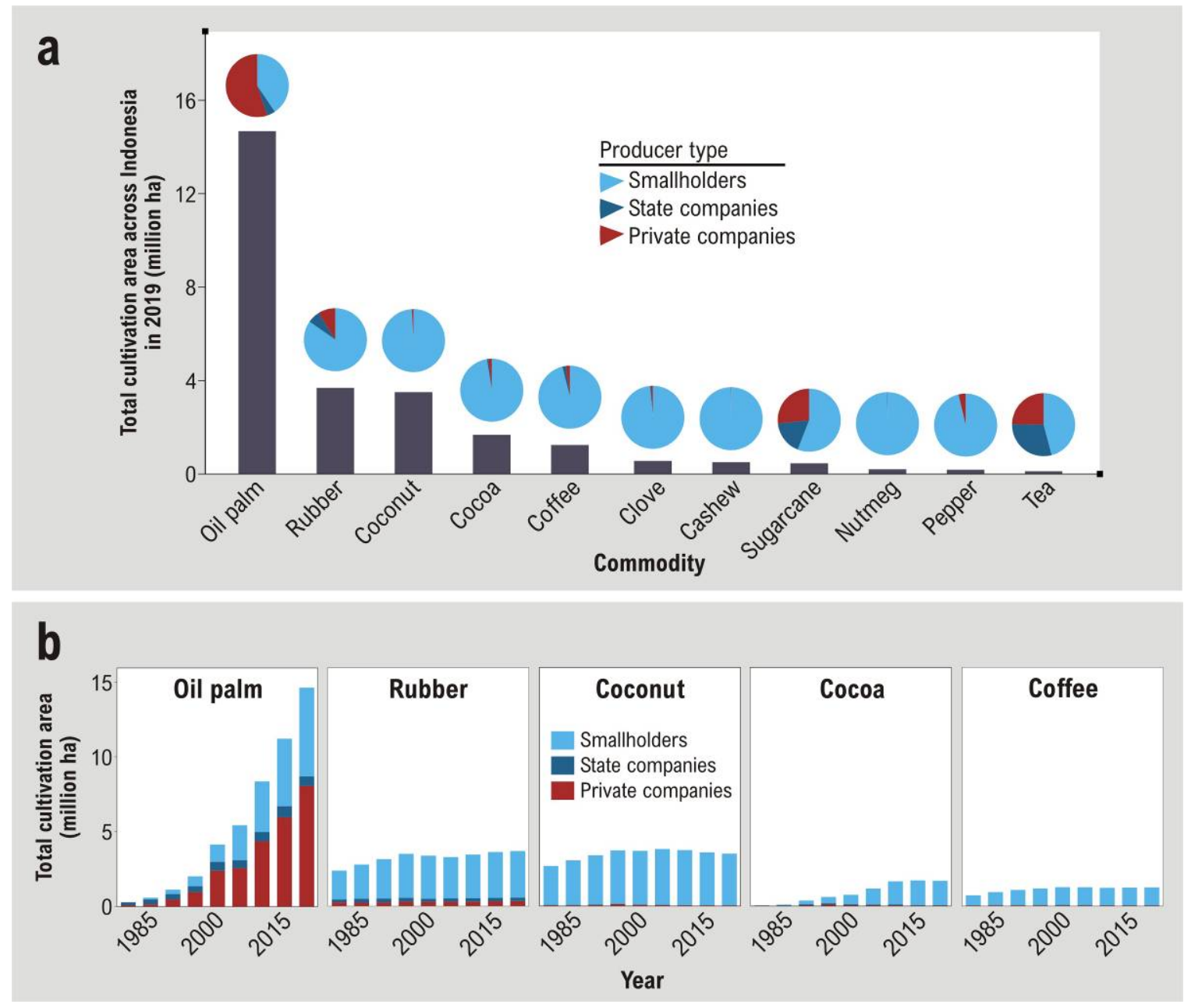

Extended Data Figure 1. Total plantation area for key agricultural commodities across Indonesia and types of ownerships. (a) Bar chart representing the total plantation area in 2019 for key agricultural commodities across Indonesia, and pie chart (above the bar) representing the proportion of different type of producer for each commodity, including smallholders, state or public-run companies, and private companies. (b) The change in cultivation area of the top five commodities (oil palm, rubber, coconut, cocoa, and coffee) every five years between 1980 and 2019, by producer type. Data were obtained from the Directorate General of Estate Crops Indonesia (2019). 


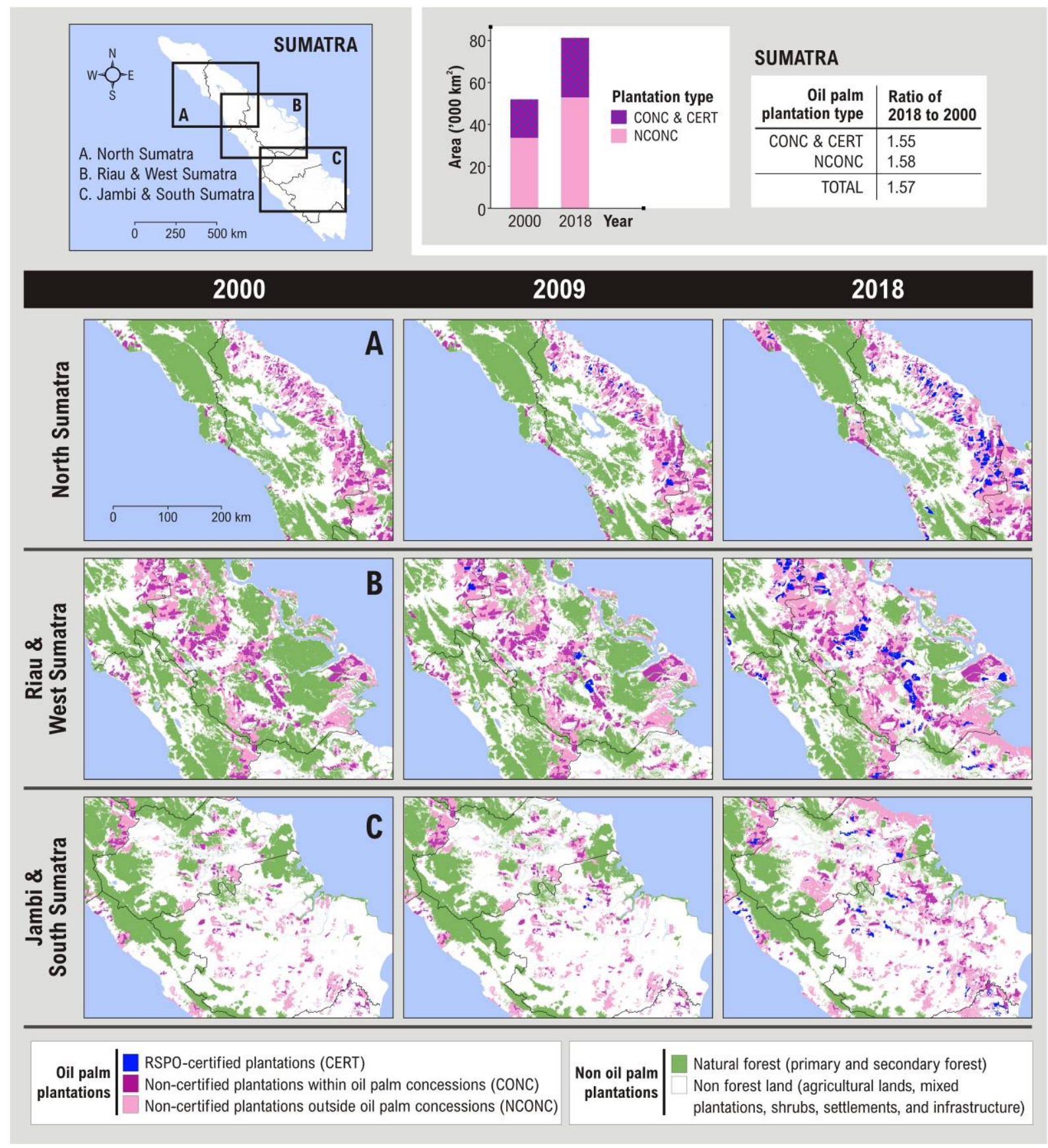

Extended Data Figure 2. Detailed change in distribution of forest and oil palm plantations in Sumatra. Detailed change in the distribution of natural forest and oil palm plantations every 9 years between 2000 and 2018 in three major oil palm regions in Sumatra. Oil palm plantations are grouped into three categories: (1) RSPO-certified plantations (CERT), (2) non-certified plantations within oil palm concessions (CONC), and (3) non-certified plantations outside known oil palm concessions (NCONC). 


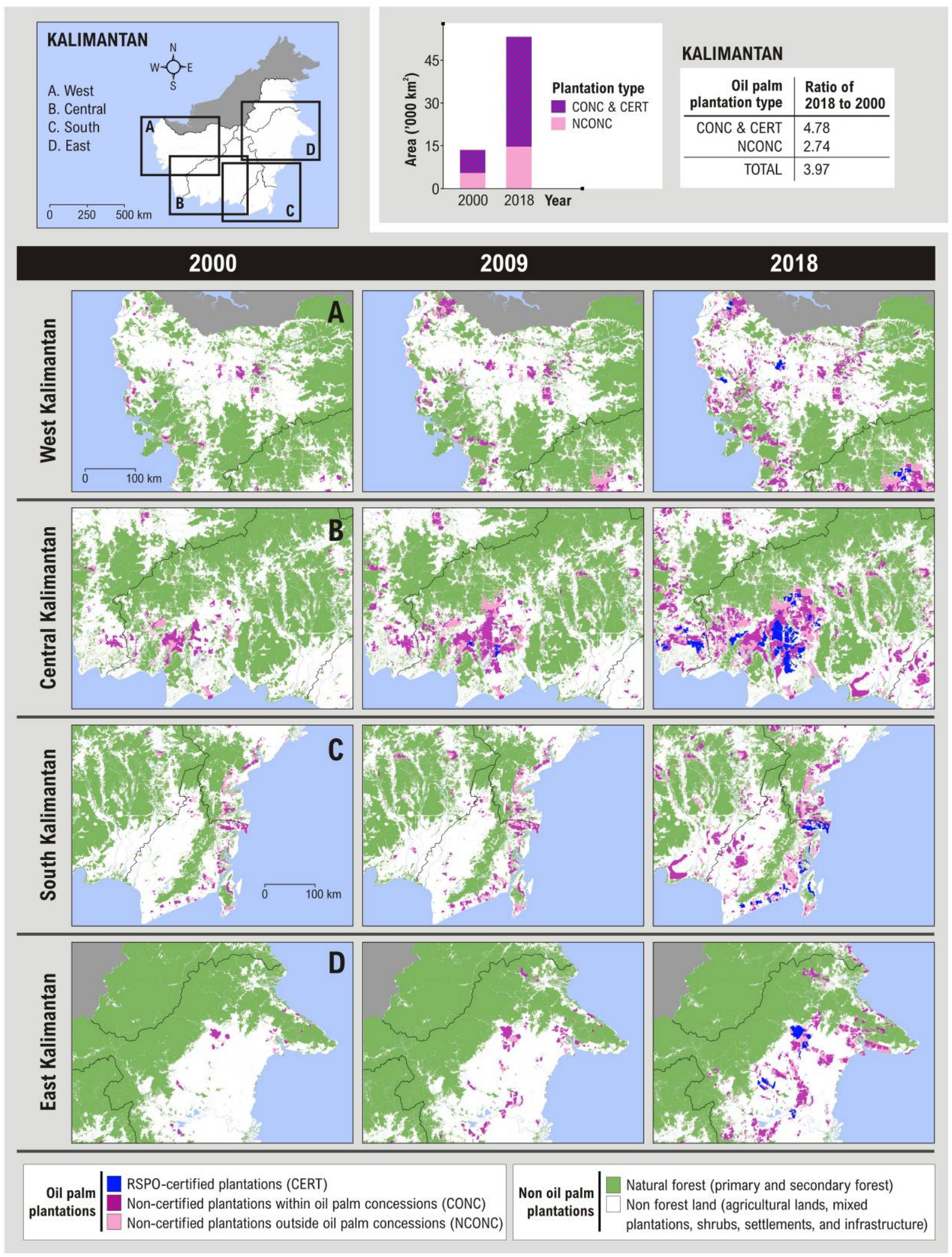

\section{Extended Data Figure 3. Detailed change in distribution of forest and oil palm plantations in}

Kalimantan. Detailed change in the distribution of natural forest and oil palm plantations every 9 years between 2000 and 2018 in four oil palm regions in Kalimantan. Oil palm plantations are grouped into three categories: (1) RSPO-certified plantations (CERT), (2) non-certified plantations within oil palm concessions (CONC), and (3) non-certified plantations outside known oil palm concessions (NCONC). 

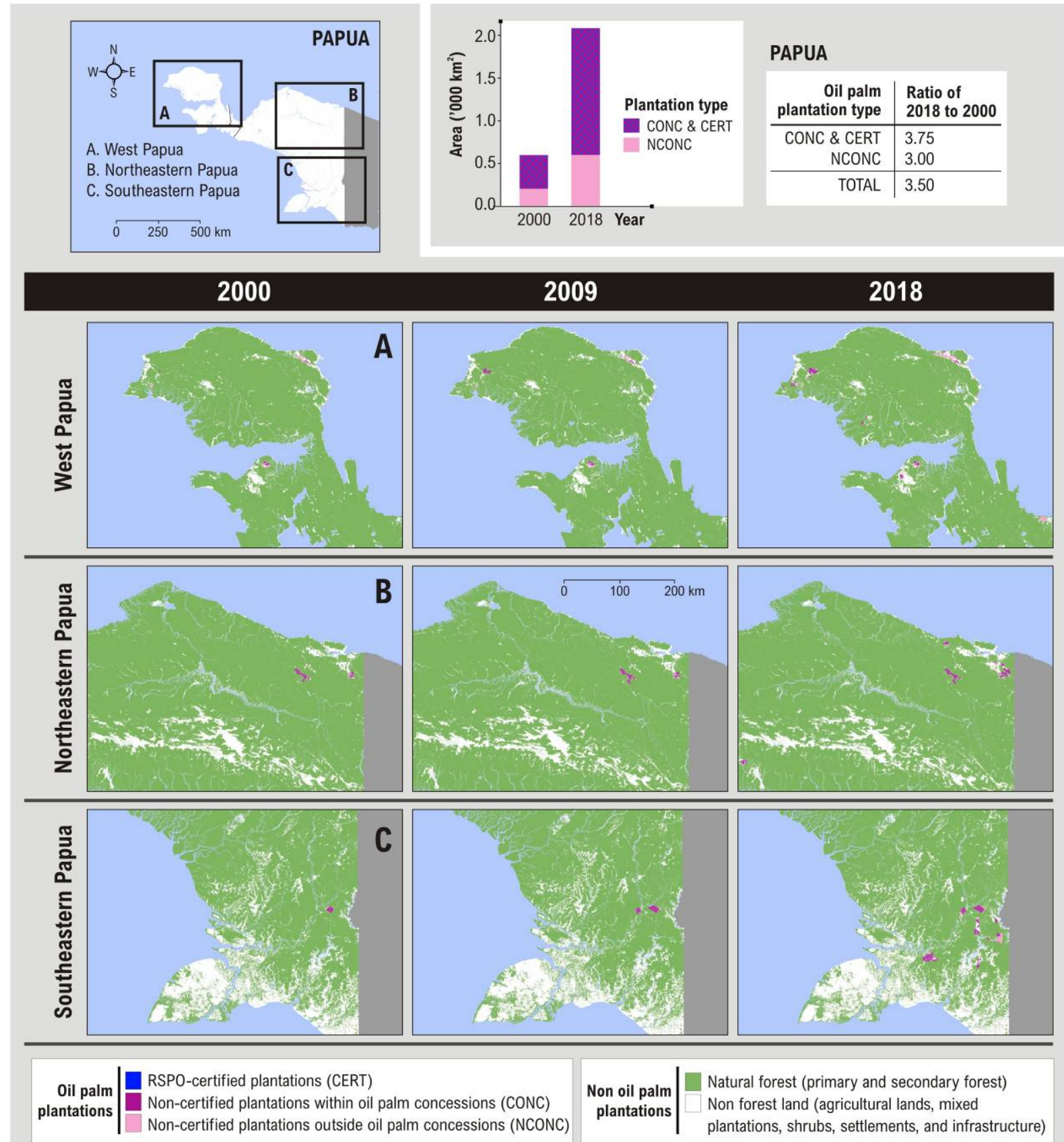

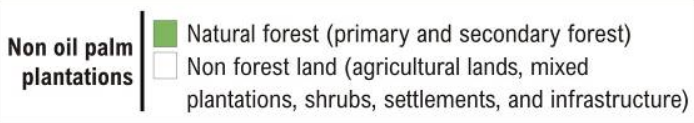

Extended Data Figure 4. Detailed change in distribution of forest and oil palm plantations in Papua. Detailed change in the distribution of natural forest and oil palm plantations every 9 years between 2000 and 2018 in three oil palm regions in Papua. Oil palm plantations are grouped into three categories: (1) RSPOcertified plantations (CERT), (2) non-certified plantations within oil palm concessions (CONC), and (3) noncertified plantations outside known oil palm concessions (NCONC). 


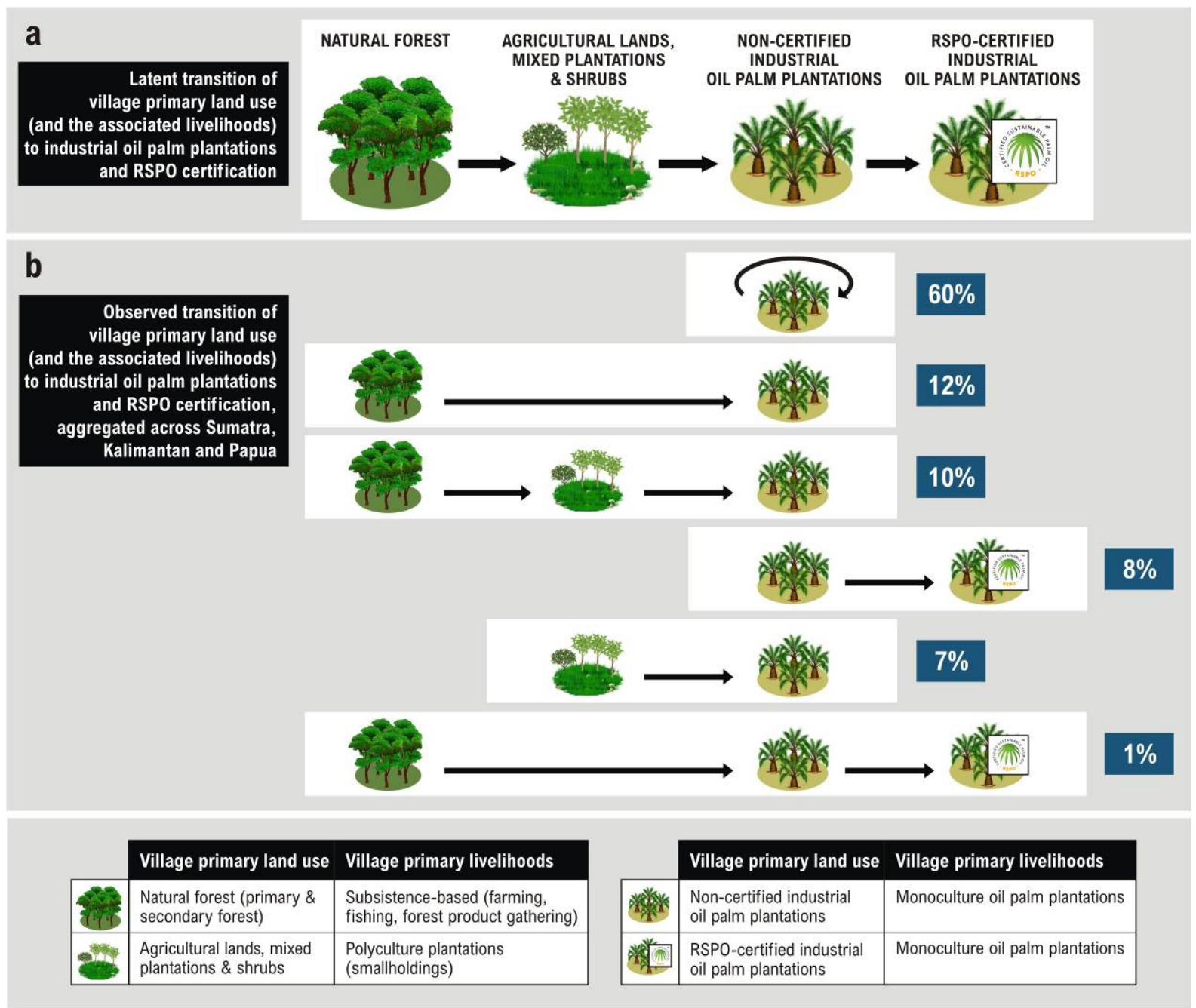

Extended Data Figure 5. Latent and observed change in village primary land use (and the associated livelihoods) to oil palm certification. (a) Latent change in village primary land use (and the associated livelihoods), from high natural forest cover, to agricultural lands, mixed plantations and shrubs, followed by industrial oil palm plantations (non-certified), then finally becoming RSPO-certified industrial plantations. (b) Observed change in village primary land use (and the associated livelihoods) to industrial oil palm plantations and certification based on land cover data and PODES censuses 2000, 2005, 2011, and 2018 (see Methods), aggregated across Sumatra, Kalimantan, and Papua. Percentage on the right hand side of each row represents the proportion of villages with the associated transition between 2000 and 2018 . 


\section{$O P \rightarrow$ CERT}
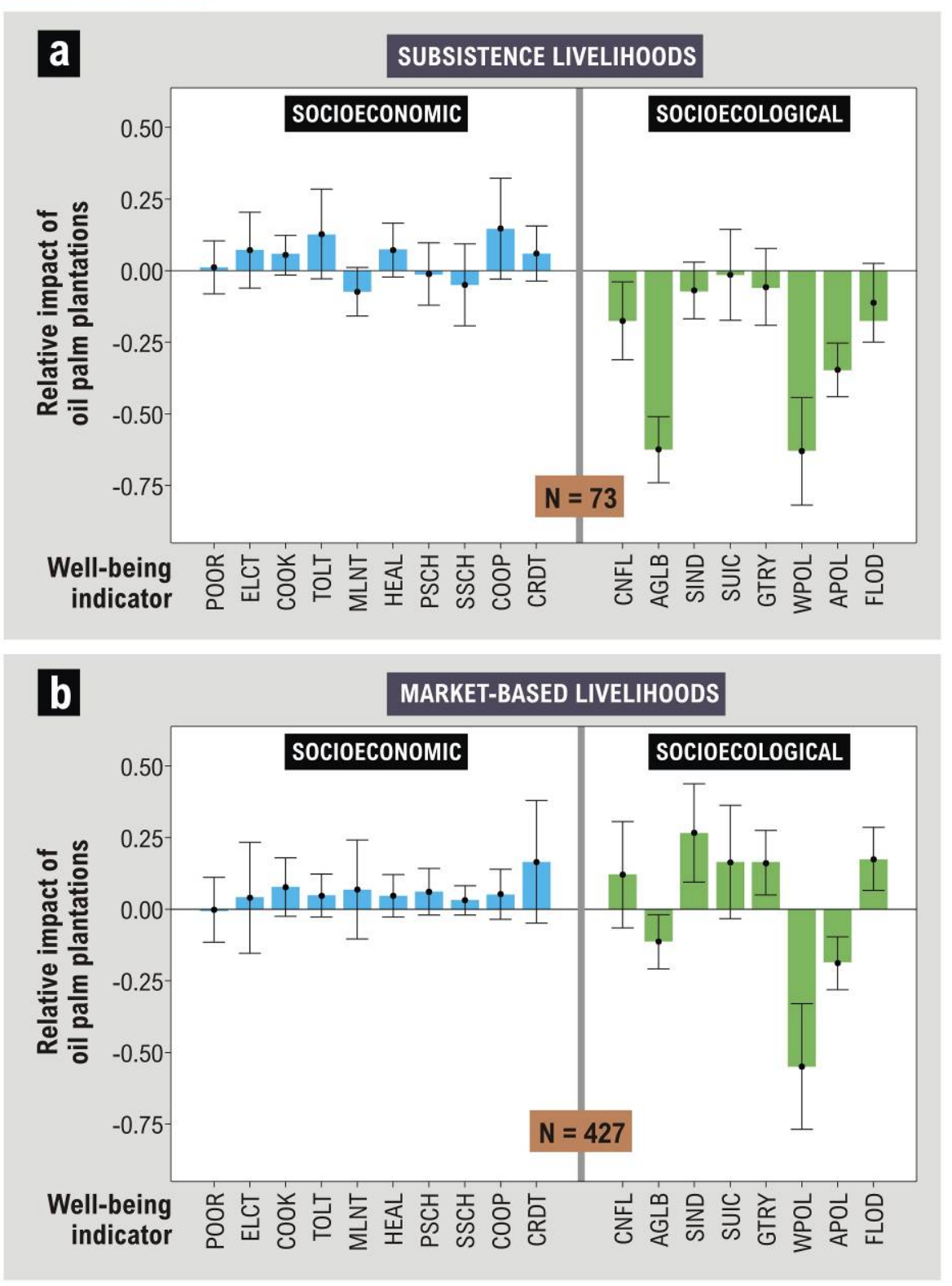

Extended Data Figure 6. Impacts of RSPO-certification on indicators of well-being by village primary livelihoods. The impact of oil palm certification (transition from oil palm villages to certified plantation villages) on each indicator of well-being in villages with primary livelihoods: (a) subsistence production, and (b) market-based. Indicators of well-being were grouped to socioeconomic and socioecological dimensions. Socioeconomic indicators include housing conditions (POOR), access to electricity (ELCT), cooking fuel (COOK), and toilet facilities (TOLT), child malnutrition incidence (MLNT), distance to healthcare facility (HEAL), primary school (PSCH), and secondary school (SSCH), and access to cooperative scheme (COOP) and credit facilities (CRDT). Socioecological indicators include the prevalence of conflicts (CNFL), agricultural labourers (AGLB), small industries (SIND), suicidal rates (SUIC), voluntary cleaning and maintenance (GTRY), water pollution (WPOL), air pollution (APOL), and floods and landslides (FLOD). Results were derived across 3 time periods and two islands (Sumatra and Kalimantan). $\mathrm{N}$ represents the number of villages used to derive the impact estimates for each well-being indicator. Error bars represent 95\% confidence intervals. See Supplementary Table 1 for description of each well-being indicator. 


\section{Non-OP $\rightarrow$ OP}

a SUBSISTENCE LIVELIHOODS
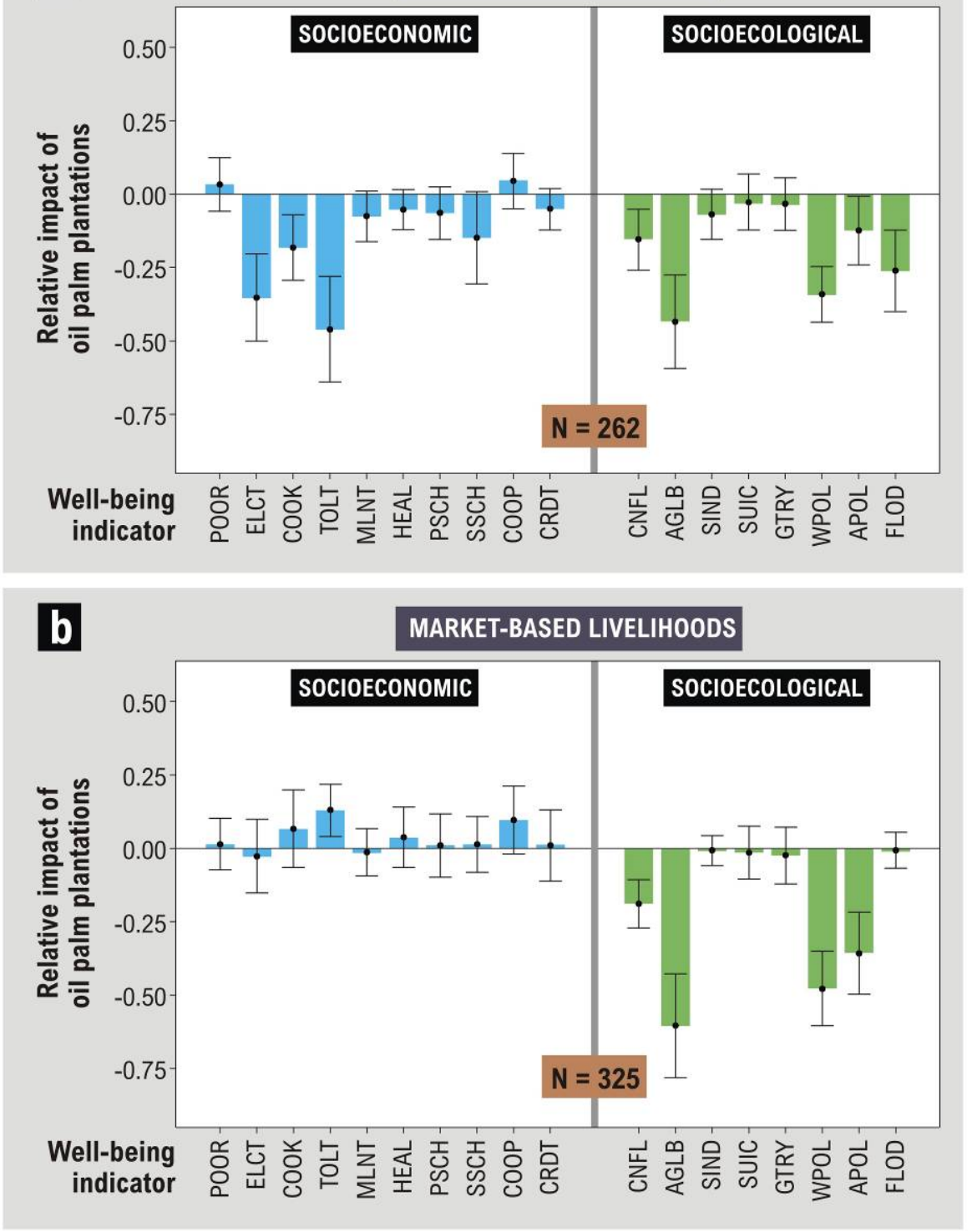

Extended Data Figure 7. Impacts of industrial oil palm plantation development on indicators of wellbeing by village primary livelihoods. The impact of industrial oil palm plantation development (transition from non oil palm villages to oil palm villages) on each indicator of well-being in villages with primary livelihoods: (a) subsistence production, and (b) market-based. Indicators of well-being were grouped to socioeconomic and socioecological dimensions. . Socioeconomic indicators include housing conditions (POOR), access to electricity (ELCT), cooking fuel (COOK), and toilet facilities (TOLT), child malnutrition incidence (MLNT), distance to healthcare facility (HEAL), primary school (PSCH), and secondary school (SSCH), and access to cooperative scheme (COOP) and credit facilities (CRDT). Socioecological indicators include the prevalence of conflicts (CNFL), agricultural labourers (AGLB), small industries (SIND), suicidal rates (SUIC), voluntary cleaning and maintenance (GTRY), water pollution (WPOL), air pollution (APOL), and floods and landslides (FLOD). Results were derived across 11 time periods and three islands (Sumatra, Kalimantan, and Papua). $\mathrm{N}$ represents the number of villages used to derive the impact estimates for each well-being indicator. Error bars represent $95 \%$ confidence intervals. See Supplementary Table 1 for description of each well-being indicator. 

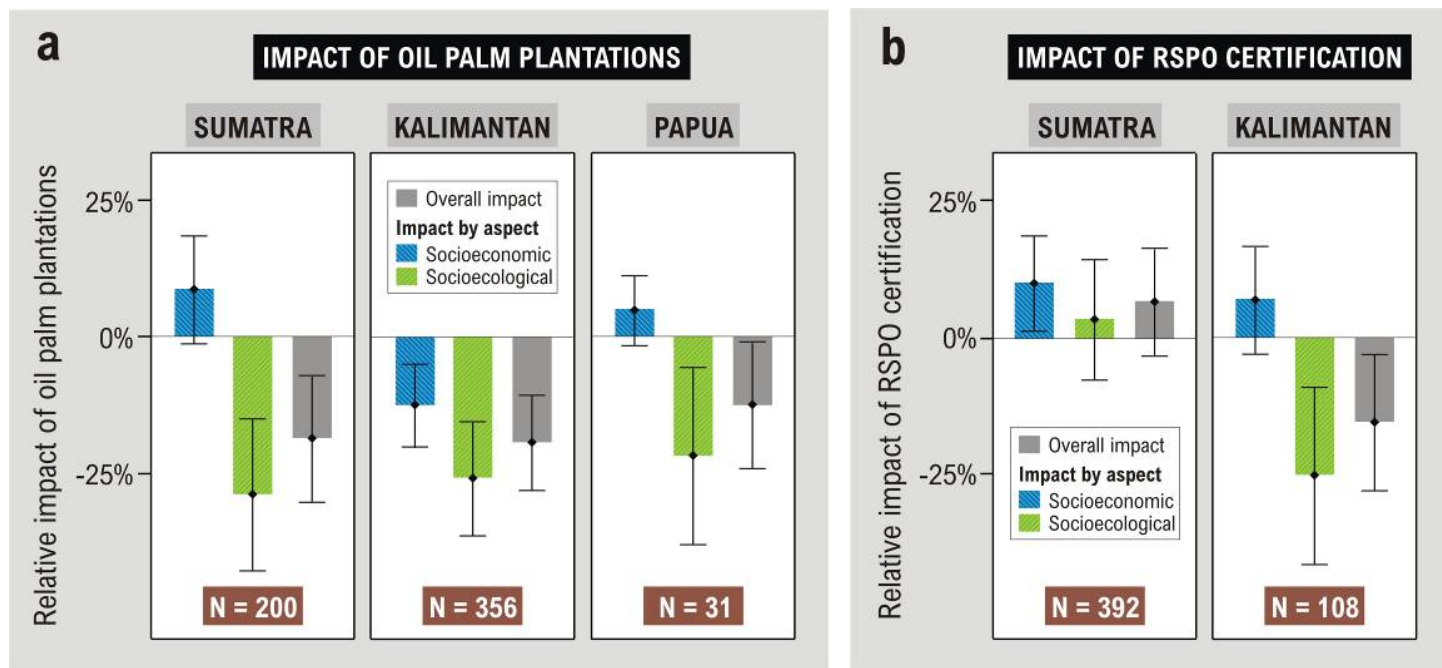

Extended Data Figure 8. Impact of oil palm plantation development and certification on well-being in oil palm growing villages by island. (a) Impact of oil palm plantations on village well-being in Sumatra, Kalimantan, and Papua, evaluated by comparing the change in well-being indicators in villages 5-11 years after industrial oil palm plantation development against the change in well-being in villages without industrial oil palm plantation, while ensuring similar baseline characteristics in both types of villages. (b) Impact of RSPO certification on village well-being in Sumatra and Kalimantan, evaluated by comparing the change in well-being indicators in villages 5-11 years after certification against the change in well-being in villages with non-certified industrial oil palm plantations, while ensuring similar baseline characteristics in both types of villages. $\mathrm{N}$ represents the number of villages assessed in each panel. Error bars represent $95 \%$ confidence intervals.
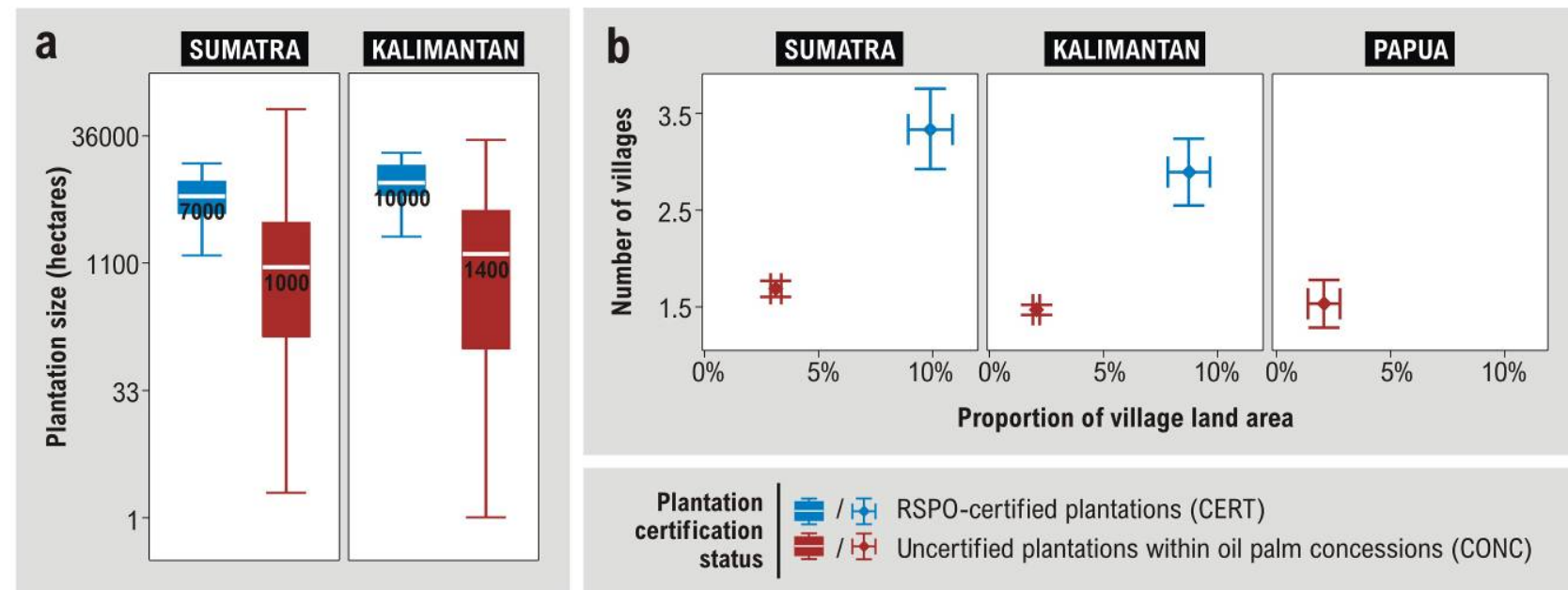

Extended Data Figure 9. Size of individual industrial oil palm plantation and number of villages covered by one plantation, by certification status. (a) Size of each large-scale plantation by certification status in the islands of Sumatra, Kalimantan, and Papua. (b) Number of villages covered by each large-scale industrial plantation and the proportion of village land area allocated to each plantation, by certification status. Plantation certification status includes (1) RSPO-certified plantations, i.e. certified large-scale industrial plantations (CERT) and (2) non-certified plantations within oil palm concession boundaries, i.e. non-certified large-scale industrial plantations (CONC). 


\section{Supplementary Information}

\section{Impact of palm oil sustainability certification on village well-being and poverty in Indonesia}

Truly Santika ${ }^{1,2,3}$, Kerrie A. Wilson ${ }^{3,4}$, Elizabeth A. Law ${ }^{3,5}$, Freya A.V. St. John ${ }^{6}$, Kimberly M. Carlson ${ }^{7,8}$, Holly Gibbs $^{9}$, Courtney L. Morgans ${ }^{2,3}$, Marc Ancrenaz ${ }^{10,11}$, Erik Meijaard ${ }^{2,3,11}$ \& Matthew J. Struebig ${ }^{2}$

This file contains:

- $\quad$ Supplementary Methods (p. 1-9)

- Supplementary Methods 1: Subsistence to market economy (p. 1-2)

- Supplementary Methods 2: Well-being indicators and classification (p. 2-3)

- Supplementary Methods 3: Data on oil palm plantations and certification and land cover (p. 4-5)

- Supplementary Methods 4: Impact evaluation analysis (p. 5-9)

- $\quad$ Supplementary Tables 1-8 (p. 10-17)

- $\quad$ Supplementary Figures 1-13 (p. 18-28)

- $\quad$ Supplementary References (p. 29-34)

\footnotetext{
${ }^{1}$ Natural Resources Institute (NRI), University of Greenwich, Chatham Maritime, ME4 4TB, UK. ${ }^{2}$ Durrell Institute of Conservation and Ecology (DICE), School of Anthropology and Conservation, University of Kent, Canterbury, CT2 7NR, UK. ${ }^{3}$ Centre of Excellence for Environmental Decisions (CEED), The University of Queensland, Brisbane, Australia. ${ }^{4}$ Institute for Future Environments, Queensland University of Technology, Brisbane, Australia. ${ }^{5}$ Norwegian Institute for Nature Research (NINA), Trondheim, Norway. ${ }^{6}$ School of Natural Resources, Bangor University, Bangor, UK. ${ }^{7}$ Department of Natural Resources and Environmental Management, University of Hawaii, Honolulu, USA. ${ }^{8}$ Department of Environmental Studies, New York University, New York, USA. ${ }^{9}$ Department of Geography and Nelson Institute for Environmental Studies, University of Wisconsin-Madison, Madison, Wisconsin, USA. ${ }^{10}$ Kinabatangan Orang-utan Conservation Programme, Sandakan, Sabah, Malaysia. ${ }^{11}$ Borneo Futures, Brunei Darussalam. Correspondence: T.S. (T.Santika@greenwich.ac.uk) and M.J.S (M.J.Struebig@kent.ac.uk)
} 


\section{Supplementary Methods}

\section{Supplementary Methods 1: Subsistence to market economy}

\section{The global multidisciplinary context}

Subsistence economies are those in which people produce food, clothes and other basic needs for their own use and where such items are not bought or sold ${ }^{1}$. Such economies remain today in large parts of the developing world $^{2,3}$ and also in some rural areas in developed countries ${ }^{4,5}$, in many cases in areas with sizeable traditional and native indigenous communities ${ }^{6,7}$. Wage and money play a growing role in many of these communities today, but cash is generally considered important only to support the continuance of their subsistence activities, such as for purchasing equipment for hunting or fishing ${ }^{8}$. Many native peoples were marginalized through processes of colonialism; for many, marginalization and alienation continues in the guise of state-building and includes removal of land access and usufruct rights ${ }^{9-11}$. As many subsistence communities inhabit resource rich areas, the arrival of corporations into these areas has often led to enduring conflicts ${ }^{12,13}$. Well intentioned efforts aimed at sustainable development and community empowerment have often failed to provide the envisaged benefits ${ }^{14,15}$. Across the globe, these communities encounter similar recurring predicaments regarding the articulation of socio-spatial identities and the affirmation of rights against states and corporations ${ }^{16-18}$. Development programmes often fail to recognise indigenous or traditional knowledge as ontologically different yet equally important to securing project success ${ }^{19}$.

Numerous literature from sociology and development studies argue that economic activities in native indigenous communities differ fundamentally from similar activities or entrepreneurship in other societies, so they should be approached differently ${ }^{20,21}$. With the growing influence of the market system through time, the characteristics associated with the indigeneity and traditionalism within the same broad ethnic group may vary horizontally (between different families, clans, or tribes) and vertically (between different generations) ${ }^{22}$. The rate of transfer in market orientation and technology determine the viability of technology diffusion. Too rapid transfers often create more harm than good due to the lack of time and opportunity for the community adopters to filter and choose, experiment and innovate, conduct sufficient trial and error, and make appropriate adjustment to suit the community needs ${ }^{23,24}$.

In environmental studies, there is a growing recognition of the importance of cultural values in ecosystem service provisioning ${ }^{25}$. Different ethnic groups, regardless of whether they are part of indigenous culture, can bring different social and cultural nuances about nature's intrinsic values and connections to humanity ${ }^{26,27}$. The level of subsistence also plays a critical role in shaping the views and values on natural environments in a community ${ }^{27}$. Subsistence production (farming, fishing, hunting, or gathering) can be more important to some communities than others. This implies that reduction in subsistence harvest (e.g. reduced fish capture due to water pollution ${ }^{28}$, reduced food harvest due to loss in farming area or change in climate patterns ${ }^{29,30}$, reduced non-timber forest products due to forest loss ${ }^{31,32}$ can have more detrimental impacts on the overall well-being of communities who rely on subsistence production than those who rely more on products available from the market to meet their daily requirements. 


\section{The Indonesian context}

There are numerous communities participating in subsistence production throughout Indonesia. According to recent village-level census PODES data in $2018^{33}$, subsistence production currently supports the economy of $50 \%$ of villages across the 'Outer Islands' (i.e. those other than the already developed regions of Java and Bali) (Supplementary Figure 11a). Subsistence-based villages are less prevalent in western Indonesia (i.e. Sumatra) than in the central (Kalimantan and Sulawesi) and eastern islands (Nusa Tenggara, Maluku, and Papua) (Supplementary Figure 11a). These variations are a reflection of different stages or extent of market influence in each island, mainly due to proximity to the central governance of Java ${ }^{34,35}$.

The prevalence of villages with subsistence production in each island reduced between 2000 and 2018 (Supplementary Figure 11b). Based on these changes alone, we could proximate that the extent of market orientation in Kalimantan overall is about a decade behind Sumatra; and Papua overall is about two decades behind Kalimantan. Within each island, the stage of market influence between urban and rural areas also differs 36 .

\section{Supplementary Methods 2: Well-being indicators and classification}

Village-level PODES data from census 2000, 2003, 2005, 2008, 2011, 2014 and 2018 were used as proxy indicators for two aspects of village well-being, i.e. socioeconomic and socioecological ${ }^{37,38}$ (Supplementary Table 1). These terms mean different things to different people. Here and in our previous studies on oil palm ${ }^{37,38}$, the socioeconomic aspect includes indicators on living conditions, infrastructure, and income support, while the the socioecological aspect includes social (security and social equity) and environmental (natural hazard prevention) indicators ${ }^{39,40}$. PODES provides the most comprehensive public information on land use, population demographics, and village infrastructure available in Indonesia, and has been used extensively to inform government policy and development studies ${ }^{41-44}$. The choice of indicators and directionality of the effects on wellbeing listed in Supplementary Table 1 correspond to existing methodologies used to assess poverty and livelihoods ${ }^{37,38}$, such as the Sustainable Livelihood Approach $\left(\mathrm{SLA}^{45}\right.$ ), the Multidimensional Poverty Index (MPI ${ }^{46}$ ), and the Nested Spheres of Poverty (NESP ${ }^{47}$ ). PODES includes more information than the indicators used here, but the census has changed over time. The indicators used here remained consistent across the 18-year study period. i.e. the same questions were present in each of the seven censuses available.

Indicators for living conditions include the proportion of households with poor housing conditions, proportion with electricity, incidents of child malnutrition, and the use of cooking fuel and toilet facilities for the majority of households (Supplementary Table 1). The directional effect of the change in the electricity indicator is positive, while other indicators are negative. This means that an increase in households with electricity represents improvement in well-being. A decrease in households with poor housing conditions or incidents of child malnutrition, or a change from one category to a lower category in cooking fuel or toilet facilities (e.g. change from category 2 for 'joint toilet' to category 1 for 'own toilet') represents improvement in well-being. Indicators for infrastructure include distance to nearest health facilities and primary and secondary schools (Supplementary Table 1). The directional effect of the change in these indicators is negative, implying that reduced distance to nearest health facilities or schools represents improvement in access to health and education. Indicators for income support include the prevalence of active village cooperative schemes and credit available for farmers and communities (Supplementary Table 1). The directional effect of the change in these indicators is positive, implying that an increase in the prevalence of cooperative schemes or credits represents 
improved financial support for communities. While information about the rates of community participation in cooperative schemes and credits may provide a better proxy for well-being than merely the prevalence of these programs, such data are not available over spatial and temporal scale of our study.

Indicators for social well-being include the prevalence of conflicts among communities, families with agricultural wage labourers, small enterprises ( $<20$ employees), voluntary cleaning and maintenance, and suicidal events (Supplementary Table 1). The directional effect of the change in the prevalence of conflicts, agricultural labourers, and suicidal events is negative, implying that a decrease in the prevalence of conflicts, families with agricultural wage labourers, or suicides represents improvement in social well-being. The directional effect of the change in the prevalence of small enterprises and voluntary cleaning and maintenance is positive, implying that an increase in these activities represents improved social well-being. PODES defines an agricultural wage labourer as a person who works in the agricultural sector for one or more employers or companies and receives wages on a daily or wholesale basis. Examples of agricultural wage labourer include rice harvesting worker, labourer for preparing paddy fields with hoes, rubber tapping worker, coffee picker, oil palm fruit bunch harvester, and oil palm labourer for fertilization and chemical spraying. In Kalimantan, agricultural wage labourers form a larger part of village communities where cash crop (mainly oil palm) plantations predominate, than in villages dominated by dryland rice (swidden) farming communities ${ }^{48,49}$. Increased agricultural wage labourers associated with the spread of industrial oil palm plantations has also aggravated food insecurity, because monoculture displaces subsistence-based agriculture and thereby pre-empt alternatives to wage labour for accessing food ${ }^{49}$. Small farmers and agricultural wage labourers remain the poorest segment of society with low purchasing power in developing countries, and in Indonesia this condition has exacerbated despite the country's economic growth ${ }^{50-52}$. An increase in the prevalence of small-scale enterprises represents improvement in social well-being, because it reflects improved distribution of income among communities and the maintenance of local livelihoods (e.g. small-scale industries of non-timber forest products (NTFPs), such as rattans, honey, gaharu, and dammar) ${ }^{53,54}$, as opposed to the dependency of communities on a single sector income, such as monoculture plantation industries ${ }^{55}$.

Indicators for environmental well-being include the prevalence of floods and landslides and the level of water and air pollution (Supplementary Table 1). The directional effect of the change in these indicators is negative, implying that a change from one category to a lower category in water or air pollution (e.g. change from category 3 for 'severe' to category 2 for 'mild') or a decrease in the prevalence of floods and landslides represents improvement in ecological well-being.

The categorization of indicators under the socioeconomic and socioecological aspects is closely related to the classification advocated by the SLA ${ }^{45}$, in which the socioeconomic aspect mainly encapsulates the human (basic), physical, and financial dimensions of well-being, whereas the socioecological aspect mainly encapsulates the social and natural dimensions (Supplementary Figure 12). The analytical framework of the SLA by Scoones ${ }^{45}$ remains in frequent use for assessing the sustainability and resilience of rural livelihoods and development ${ }^{56-59}$. In addition to this main categorization of indicators, we also conducted a sensitive analysis to assess how the impact estimates for industrial oil palm plantations and certification changes with different grouping of well-being indicators under socioeconomic and socioecological aspects. Further discussion on this is provided in Methods and Supplementary Methods 4. 


\section{Supplementary Methods 3: Data on oil palm plantations and certification and land cover}

Our study covered Sumatra (comprising eight provinces), Kalimantan (five provinces), and Papua (two provinces)

${ }^{60}$ (Figure 1 and Extended Data Figures 2-4). In 2017, the population of Sumatra, Kalimantan, and Papua was estimated at 53 million, 16 million, and 4 million, respectively ${ }^{52}$, with many people residing in coastal areas. Based on ethnic characteristics reported in census data, villages in these islands can be categorized into three groups: (1) those where the entire population all identify themselves belonging to ethnic groups native to the island, (2) those where the majority of the population identify themselves belonging to ethnic groups native to the island, and (3) those where the majority of population identify themselves belonging to ethnic groups outside the island. The third group is primarily associated with government-supported transmigration programs or through spontaneous migration since the 1960s.

We used spatial maps on planted oil palm plantations every three years between 1997 and 2014, described in Santika et al. ${ }^{37,38}$, and expanded the time coverage to 2018 and spatial coverage to Sumatra and Papua. These plantations include medium and large-scale industrial plantations (25-100 ha and >100 ha, respectively) and smallholder plots (<25 ha). Maps were generated by combining spatiotemporal data on plantations and land cover provided by the Indonesia's Ministry of Environment and Forestry every three years between 1997 and $2017^{61}$ and the Atlas of Deforestation and Industrial Plantation for Kalimantan and Papua annually between 2000 and $2018^{62}$. We also performed thorough visual inspection and delineation of plantation boundaries from the Google Earth engine, supplemented by Sentinel 2A images (10 m resolution, available from https://earth.esa.int/web/sentinel/missions/sentinel-2), to validate the existing data, fill the missing years, and capture small to medium-size oil palm plantations.

We further used spatial data on oil palm concessions and RSPO member plantations (certified and noncertified) across Indonesia described in Carlson et al. ${ }^{63}$. The data contain concessions that had been certified by 2015. We updated these data to include concessions that had recently been certified or proposed for certification between 2015 and 2018 through web searching of records of RSPO certified mills and supply estates. The RSPO-certified concession dataset is considered to be of the highest quality and reliability given that all certification records are transparently available in the RSPO database. The non-certified concession dataset contains large proportions of the existing industrial-scale oil palm concessions, but not all. This is due to difficulties in assembling concession permits and boundaries that are scattered across different government institutions and levels of authorities. Nonetheless, the data represent the best information available about the distributions of the majority of oil palm concessions across Indonesia.

Forest cover was estimated annually between 2001 and 2018 by overlaying the extent of natural forest across Indonesia in 2000 provided by Margono et al. ${ }^{64}$ and the annual deforestation locations derived from the Global Forest Change (GFC) from 2001 to $2018^{65}$. Natural forest comprised old-growth forest that had not been completely cleared in the last thirty years ${ }^{64}$. We note that the GFC database also provides forest cover data for 2000 , but these data include timber plantation estates in the forest class ${ }^{64}$. The natural forest data for 2000 and the GFC dataset both have a pixel size of $30 \times 30$ metres.

Combining information on forest cover, planted oil palm plantations, oil palm concession boundaries, and RSPO member plantations (certified and non-certified), we estimated the distributions of natural forest and three plantation ownership types (Figure 1): (1) RSPO-certified industrial plantations (CERT); (2) non-certified oil palm plantations within concession boundaries (which mainly includes the non-certified RSPO-member plantations and non-RSPO industrial-scale plantations) (CONC); (3) non-certified oil palm plantations outside concession boundaries (which largely includes independent oil palm smallholders (<25 ha) and smaller proportion of medium 
to large-size plantations ( $\geq 25 \mathrm{ha}$ ) with unknown concession permit) (NCONC) (Supplementary Figure 1). Areas outside natural forest and oil palm plantations mainly consist of agricultural lands, mixed plantations (e.g. rubber, coffee), shrubs, settlements, and infrastructure (Figure 1). For the third category of oil palm plantations (NCONC), we estimated the presence of different types of plantations, including those appearing to be large industrial scale and those appearing to be small-medium scale. Large-scale industrial plantations are typically characterized by an organized rectilinear grid form of planted blocks and plantation roads if they are located in flat terrain, or an organized curvy pattern if they are located on steep terrain ${ }^{66}$. Small-medium scale plantations are typically characterized by a patchy arrangement in a landscape mosaic (in which each patch can represent different ownership), or a more clustered arrangement but with less uniform plantation age or tree size than those found in industrial plantations (in which the different plantation age can be used to represent different ownerships). Our impact evaluation focussed specifically on oil palm plantations within concession boundaries (CONC) and RSPOcertified plantations (CERT), and excluded those outside known concession permits (NCONC).

It is worth noting that besides the RSPO, there is a mandatory sustainability standard and certification scheme for palm oil developed by the Indonesian government, known as the Indonesian Sustainable Palm Oil (ISPO). The ISPO standard was launched in 2011. By 2014, 40 oil palm companies had obtained the ISPO certification across Indonesia, and nearly all of these companies were also RSPO-certified ${ }^{67}$. The ISPO standard can theoretically provide a stronger compliance measure than the RSPO, e.g. ISPO can revoke a palm oil company's business permit whereas the RSPO can only withdraw the certificate. However, numerous studies have pointed out fundamental shortcomings of the ISPO mechanism, especially pertaining to the loose problem definition and lacking authority of the implementing organizations to enforce the sustainability standards (due to overlapping jurisdictions and absence of independency) ${ }^{68,69}$. Thus, we can stipulate that the impact of ISPO on village well-being over the study period is likely limited or negligible.

\section{Supplementary Methods 4: Impact evaluation analysis}

We conducted two separate impact evaluation analyses on poverty: (A) the impact of industrial oil palm plantations, and (B) the impact of RSPO certification. For each of two impact evaluations, we conducted a sequence of analytical steps as follows.

1. For each island and time period (or paired PODES censuses) we generated the propensity score or likelihood for the spatial assignment of industrial oil palm plantations (for analysis A) or certification (for analysis B) based on a given set of biophysical and socioeconomic variables.

2. We applied a binary matching method for each island and time period to select control villages with similar baseline characteristics as those in the treated villages through nearest neighbour matching or search of propensity score and exact matching of key categorical variables.

3. We applied difference-in-difference regression to the matched dataset.

4. We conducted diagnostic tests and sensitivity analyses to verify the robustness of our estimates against modelling specification and approach.

\section{Step 1: Generating propensity scores}

We generated the propensity scores for each island (i.e. Sumatra, Kalimantan and Papua for analysis A; Sumatra and Kalimantan for analysis B) and time period by employing a non-parametric generalized boosted regression model (GBM) for binary outcomes implemented in the R-package $\mathrm{gbm}^{70}$. The GBM model allows flexibility in fitting non-linear response curves for predicting treatment assignment and can incorporate a large 
number of covariates without negatively affecting model prediction. We controlled for potentially confounding variables in each impact assessment in terms of both selections of villages for treatment and the outcome being measured (Supplementary Table 2). To achieve this, we included variables representing: (a) socio-political factors, (b) accessibility, (c) agricultural productivity, and (d) baseline village socioeconomic conditions. This selection is based on previous analyses of oil palm expansion without certification in Kalimantan ${ }^{37,38}$.

We used the administration boundaries of the regency (kabupaten) (variable KBPT in Supplementary Table 2) and land use regulation or zoning ( $L Z O N)$ as proxies for socio-political factors. Mean elevation (ELEV) and slope (SLOP), proximity to large cities or arterial roads (CITY), baseline human population density (POPB), and baseline forest cover class (FORB) were used as proxies for accessibility. We used long-term rainfall patterns during the dry and wet seasons (SDRY and SWET), presence of peat soil (PEAT), and distance to transmigration areas (TRNS), as proxies for agricultural productivity. Village primary livelihoods $(L V H D)$ and wellbeing conditions (WLBN) at the initial stage of oil palm development or certification, and the extent of village (VILA) were used as proxies for baseline village socioeconomic conditions. In addition to these variables, for the certification impact assessment (analysis B) we included the proportion of village land area allocated to (noncertified) industrial oil palm plantations five years prior to certification (OPV).

\section{Step 2: Applying the matching method}

For analysis A, we employed a binary matching method ${ }^{71}$ to select a set of control villages in which oil palm plantations had not been developed and that exhibited the same baseline characteristics as villages where plantations had been established. For analysis B, we applied the matching to select a set of control oil palm villages without certification and which exhibited the same baseline characteristics as oil palm villages where certification had been granted. Both analyses $A$ and $B$ were performed based on nearest-neighbour matching of propensity scores using all variables described in Supplementary Table 2 and exact matching of the categorical baseline variables (i.e. KBPT, LZON, FORB, SOIL, and $L V H D$ ). We applied a 0.25 calliper width of the propensity scores' standard deviations in the nearest neighbour approach, as this width was previously shown to be optimal

72. Matching algorithms were implemented separately for each of the 18 indicators of well-being (Supplementary Table 1) in the R-package Matching ${ }^{73}$.

For analysis A, the matching method was applied for each of the indicators (Supplementary Table 1), three islands (Sumatra, Kalimantan, and Papua), and 11 time periods (Supplementary Table 4), separately. We observed substantial improvement in the extent of overlapping areas of all continuous variables (ELEV, SLOP, CITY, POPB, SDRY, SWET, TRNS, and VILA) between villages with and without industrial oil palm plantation development in the matched dataset compared to the original (unmatched) dataset (Supplementary Figure 7 and Supplementary Table 5; aggregated across 18 indicators of well-being, three islands, and 11 time periods). Thus, our matched dataset for assessing the impact of oil palm plantations comprises numerous paired villages with and without oil palm development, where each pair has similar values in mean elevation (ELEV) and slope (SLOP), proximity to large cities or arterial roads (CITY), long-term seasonal rainfall (SDRY and SWET), extent of village (VILA), and population density and distance to transmigration areas before oil palm development (POPB and TRNS), are located within the same regency (KBPT), and has an identical dominant soil type (SOIL), dominant land use zone $(L Z O N)$, forest cover class and village primary livelihoods at initial stage of oil palm development (FORB and $L V H D)$.

For analysis B, the matching method was applied for each indicator (Supplementary Table 1), two islands (Sumatra and Kalimantan), and three time periods (Supplementary Table 4), separately. Again, we observed substantial improvement in the extent of overlapping areas of all continuous variables (ELEV, SLOP, CITY, POPB, SDRY, SWET, TRNS, VILA, and OPV) in the oil palm villages with and without certification after 
matching was performed (Supplementary Figure 8 and Supplementary Table 6; aggregated across 18 indicators of well-being, two islands, and three time periods). Thus, our matched dataset for assessing the impact of RSPOcertification comprises numerous paired oil palm villages with and without certification, where each pair has similar values in variables as those described in analysis $\mathrm{A}$, and also a similar proportion of village land area allocated to (non-certified) industrial oil palm plantations three years prior to certification (OPV).

\section{Step 3: Fitting difference-in-difference regression to the matched datasets}

For each indicator of well-being $k$, we first calculated the change or difference over 5-11 years (i.e. between two PODES censuses), and then multiplied the change by $w_{k}$ (Supplementary Table 1 ). The value of $w_{k}$ represents the directional effect of the change in indicator $k$ that defines improvement in well-being, i.e. $w_{k}=1$ if positive change (or an increase) in indicator $k$ represents improvement in well-being (e.g. proportion of household with electricity) and $w_{k}=-1$ if negative change (or a reduction) in indicator $k$ represents improvement in well-being (e.g. prevalence of malnutrition, frequency of conflicts). We then divided the value by the maximum of the absolute change of well-being across all villages and time periods. Thus, we obtained values that ranged roughly between -1 and 1, where -1 and 1 denote the largest reduction and improvement in the well-being indicator across all study villages, respectively, and 0 denotes no change in the well-being indicator after 5-11 years. We applied this transformation approach mainly to preserve information about the directionality of change in wellbeing (i.e. relative improvement or reduction) over time, and to allow comparable measures across different indicators. Hence, for each island (i.e. Sumatra, Kalimantan, and Papua), time period (i.e. paired PODES censuses; Supplementary Table 4), and village livelihood type (i.e. subsistence and market-based livelihoods), we obtained $C_{k, i}$ as the change or difference in well-being $k$ in village $i$.

The impact of industrial oil palm plantations (analysis A) on village-level well-being was estimated by comparing the change in well-being indicators in villages with oil palm plantation development with the change in control villages without plantations, i.e. the difference in the differences in well-being indicators between two PODES censuses between oil palm and non oil palm villages (see Supplementary Table 3 for the number of villages assessed). For each well-being indicator $k$ for each island and village livelihood type, we fitted an ordinary linear regression model to $C_{k, i}$ with a dummy variable representing the treated and the control villages $\left(O P_{i}\right)$ and a variable representing time period or paired PODES censuses $\left(P R D_{i}\right)$ as predictors, i.e.

$$
C_{k, i}=\alpha_{k, 0}+\alpha_{k, 1} \cdot O P_{i}+\alpha_{k, 2} \cdot P R D_{i}
$$

The overall effect (and confidence interval) of industrial oil palm plantations on improving each aspect of wellbeing $m$ (i.e. socioeconomic and socioecological) for each island and livelihood type, i.e. $\dot{A}_{m}$, was obtained by pooling estimates $\alpha_{k, 1}$ across all indicators $k$ belonging to the same group of well-being aspect $m$ (Supplementary Table 1).

The impact of oil palm certification (analysis B) on village-level well-being was estimated by comparing the change in well-being indicators in oil palm villages with certified plantations with the change in control oil palm villages without certification, i.e. the difference in the differences in well-being indicators between two PODES censuses between certified and non certified oil palm villages (see Supplementary Table 3 for the number of villages assessed). We again fitted an ordinary linear regression model to $C_{k, i}$ with a dummy variable representing the treated and the control oil palm villages $\left(C E R T_{i}\right)$ and a variable representing time period or paired PODES censuses $\left(P R D_{i}\right)$ as predictors, i.e.

$$
C_{k, i}=\beta_{k, 0}+\beta_{k, 1} \cdot C E R T_{i}+\beta_{k, 2} \cdot P R D_{i}
$$

The overall effect (and confidence interval) of oil palm certification on improving each aspect of well-being $m$ for each island and livelihood type, i.e. $\dot{B}_{m}$, was obtained by pooling estimates $\beta_{k, 1}$ across all indicators $k$ belonging to the same group of well-being aspect $m$ (Supplementary Table 1). 


\section{Step 4: Conducting diagnostic tests and sensitivity analyses}

To assess the quality of our matched dataset we examined the change in the distributions of variables potentially affecting the assignments of industrial oil palm plantation villages (for analysis A) or certified plantation villages (for analysis B) before and after matching procedure. We achieved bias reduction of 92.9-98.6\% for covariates matched in analysis A (Supplementary Table 5), and $81.7-98.3 \%$ for analysis B (Supplementary Table 6), indicating that samples were strongly matched in both assessments.

We conducted sensitivity analyses to verify the robustness of our estimates against modelling specification and approach. This included: (1) generating propensity scores separately within island, time period, and livelihood type, in contrast to our main approach of generating the scores within island and time period; and (2) applying different categorization of well-being indicators by shifting the 'social' indicators (i.e. security and social equity) from socioecological to socioeconomic aspects.

\section{(1) Generating propensity scores within island, time period, and livelihood type}

For this alternative propensity score matching approach, we applied a sequence of impact evaluation analyses analogous to those described in the main manuscript, which includes: (1) generating propensity score or likelihood for the spatial assignment of industrial oil palm plantations (for analysis A) or certification (for analysis B) based on a given set of biophysical and socioeconomic variables within each island, livelihood type, and time period (or paired PODES censuses) (as opposed to within each island and time period applied in our main approach); (2) applying a binary matching method for each island, livelihood type, and time period to select control villages with similar baseline characteristics as those in the treated villages; and (3) applying differencein-difference regression to the matched dataset for each island and livelihood type.

The covariate balance table generated from this approach for the oil palm impact analysis (analysis A) for each type of livelihoods (subsistence and market-based livelihoods), aggregated across 11 time periods and three islands (Sumatra, Kalimantan, and Papua), is shown in Supplementary Table 7. We obtained bias reduction of $80.3-95.7 \%$ and $81.8-96.1 \%$ for covariates matched for villages with baseline subsistence production and market-based livelihoods, respectively (Supplementary Table 7). The covariate balance table generated for the RSPO-certification impact analysis (analysis B) for each livelihood type, aggregated across 3 time periods and two islands (Sumatra and Kalimantan), is shown in Supplementary Table 8. We obtained bias reduction of 81.6-93.3\% and $80.5-99.5 \%$ for covariates matched for villages with baseline subsistence production and marketbased livelihoods, respectively (Supplementary Table 8).

This alternative method for generating the propensity scores yielded similar conclusions about the impact of oil palm development (analysis A) and certification (analysis B) on well-being (Supplementary Figure 9) as those generated by the main approach (Figure 5). The estimated effects of oil palm plantations (analysis A) or RSPO certification (analysis B) on individual well-being indicator in subsistence and market-based villages obtained from the alternative method conform to those obtained from the main approach (Supplementary Figure 13). This suggests that our conclusions derived from the main method are robust against modelling specification.

\section{(2) Applying different indicators under the socioeconomic and socioecological aspects}

Our main approach classified indicators living conditions, infrastructure, and income support under the socioeconomic aspect and indicators security, social equity and natural hazard prevention under the socioecological aspect (Supplementary Table 1). However, it could be argued that the security and social equity indicators could also be classified under the socioeconomic aspect. Therefore, as an alternative well-being classification we used the living conditions, infrastructure, income support, security, and social equity indicators 
to define the socioeconomic aspect, leaving the natural hazard indicators to define the socioecological aspect. With respect to the Sustainable Livelihoods Analysis framework ${ }^{45}$ (Supplementary Figure 12), this implies that the alternative well-being classification considers the socioeconomic aspect to be represented by the human (basic), physical, financial, and social dimensions of well-being, and the socioecological aspect to be represented solely by the natural dimension.

For this alternative classification we only needed to modify the analysis step 3 in the impact evaluation analysis. This was achieved by pooling the estimated effects of oil palm development or certification on wellbeing indicators (obtained from the difference-in-difference regression) across alternative well-being grouping described above. The alternative grouping of indicators under the socioeconomic and socioecological aspects resulted in worsened performance of industrial oil palm development (analysis A) and certification (analysis B) on village well-being compared to the original approach taken (Supplementary Figure 10). This was because the negative impacts on key indicators of social well-being (i.e. prevalence of conflicts and low wage agricultural labourers) tended to be less pronounced than those on natural hazard prevalence, but worse than the impact on living conditions, infrastructure provision, and income support (Extended Data Figures 6-7). 


\section{Supplementary Tables}

Supplementary Table 1. PODES indicators used as proxies for two dimensions of well-being: socioeconomic and socioecological. Variable $w_{k}$ denotes the directional effect of the change in indicator $k$ that defines improvement in well-being. If $w_{k}=1$, then positive change (i.e. an increase) in indicator $k$ represents improvement in well-being. If $w_{k}=-1$, then negative change (i.e. a reduction) in indicator $k$ represents improvement in wellbeing.

\begin{tabular}{|c|c|c|c|c|c|c|}
\hline \multirow[t]{2}{*}{$\begin{array}{l}\text { Dimension } \\
\text { of } \\
\text { well-being }\end{array}$} & \multirow[t]{2}{*}{$\begin{array}{l}\text { PODES } \\
\text { indicator } \\
(k)\end{array}$} & \multirow[t]{2}{*}{ Description } & \multirow[t]{2}{*}{ Response } & \multicolumn{2}{|c|}{$\begin{array}{l}\text { Directional effect of the change } \\
\text { in variable } k \text { that defines } \\
\text { improvement }\end{array}$} & \multirow[t]{2}{*}{ Refs. } \\
\hline & & & & $w_{k}$ & Meaning & \\
\hline \multicolumn{7}{|c|}{ SOCIOECONOMIC } \\
\hline \multirow[t]{5}{*}{$\begin{array}{l}\text { BASIC } \\
\text { (Living } \\
\text { conditions) }\end{array}$} & POOR & $\begin{array}{l}\text { Proportions of } \\
\text { households with poor } \\
\text { housing conditions * }\end{array}$ & Continuous & -1 & $\begin{array}{l}\text { Well-being improves when } \\
\text { fewer households have } \\
\text { poor housing conditions. }\end{array}$ & 74,75 \\
\hline & ELCT & $\begin{array}{l}\text { Proportions of } \\
\text { households with } \\
\text { electricity * }\end{array}$ & Continuous & 1 & $\begin{array}{l}\text { Well-being improves when } \\
\text { more households have } \\
\text { electricity. }\end{array}$ & 76,77 \\
\hline & COOK & $\begin{array}{l}\text { Cooking fuel for } \\
\text { majority of } \\
\text { households }\end{array}$ & $\begin{array}{l}\text { Categorical } \\
\text { (1=electricity or } \\
\text { liquefied petroleum } \\
\text { gas, } 2=\text { kerosene, } \\
\text { 3=wood/others) }\end{array}$ & -1 & $\begin{array}{l}\text { Well-being improves when } \\
\text { there is change to lower } \\
\text { fuel, e.g. a change from } \\
\text { category } 3 \text { (wood/others) } \\
\text { to } 2 \text { (kerosene). }\end{array}$ & 78,79 \\
\hline & TOLT & $\begin{array}{l}\text { Toilet facilities for } \\
\text { majority of } \\
\text { households }\end{array}$ & $\begin{array}{l}\text { Categorical (1=own } \\
\text { toilet, } 2=\text { =joint toilet, } \\
3=\text { public toilet, } \\
4=\text { non-toilet) }\end{array}$ & -1 & $\begin{array}{l}\text { Well-being improves when } \\
\text { there is change to a lower } \\
\text { category, e.g. a change } \\
\text { from category } 2 \text { (joint } \\
\text { toilet) to } 1 \text { (own toilet). }\end{array}$ & 80,81 \\
\hline & MLNT & $\begin{array}{l}\text { Child malnutrition } \\
\text { incidence in the last } \\
\text { year } \dagger\end{array}$ & Continuous & -1 & $\begin{array}{l}\text { Well-being improves when } \\
\text { there are fewer } \\
\text { malnutrition incidents. }\end{array}$ & 41,82 \\
\hline \multirow{3}{*}{$\begin{array}{l}\text { PHYSICAL } \\
\text { (Health and } \\
\text { education } \\
\text { infrastructure }\end{array}$} & HEAL & $\begin{array}{l}\text { Distance to nearest } \\
\text { healthcare facility }\end{array}$ & Continuous & -1 & $\begin{array}{l}\text { Well-being improves when } \\
\text { health facilities are nearby. }\end{array}$ & 83,84 \\
\hline & $\mathrm{PSCH}$ & $\begin{array}{l}\text { Distance to nearest } \\
\text { primary school }\end{array}$ & Continuous & -1 & $\begin{array}{l}\text { Well-being improves when } \\
\text { primary schools are } \\
\text { nearby. }\end{array}$ & 85,86 \\
\hline & $\mathrm{SSCH}$ & $\begin{array}{l}\text { Distance to nearest } \\
\text { secondary school }\end{array}$ & Continuous & -1 & $\begin{array}{l}\text { Well-being improves when } \\
\text { secondary schools are } \\
\text { nearby. }\end{array}$ & 87,88 \\
\hline \multirow[t]{2}{*}{$\begin{array}{l}\text { FINANCIAL } \\
\text { (Income support) }\end{array}$} & COOP & $\begin{array}{l}\text { Number of active } \\
\text { village cooperative } \\
\text { schemes or other } \\
\text { schemes } \ddagger\end{array}$ & Continuous & 1 & $\begin{array}{l}\text { Well-being improves when } \\
\text { active cooperative } \\
\text { schemes or other related } \\
\text { schemes are more } \\
\text { prevalent. }\end{array}$ & \begin{tabular}{|l|l|}
68,89 \\
\end{tabular} \\
\hline & CRDT & $\begin{array}{l}\text { Number of credit } \\
\text { facilities for farmers } \\
\text { or communities } \ddagger\end{array}$ & Continuous & 1 & $\begin{array}{l}\text { Well-being improves when } \\
\text { there are more credit } \\
\text { available for farmers or } \\
\text { communities. }\end{array}$ & 90,91 \\
\hline
\end{tabular}




\begin{tabular}{|c|c|c|c|c|c|c|}
\hline \multicolumn{7}{|c|}{ SOCIOECOLOGICAL } \\
\hline \multirow[t]{5}{*}{$\begin{array}{l}\text { SOCIAL } \\
\text { (Security and } \\
\text { social equity) }\end{array}$} & CNFL & $\begin{array}{l}\text { Frequency of } \\
\text { conflicts among } \\
\text { communities in the } \\
\text { last year }\end{array}$ & Continuous & -1 & $\begin{array}{l}\text { Well-being improves when } \\
\text { conflicts are less prevalent. }\end{array}$ & \begin{tabular}{|c|}
92,93 \\
\end{tabular} \\
\hline & AGLB & $\begin{array}{l}\text { Proportion of families } \\
\text { with agricultural } \\
\text { wage labourers ** }\end{array}$ & Continuous & -1 & $\begin{array}{l}\text { Well-being improves when } \\
\text { families with agricultural } \\
\text { wage labourers are less } \\
\text { prevalent. }\end{array}$ & 94,95 \\
\hline & SIND & $\begin{array}{l}\text { Number of small } \\
\text { industries }(<20 \\
\text { employees }) \ddagger\end{array}$ & Continuous & 1 & $\begin{array}{l}\text { Well-being improves when } \\
\text { small enterprises are more } \\
\text { prevalent. }\end{array}$ & 96,97 \\
\hline & SUIC & $\begin{array}{l}\text { Suicidal rates in the } \\
\text { last year } \dagger\end{array}$ & Continuous & -1 & $\begin{array}{l}\text { Well-being improves when } \\
\text { suicidal events are less } \\
\text { prevalent. }\end{array}$ & 98,99 \\
\hline & GTRY & $\begin{array}{l}\text { Frequency of } \\
\text { voluntary community } \\
\text { cleaning and } \\
\text { maintenance (gotong } \\
\text { royong) in the last } \\
\text { year }\end{array}$ & Continuous & 1 & $\begin{array}{l}\text { Well-being improves when } \\
\text { gotong royong are more } \\
\text { frequent. }\end{array}$ & 100,101 \\
\hline \multirow[t]{3}{*}{$\begin{array}{l}\text { ENIRONMENT, } \\
\text { (Natural hazard } \\
\text { prevention) }\end{array}$} & WPOL & $\begin{array}{l}\text { Water pollution over } \\
\text { the last } 3 \text { years }\end{array}$ & $\begin{array}{l}\text { Categorical } \\
(1=\text { none, } 2=\text { mild, } \\
3=\text { severe })\end{array}$ & -1 & $\begin{array}{l}\text { Well-being improves when } \\
\text { there is a change to a } \\
\text { lower water pollution } \\
\text { category, e.g. a change } \\
\text { from category } 2 \text { (mild) to } 1 \\
\text { (none). }\end{array}$ & 102,103 \\
\hline & APOL & $\begin{array}{l}\text { Air pollution over the } \\
\text { last } 3 \text { years }\end{array}$ & $\begin{array}{l}\text { Categorical } \\
(1=\text { none, } 2=\text { mild, } \\
3=\text { severe })\end{array}$ & -1 & $\begin{array}{l}\text { Well-being improves when } \\
\text { there is change to lower } \\
\text { air pollution category, e.g. } \\
\text { a change from category } 2 \\
\text { (mild) to } 1 \text { (none). }\end{array}$ & 104,105 \\
\hline & FLOD & $\begin{array}{l}\text { Frequency of floods } \\
\text { and landslides over } \\
\text { the last } 3 \text { years }\end{array}$ & Continuous & -1 & $\begin{array}{l}\text { Well-being improves when } \\
\text { floods and landslides are } \\
\text { less frequent. }\end{array}$ & 106,107 \\
\hline
\end{tabular}

† per 1000 people, $\ddagger$ per 100 households, ${ }^{*}$ of total households, ${ }^{* \star}$ of total agricultural families 
Supplementary Table 2. Confounding variables controlled for in the assessment of the oil-palm impact and RSPO certification impact on village well-being.

\begin{tabular}{|c|c|c|c|}
\hline Variable & Description & Type (Scale) & Data source \\
\hline \multicolumn{4}{|c|}{ SOCIO-POLITICAL FACTORS } \\
\hline KBPT & Regency (kabupaten) boundaries & Categorical & Potensi Desa (PODES) ${ }^{33}$ \\
\hline$\angle Z O N$ & Majority of legalized land use zone & $\begin{array}{l}\text { Categorical } \\
\text { (HP=Production Forest; } \\
\text { APL=Non Forest Estate) }\end{array}$ & $\begin{array}{l}\text { Peta Kawasan Hutan or Forest } \\
\text { Zone Map }{ }^{108}\end{array}$ \\
\hline \multicolumn{4}{|c|}{$\overline{\text { ACCESSIBILITY }}$} \\
\hline$E L E V$ & Mean elevation & Continuous (m a.s.l) & $\begin{array}{l}\text { SRTM 90m Digital Elevation } \\
\text { Database v4.1 }\end{array}$ \\
\hline SLOP & Mean slope & Continuous (degree) & $\begin{array}{l}\text { SRTM 90m Digital Elevation } \\
\text { Database } v 4.1_{109}\end{array}$ \\
\hline CITY & $\begin{array}{l}\text { Mean distance to large cities or arterial } \\
\text { roads }\end{array}$ & Continuous $(\log (\mathrm{km}))$ & $\begin{array}{l}\text { Provincial map from Geospatial } \\
\text { Information Agency Indonesia }\end{array}$ \\
\hline$P O P B$ & $\begin{array}{l}\text { Mean human population density per } \\
\mathrm{km}^{2} \text { prior to of oil palm development }\end{array}$ & Continuous (log(people)) & Potensi Desa (PODES) ${ }^{33}$ \\
\hline FORB & $\begin{array}{l}\% \text { natural forest cover a year prior to } \\
\text { oil-palm development }\end{array}$ & $\begin{array}{l}\text { Categorical } \\
(1=0-25 \% ; 2=26-50 \% ; \\
3=51-75 \% ; 4=76-100 \%)\end{array}$ & $\begin{array}{l}\text { Global Forest Change dataset } \\
\text { and Indonesia's primary and } \\
\text { secondary forest map }\end{array}$ \\
\hline \multicolumn{4}{|c|}{ AGRICULTURAL PRODUCTIVITY } \\
\hline$S D R Y$ & $\begin{array}{l}\text { Mean long-term monthly rainfall during } \\
\text { dry season }\end{array}$ & Continuous (mm) & WorldClim ${ }^{111}$ \\
\hline SWET & $\begin{array}{l}\text { Mean long-term monthly rainfall during } \\
\text { wet season }\end{array}$ & Continuous (mm) & WorldClim ${ }^{111}$ \\
\hline SOIL & Presence of peat soil & $\begin{array}{l}\text { Categorical } \\
(1=\text { Peat; } 0=\text { Mineral })\end{array}$ & $\begin{array}{l}\text { Peta Kesatuan Hidrologi Gambut } \\
\text { or Peat Hydrological Area Map } \\
112\end{array}$ \\
\hline TRNS & $\begin{array}{l}\text { Mean distance to transmigration areas } \\
\text { prior to oil palm development }\end{array}$ & Continuous $(\log (\mathrm{km}))$ & $\begin{array}{l}\text { Peta Penutupan Lahan or Land } \\
\text { Cover Map }\end{array}$ \\
\hline \multicolumn{4}{|c|}{ BASELINE VILLAGE SOCIOECONOMIC CONDITION } \\
\hline$L V H D$ & $\begin{array}{l}\text { Village primary livelihood at initial stage } \\
\text { of oil palm development }\end{array}$ & $\begin{array}{l}\text { Categorical } \\
\text { (1=Subsistence livelihoods; } \\
2=\text { Agricultural plantations } \\
\text { (polyculture and } \\
\text { monoculture); } 3=\text { Other } \\
\text { sectors. }\end{array}$ & Potensi Desa (PODES) ${ }^{33}$ \\
\hline$W L B N_{k}$ & $\begin{array}{l}\text { Baseline well-being indicator } k \text { (Table } \\
\text { S1) at initial stage of oil palm } \\
\text { development }\end{array}$ & $\begin{array}{l}\text { Either continuous or } \\
\text { categorical }\end{array}$ & Potensi Desa (PODES) ${ }^{33}$ \\
\hline VILA & Extent of village & Continuous $\left(\log \left(\mathrm{km}^{2}\right)\right)$ & Potensi Desa (PODES) ${ }^{33}$ \\
\hline OPVF & $\begin{array}{l}\text { Proportion of village land area allocated } \\
\text { to industrial oil palm plantations three } \\
\text { years prior to certification }\end{array}$ & Continuous (\%) & $\begin{array}{l}\text { Oil palm plantation maps }{ }^{37,38} \\
\text { and oil palm concession } \\
\text { boundaries }{ }^{63} \text {. See Methods for } \\
\text { detailed approach and } \\
\text { references. }\end{array}$ \\
\hline
\end{tabular}

$\mp$ This variable is used only for assessing the RSPO-certification impact. 
Supplementary Table 3. Number of villages used in: (1) land-use and livelihood change analysis at village level, and (2) impact evaluation analysis, consist of evaluating: (A) impact of industrial oil palm plantations, and (B) impact of RSPO certified plantations.

\begin{tabular}{lccccr}
\hline Analysis & Total & \multicolumn{3}{c}{ By island } \\
\cline { 5 - 6 } & villages & Sumatra & Kalimantan & Papua \\
\hline (1) & Land use and livelihood change analysis & 3,396 & 2,065 & 1,295 & 36 \\
\hline (2) & $\begin{array}{l}\text { Impact evaluation analysis (with number of treated } \\
\text { villages, excluding controls) }\end{array}$ & & & & \\
\hline$\quad$ Analysis A: Impact of industrial oil palm plantations & 587 & 200 & 356 & 31 \\
\hline$\quad$ Analysis B: Impact of RSPO-certified plantations & 500 & 392 & 108 & 0 \\
\hline
\end{tabular}

Supplementary Table 4. PODES censuses used to assess the change in village well-being (indicated in check marks) 5-11 years after the industrial oil palm plantations had been developed and 5-11 years after the certification had been issued or proposed. The first certification was issued or proposed in 2009.

\begin{tabular}{|c|c|c|c|c|c|c|c|c|c|c|}
\hline \multirow[b]{2}{*}{ Analysis type } & \multirow{2}{*}{$\begin{array}{l}\text { Plantation or } \\
\text { certification } \\
\text { age (years) }\end{array}$} & \multirow{2}{*}{$\begin{array}{l}\text { Analysis } \\
\text { time frame }\end{array}$} & \multirow{2}{*}{$\begin{array}{c}\text { Baseline } \\
\text { year }\end{array}$} & \multicolumn{7}{|c|}{ PODES census year } \\
\hline & & & & 2000 & 2003 & 2005 & 2008 & 2011 & 2014 & 2018 \\
\hline \multirow{11}{*}{$\begin{array}{l}\text { Impact of } \\
\text { industrial oil } \\
\text { palm plantation } \\
\text { development }\end{array}$} & 5 & $2000-2005$ & 2000 & $\sqrt{ }$ & & $\sqrt{ }$ & & & & \\
\hline & 8 & $2000-2008$ & 2000 & $\sqrt{ }$ & & & $\sqrt{ }$ & & & \\
\hline & 11 & $2000-2011$ & 2000 & $\sqrt{ }$ & & & & $\sqrt{ }$ & & \\
\hline & 5 & $2003-2008$ & 2003 & & $\sqrt{ }$ & & $\sqrt{ }$ & & & \\
\hline & 8 & $2003-2011$ & 2003 & & $\sqrt{ }$ & & & $\sqrt{ }$ & & \\
\hline & 11 & $2003-2014$ & 2003 & & $\sqrt{ }$ & & & & $\sqrt{ }$ & \\
\hline & 6 & $2005-2011$ & 2005 & & & $\sqrt{ }$ & & $\sqrt{ }$ & & \\
\hline & 9 & $2005-2014$ & 2005 & & & $\sqrt{ }$ & & & $\sqrt{ }$ & \\
\hline & 6 & $2008-2014$ & 2008 & & & & $\sqrt{ }$ & & $\sqrt{ }$ & \\
\hline & 10 & $2008-2018$ & 2008 & & & & $\sqrt{ }$ & & & $\sqrt{ }$ \\
\hline & 7 & $2011-2018$ & 2011 & & & & & $\sqrt{ }$ & & $\sqrt{ }$ \\
\hline Impact of & 6 & $2008-2014$ & 2008 & & & & $\sqrt{ }$ & & $\sqrt{ }$ & \\
\hline RSPO & 10 & $2008-2018$ & 2008 & & & & $\sqrt{ }$ & & & $\sqrt{ }$ \\
\hline certification & 7 & $2011-2018$ & 2011 & & & & & $\sqrt{ }$ & & $\sqrt{ }$ \\
\hline
\end{tabular}


Supplementary Table 5. Distribution of covariates before and after matching for the oil palm plantation impact analysis (analysis A). Covariate balance from the propensity score matching analysis for the oil palm plantation impact analysis. Covariates include ELEV (elevation), SLOP (slope), CITY (distance to nearest city), $P O P B$ (human population density), SDRY (long-term mean monthly rainfall during the dry period), SWET (longterm mean monthly rainfall during the wet period), TRNS (distance to transmigration areas), and VILA (the extent of villages). The results are aggregated across 11 time periods and three islands (Sumatra, Kalimantan and Papua). Percent bias, i.e. $B$, was calculated as: $100 \cdot\left(M_{t}-M_{c}\right) \cdot\left(0.5 \cdot\left(V_{t}+V_{c}\right)\right)^{-0.5}$, where $M_{t}$ and $M_{c}$ are the mean for treated and control villages, and $V_{t}$ and $V_{c}$ are the variance for the treated and control villages. Percentage bias reduction was calculated as $100 \cdot\left(B_{u}-B_{m}\right) / B_{u}$, where $B_{u}$ and $B_{m}$ are percentage bias before and after matching (or for unmatched and matched samples), respectively. Bias reduction of higher than $80 \%$ indicates satisfactory matched samples (sufficient overlap between treated and control villages).

\begin{tabular}{|c|c|c|c|c|c|c|c|}
\hline \multirow[t]{3}{*}{ Covariate } & \multicolumn{4}{|c|}{ Mean (standard deviation) } & \multicolumn{2}{|c|}{ Percent bias $(B)$} & \multirow{3}{*}{$\begin{array}{c}\text { Bias } \\
\text { reduction } \\
(\%)\end{array}$} \\
\hline & \multicolumn{2}{|c|}{ Before matching } & \multicolumn{2}{|c|}{ After matching } & \multirow{2}{*}{$\begin{array}{c}\text { Before } \\
\text { matching }\end{array}$} & \multirow{2}{*}{$\begin{array}{c}\text { After } \\
\text { matching }\end{array}$} & \\
\hline & $\begin{array}{l}\text { Treated } \\
\text { villages }\end{array}$ & $\begin{array}{l}\text { Control } \\
\text { villages }\end{array}$ & $\begin{array}{l}\text { Treated } \\
\text { villages }\end{array}$ & $\begin{array}{l}\text { Control } \\
\text { villages }\end{array}$ & & & \\
\hline ELEV & $40.08(33.33)$ & $57.89(57.95)$ & $44.09(36.19)$ & $45.06(36.36)$ & -37.66 & -2.67 & 92.92 \\
\hline SLOP & $1.95(1.24)$ & $2.72(2.66)$ & $2.06(1.30)$ & $2.09(1.31)$ & -36.99 & -2.04 & 94.49 \\
\hline $\log (\mathrm{Cl}$ & $2.54(0.93)$ & $2.06(1$ & $2.30(0.92)$ & $2.28(0.96)$ & 47.00 & 2.06 & 95.6 \\
\hline $\log (P O P B)$ & $3.46(1.22)$ & $4.31(1.78)$ & $3.70(1.28)$ & $3.74(1.27)$ & -55.73 & -2.79 & 94.99 \\
\hline$S D R Y$ & $204.83(63.74)$ & $189.96(74.16)$ & $206.42(66.13)$ & $205.39(69.07)$ & 21.50 & 1.52 & 92.91 \\
\hline SWET & $256.18(58.01)$ & $263.46(76.66)$ & $256.83(62.11)$ & $257.11(62.20)$ & -10.72 & -0.45 & 95.82 \\
\hline $\log (T R N S)$ & $1.13(1.23)$ & $1.45(1.48)$ & $1.05(1.20)$ & $1.07(1.20)$ & -23.04 & -1.63 & 92.92 \\
\hline $\log (V I L A)$ & $3.66(1.08)$ & $2.67(1.36)$ & $3.38(1.04)$ & $3.37(1.05)$ & 80.06 & 1.19 & 98.51 \\
\hline
\end{tabular}


Supplementary Table 6. Distribution of covariates before and after matching for the oil palm certification impact analysis (analysis B). Covariate balance from the propensity score matching analysis for the RSPOcertification impact analysis. Covariates include ELEV (elevation), SLOP (slope), CITY (distance to nearest city), $P O P B$ (human population density), SDRY (long-term mean monthly rainfall during the dry period), SWET (longterm mean monthly rainfall during the wet period), TRNS (distance to transmigration areas), VILA (the extent of villages), and $O P V$ (proportions of villages land area allocated to industrial oil palm plantations). The results are aggregated across 3 time periods and two islands (Sumatra and Kalimantan). Percent bias, i.e. $B$, was calculated as: $100 \cdot\left(M_{t}-M_{c}\right) \cdot\left(0.5 \cdot\left(V_{t}+V_{c}\right)\right)^{-0.5}$, where $M_{t}$ and $M_{c}$ are the mean for treated and control villages, and $V_{t}$ and $V_{c}$ are the variance for the treated and control villages. Percentage bias reduction was calculated as $100 \cdot\left(B_{u}-\right.$ $\left.B_{m}\right) / B_{u}$, where $B_{u}$ and $B_{m}$ are percentage bias before and after matching (or for unmatched and matched samples), respectively. Bias reduction of higher than $80 \%$ indicates satisfactory matched samples (sufficient overlap between treated and control villages).

\begin{tabular}{|c|c|c|c|c|c|c|c|}
\hline \multirow[t]{3}{*}{ Covariate } & \multicolumn{4}{|c|}{ Mean (standard deviation) } & \multicolumn{2}{|c|}{ Percentage bias $(B)$} & \multirow{3}{*}{$\begin{array}{c}\text { Bias } \\
\text { reduction } \\
(\%)\end{array}$} \\
\hline & \multicolumn{2}{|c|}{ Before matching } & \multicolumn{2}{|c|}{ After matching } & \multirow{2}{*}{$\begin{array}{c}\text { Before } \\
\text { matching }\end{array}$} & \multirow{2}{*}{$\begin{array}{c}\text { After } \\
\text { matching }\end{array}$} & \\
\hline & $\begin{array}{l}\text { Treated } \\
\text { villages }\end{array}$ & $\begin{array}{l}\text { Control } \\
\text { villages }\end{array}$ & $\begin{array}{l}\text { Treated } \\
\text { villages }\end{array}$ & $\begin{array}{l}\text { Control } \\
\text { villages }\end{array}$ & & & \\
\hline ELEV & $46.38(35.23)$ & $45.97(42.60)$ & $47.08(35.13)$ & $47.03(37.40)$ & 1.05 & 0.14 & 86.19 \\
\hline SLOP & $1.58(0.65)$ & $1.88(1.25)$ & $1.57(0.65)$ & $1.60(0.63)$ & -29.97 & -4.25 & 85.82 \\
\hline $\log (C / T Y)$ & $8.63(1.27)$ & $8.90(1.18)$ & $8.66(1.22)$ & $8.68(1.29)$ & -22.12 & -1.53 & 93.10 \\
\hline $\log (P O P B)$ & $4.70(1.21)$ & $4.49(1.24)$ & $4.60(1.20)$ & $4.59(1.31)$ & 17.02 & 1.10 & 93.56 \\
\hline SDRY & $241.42(57.32)$ & $210.71(63.12)$ & $242.68(56.97)$ & $242.20(57.97)$ & 50.93 & 0.84 & 98.36 \\
\hline SWET & $198.56(64.09)$ & $243.75(74.44)$ & $202.45(62.41)$ & $203.19(71.04)$ & -65.07 & -1.09 & 98.32 \\
\hline $\log (T R N S)$ & $2.42(1.71)$ & $1.31(1.50)$ & $2.40(1.74)$ & $2.28(1.83)$ & 69.08 & 6.30 & 90.88 \\
\hline $\log (V I L A)$ & $2.77(0.97)$ & $2.93(1.01)$ & $2.79(0.92)$ & $2.82(1.01)$ & -16.65 & -3.04 & 81.74 \\
\hline OPV & $79.00(17.11)$ & $46.44(25.34)$ & $77.14(17.30)$ & $75.76(20.77)$ & 150.61 & 7.23 & 95.20 \\
\hline
\end{tabular}


Supplementary Table 7. Distribution of covariates before and after matching for the oil palm plantation impact analysis (analysis A) obtained from alternative propensity score matching method, separately for subsistence and market-based villages. Covariate balance from the propensity score matching analysis for the oil palm plantation impact analysis for subsistence and market-based villages. Covariates include ELEV (elevation), SLOP (slope), CITY (distance to nearest city), POPB (human population density), SDRY (long-term mean monthly rainfall during the dry period), SWET (long-term mean monthly rainfall during the wet period), TRNS (distance to transmigration areas), and VILA (the extent of villages). Results are aggregated across 11 time periods and three islands (Sumatra, Kalimantan and Papua). See Supplementary Tables 4-5 for calculation of the percent bias and bias reduction. Bias reduction of higher than $80 \%$ indicates satisfactory matched samples.

\begin{tabular}{|c|c|c|c|c|c|c|c|}
\hline \multirow{3}{*}{$\begin{array}{c}\text { Livelihoods } \\
\& \\
\text { Covariate } \\
\end{array}$} & \multicolumn{4}{|c|}{ Mean (standard deviation) } & \multicolumn{2}{|c|}{ Percent bias } & \multirow{3}{*}{$\begin{array}{c}\text { Bias } \\
\text { reduction } \\
(\%)\end{array}$} \\
\hline & \multicolumn{2}{|c|}{ Before matching } & \multicolumn{2}{|c|}{ After matching } & \multirow{2}{*}{$\begin{array}{c}\text { Before } \\
\text { matching }\end{array}$} & \multirow{2}{*}{$\begin{array}{c}\text { After } \\
\text { matching }\end{array}$} & \\
\hline & Treated & Control & Treated & Control & & & \\
\hline \multicolumn{8}{|c|}{ SUBSISTENCE VILLAGES } \\
\hline ELEV & 34.88 (29.39) & $53.26(57.49)$ & $36.11(32.56)$ & 38.34 (45.55) & -40.26 & -5.64 & 86.00 \\
\hline SLOP & $1.88(1.33)$ & $2.54(2.64)$ & $1.84(1.40)$ & $1.90(1.50)$ & -31.57 & -4.49 & 85.77 \\
\hline $\log (C / T Y)$ & $2.69(0.94)$ & $2.12(1.16)$ & $2.46(0.95)$ & $2.44(1.06)$ & 54.35 & 2.32 & 95.74 \\
\hline $\log (P O P B)$ & $3.31(1.30)$ & $4.22(1.77)$ & $3.50(1.39)$ & $3.63(1.42)$ & -58.94 & -9.32 & 84.19 \\
\hline$S D R Y$ & $194.29(67.13)$ & $187.82(79.07$ & $195.04(73.67)$ & $193.76(75.15)$ & 8.81 & 1.71 & 80.56 \\
\hline SWET & $257.51(62.87)$ & $269.81(81.10)$ & $257.26(67.70)$ & 259.54 (68.59) & -16.96 & -3.35 & 80.26 \\
\hline $\log (T R N S)$ & $1.06(1.18)$ & $1.50(1.54)$ & $1.10(1.15)$ & $1.17(1.36)$ & -32.12 & -5.74 & 82.12 \\
\hline $\log (V I L A)$ & $3.70(1.11)$ & $2.62(1.41)$ & $3.40(1.04)$ & $3.25(1.17)$ & 85.38 & 13.66 & 84.01 \\
\hline \multicolumn{8}{|c|}{ MARKET-BASED VILLAGES } \\
\hline ELEV & $45.29(36.13)$ & $65.06(57.93)$ & $52.31(37.92)$ & $54.74(40.52)$ & -40.96 & -6.20 & 84.86 \\
\hline SLOP & $2.02(1.14)$ & $3.00(2.67)$ & $2.30(1.16)$ & $2.41(2.06)$ & -47.58 & -6.99 & 85.31 \\
\hline $\log (C I T Y)$ & $2.38(0.90)$ & $1.96(1.03)$ & $2.13(0.86)$ & $2.12(0.91)$ & 44.22 & 1.74 & 96.07 \\
\hline $\log (P O P B)$ & $3.62(1.12)$ & $4.45(1.78)$ & $3.81(1.16)$ & $3.84(1.23)$ & -56.07 & -2.65 & 95.28 \\
\hline$S D R Y$ & $215.37(58.34)$ & $193.29(65.69)$ & $218.13(58.97)$ & $214.35(60.96)$ & 35.55 & 6.31 & 82.26 \\
\hline SWET & $254.85(52.72)$ & $269.12(68.82)$ & $259.48(55.76)$ & $260.58(60.63)$ & -23.28 & -1.89 & 91.88 \\
\hline $\log (T R N S)$ & $1.21(1.27)$ & $1.36(1.37)$ & $1.22(1.25)$ & $1.24(1.28)$ & -11.76 & -2.14 & 81.76 \\
\hline $\log (V I L A)$ & $3.62(1.06)$ & $2.76(1.28)$ & $3.37(1.04)$ & $3.24(1.11)$ & 72.93 & 12.21 & 83.26 \\
\hline
\end{tabular}


Supplementary Table 8. Distribution of covariates before and after matching for the RSPO-certification impact analysis (analysis B) obtained from alternative propensity score matching method, separately for subsistence and market-based villages. Covariate balance from the propensity score matching analysis for the RSPO-certification impact analysis for subsistence and marker-based villages. Covariates include ELEV (elevation), SLOP (slope), CITY (distance to nearest city), POPB (human population density), SDRY (long-term mean monthly rainfall during the dry period), SWET (long-term mean monthly rainfall during the wet period), TRNS (distance to transmigration areas), and VILA (the extent of villages). Results are aggregated across 3 time periods and two islands (Sumatra and Kalimantan). See Supplementary Tables 4-5 for calculation of the percent bias and bias reduction. Bias reduction of higher than $80 \%$ indicates satisfactory matched samples.

\begin{tabular}{|c|c|c|c|c|c|c|c|}
\hline \multirow{3}{*}{$\begin{array}{c}\text { Livelihoods } \\
\& \\
\text { Covariate } \\
\end{array}$} & \multicolumn{4}{|c|}{ Mean (standard deviation) } & \multicolumn{2}{|c|}{ Percent bias } & \multirow{3}{*}{$\begin{array}{c}\text { Bias } \\
\text { reduction } \\
(\%)\end{array}$} \\
\hline & \multicolumn{2}{|c|}{ Before matching } & \multicolumn{2}{|c|}{ After matching } & \multirow{2}{*}{$\begin{array}{c}\text { Before } \\
\text { matching }\end{array}$} & \multirow{2}{*}{$\begin{array}{c}\text { After } \\
\text { matching }\end{array}$} & \\
\hline & Treated & Control & Treated & Control & & & \\
\hline \multicolumn{8}{|c|}{ SUBSISTENCE VILLAGES } \\
\hline ELEV & $60.26(57.86)$ & $39.16(44.42)$ & $60.55(59.19)$ & $55.93(63.36)$ & 40.93 & 7.53 & 81.61 \\
\hline SLOP & $1.30(0.30)$ & $1.69(1.27)$ & $1.31(0.31)$ & $1.34(0.40)$ & -42.16 & -6.46 & 84.67 \\
\hline $\log (C I T Y)$ & $8.41(0.83)$ & $8.86(1.17)$ & $8.42(0.88)$ & $8.47(1.15)$ & -44.40 & -4.52 & 89.81 \\
\hline $\log (P O P B)$ & $5.13(1.38)$ & $4.53(1.40)$ & $5.15(1.40)$ & $5.10(1.49)$ & 43.19 & 2.91 & 93.26 \\
\hline$S D R Y$ & $238.88(66.47)$ & $206.97(71.92)$ & $240.42(67.94)$ & $236.10(65.83)$ & 46.08 & 6.45 & 86.00 \\
\hline SWET & $179.38(75.70)$ & $239.46(85.01)$ & $178.53(70.28)$ & $183.12(78.01)$ & -74.64 & -6.19 & 91.71 \\
\hline $\log (T R N S)$ & $3.30(1.39)$ & $1.30(1.56)$ & $3.35(1.39)$ & $3.16(1.73)$ & 135.59 & 12.03 & 91.13 \\
\hline $\log (V I L A)$ & $2.57(1.08)$ & $2.79(1.08)$ & $2.52(1.09)$ & $2.56(1.12)$ & -20.41 & -3.06 & 85.00 \\
\hline OPV & $71.93(15.48)$ & $46.61(25.14)$ & $72.68(16.05)$ & $69.31(18.47)$ & 121.31 & 19.47 & 83.95 \\
\hline \multicolumn{8}{|c|}{ MARKET-BASED VILLAGES } \\
\hline$E L E V$ & 44.49 (30.64) & $48.72(41.53)$ & $45.07(29.75)$ & $45.77(31.78)$ & -11.59 & -2.26 & 80.54 \\
\hline SLOP & $1.62(0.68)$ & $1.95(1.24)$ & $1.60(0.69)$ & $1.64(0.64)$ & -33.82 & -5.26 & 84.43 \\
\hline $\log (C / T Y)$ & $8.66(1.31)$ & $8.92(1.18)$ & $8.60(1.27)$ & $8.63(1.21)$ & -20.55 & -2.63 & 87.20 \\
\hline $\log (P O P B)$ & $4.64(1.18)$ & $4.47(1.17)$ & $4.61(1.19)$ & $4.59(1.21)$ & 14.20 & 2.08 & 85.37 \\
\hline SDRY & $241.76(56.13)$ & $212.22(59.15)$ & $242.13(55.17)$ & $237.22(56.79)$ & 51.23 & 8.77 & 82.89 \\
\hline SWET & 201.17 (62.09) & $245.49(69.66)$ & $206.87(60.58)$ & 207.09 (69.24) & -67.17 & -0.34 & 99.49 \\
\hline $\log (T R N S)$ & $2.30(1.72)$ & $1.31(1.48)$ & $2.29(1.74)$ & $2.10(1.82)$ & 61.66 & 10.48 & 83.01 \\
\hline $\log (V I L A)$ & $2.79(0.96)$ & $2.99(0.98)$ & $2.87(0.88)$ & $2.89(0.95)$ & -20.14 & -2.67 & 86.76 \\
\hline OPV & 79.96 (17.13) & $46.38(25.41)$ & 79.05 (17.39) & 74.69 (24.34) & 154.97 & 20.61 & 86.70 \\
\hline
\end{tabular}




\section{Supplementary Figures}

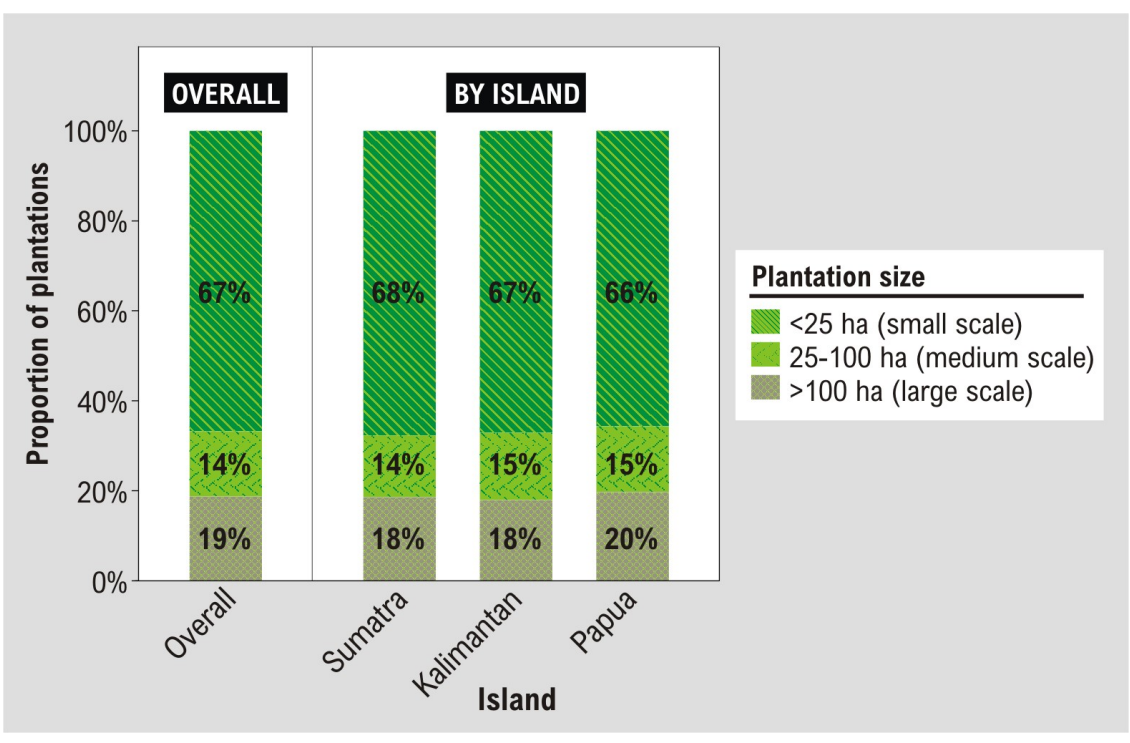

Supplementary Figure 1. Estimated plantation size outside the known concession boundaries (NCONC). Distributions of plantation size outside the known concession boundaries, i.e. <25 ha for small-scale, 25-100 ha for medium-scale, $>100$ ha for large industrial-scale plantations. Large scale industrial plantations are typically characterized by (1) an organized rectilinear grid form or trails if they are located in flat terrain, or (2) an organized curvy trail if they are located on steep terrain. The boundary of one large-scale plantation was defined as the area covered by one contiguous block of planted oil palms. Small to medium scale plantations are typically characterized by (1) a patchy arrangement in landscape mosaic, or (2) a more clustered arrangement but with less uniform plantation age or tree size than those found in industrial plantations. For the first type of the small to medium scale plantations, one patch of oil palms was used to represent one plantation, whereas for the second type one plantation was defined as a patch with similar plantation age or tree size.

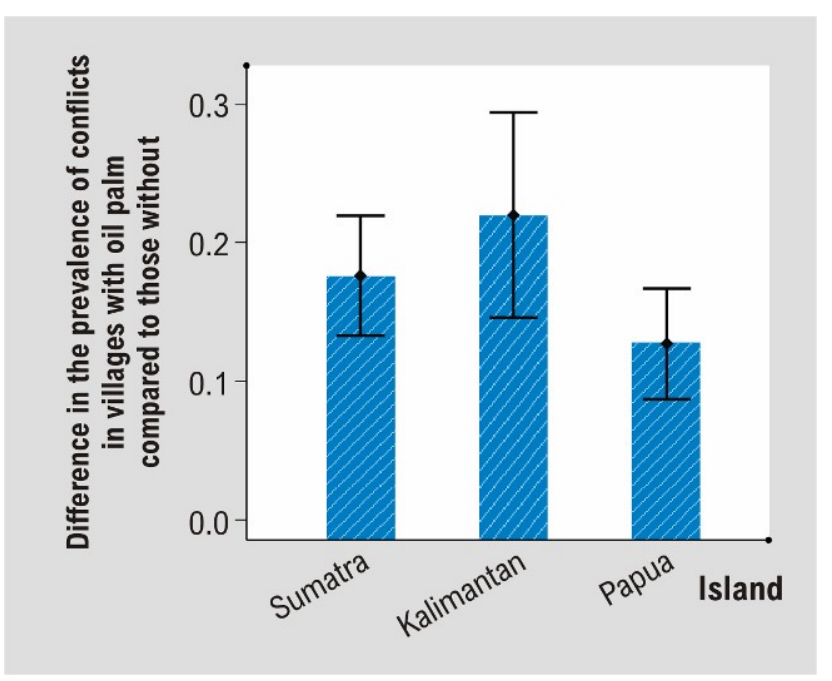

Supplementary Figure 2. Prevalence of conflicts in villages with industrial oil palm plantations by island. The difference in the prevalence of social conflicts in villages with industrial oil palm plantations compared to those without, in Sumatra, Kalimantan, and Papua, based on PODES data. Error bars represent 95\% confidence intervals. 


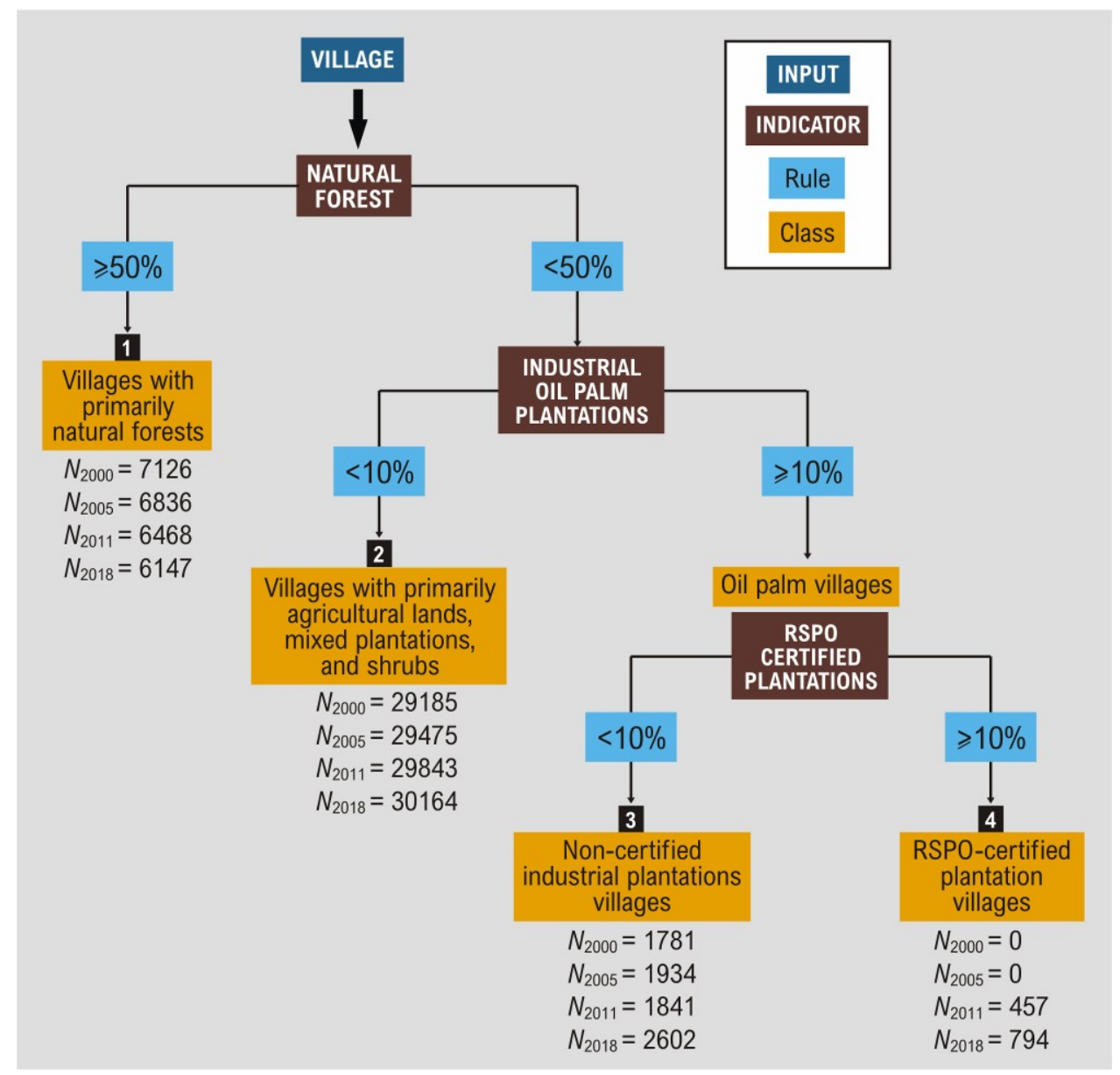

Supplementary Figure 3. Classification tree rules used in land use change analysis for defining villages based on primary land cover. Classification rules for defining villages to each of the four categories based on their primary land cover: (1) natural forest; (2) agricultural lands, mixed plantations and shrubs; (3) non-certified industrial oil palm plantations; and (4) RSPO-certified industrial oil palm plantations. $N_{t}$ below each class represents the total number of villages in each category across Sumatra, Kalimantan, and Papua at census year $t$, where $t=\{2000,2005,2011,2018\}$. 

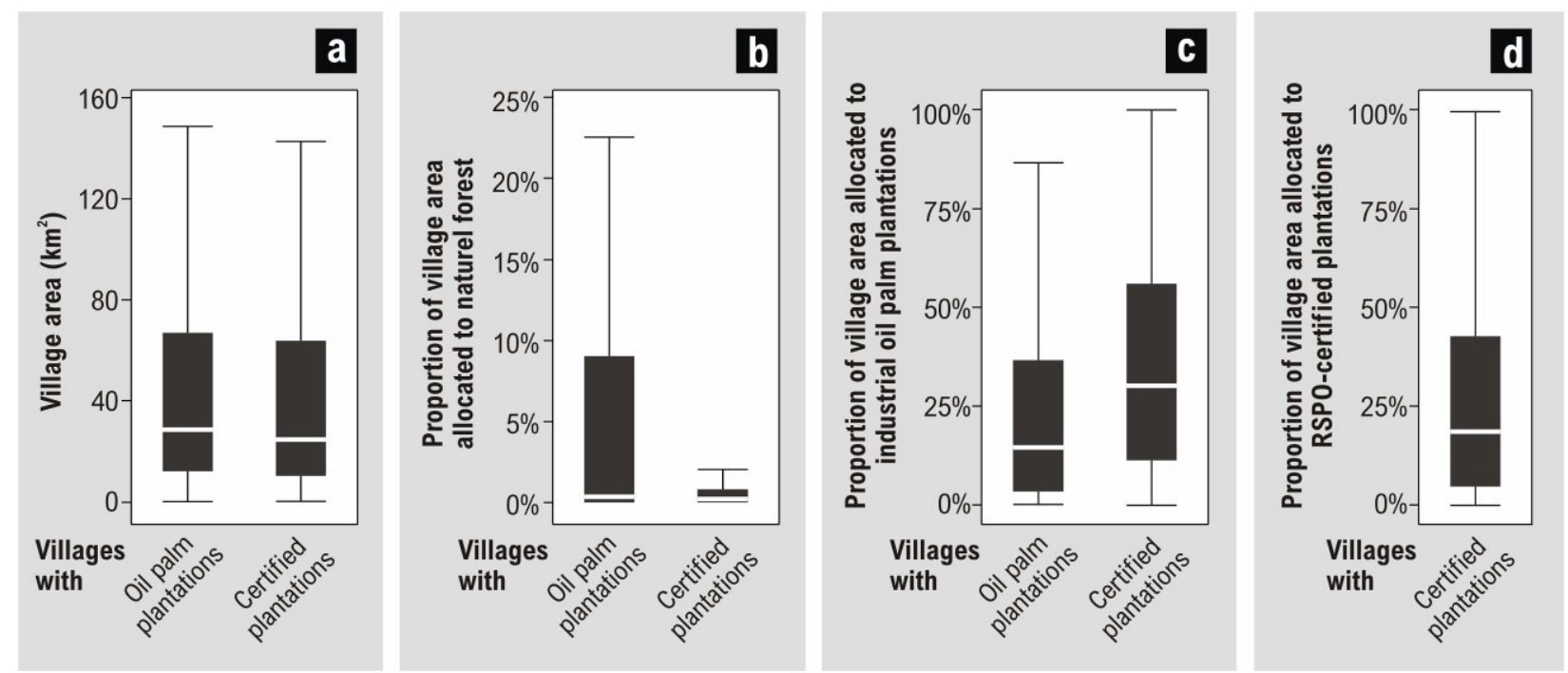

Supplementary Figure 4. Village land area and proportions of village land area allocated to different land uses in villages with the presence of industrial oil palm plantations and RSPO-certified plantations. Distribution of (a) village land area, (b) proportion of village land area allocated to natural forest, (c) proportion of village land area allocated to industrial oil palm plantations across Sumatra, Kalimantan, and Papua (left plot), and in villages with RSPO-certified plantations across Sumatra and Kalimantan (right plot), and (d) RSPOcertified plantations in villages across Sumatra and Kalimantan. 


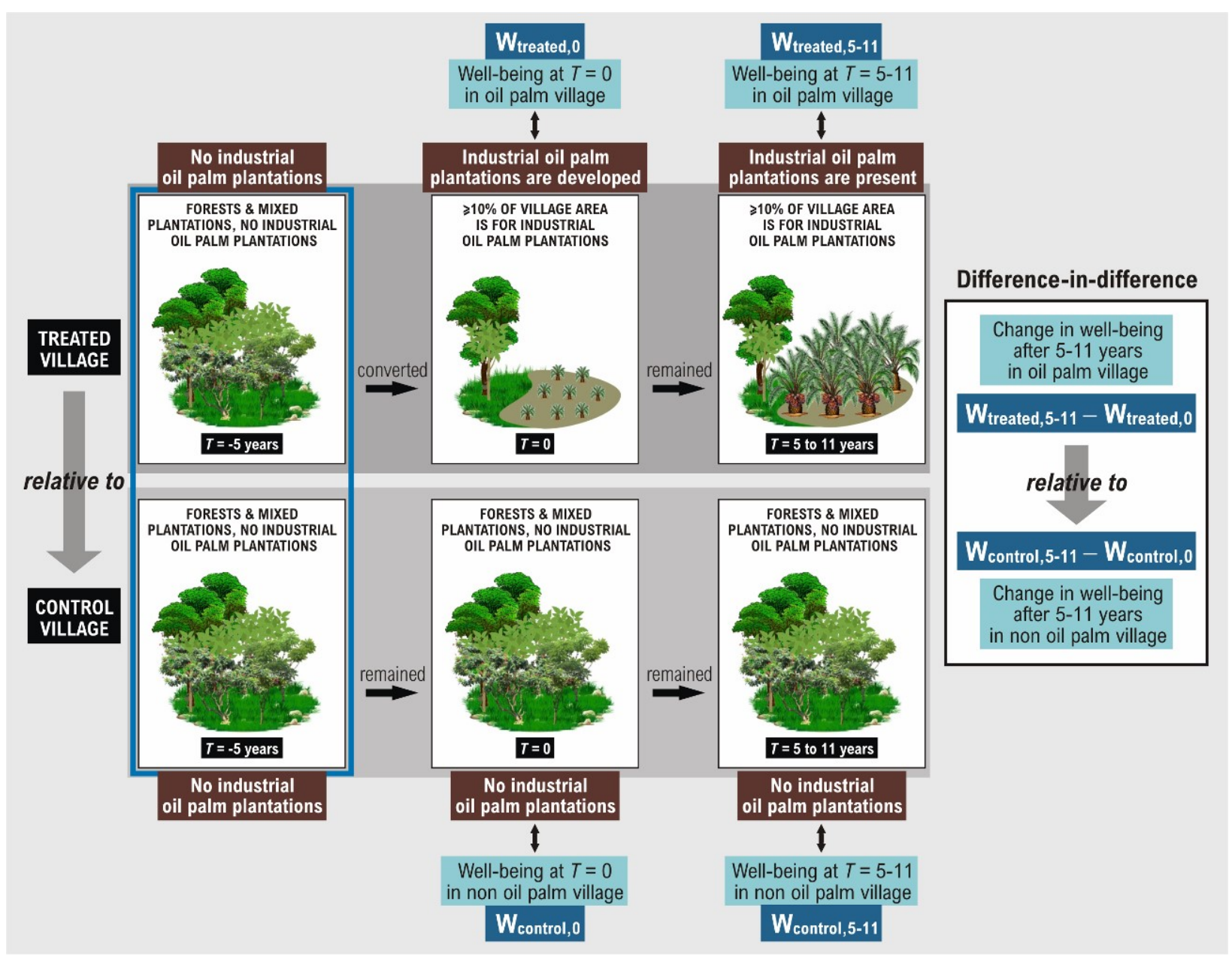

Supplementary Figure 5. Diagram representing the treated and control unit for analysing oil palm plantation impacts. Diagram illustrating the selection of treated and control (counterfactual) villages for analysing the impact of industrial oil palm plantations on village well-being (analysis $A$ ). The units receiving treatment were villages with $\geq 10 \%$ of their land area allocated to industrial oil palm plantation over the full study periods, but not within the previous five years. The 10\% threshold was based on the median proportion of village land area allocated to industrial oil palm plantations across Sumatra, Kalimantan and Papua (Supplementary Figure $5 \mathrm{c}$, left plot). As the units for counterfactuals or controls we used villages where none of the land areas were allocated to industrial oil palm plantations over the range of the analysis period, nor in the five years prior to that. For example, to assess the impact of oil palm on the change in village well-being between the 2005 and 2011 census (i.e. 6 years after plantations were established), the units receiving treatment were villages where industrial oil palm plantations account for $\geq 10 \%$ of land areas between 2005 and 2011 , but no plantation was detected in 2000 , and the control units were villages where no industrial oil palm plantations was detected between 2000 and 2011. The number of villages in the treated and control unit analyses $A$ and $B$ varied depending on the timeframe of analysis. 


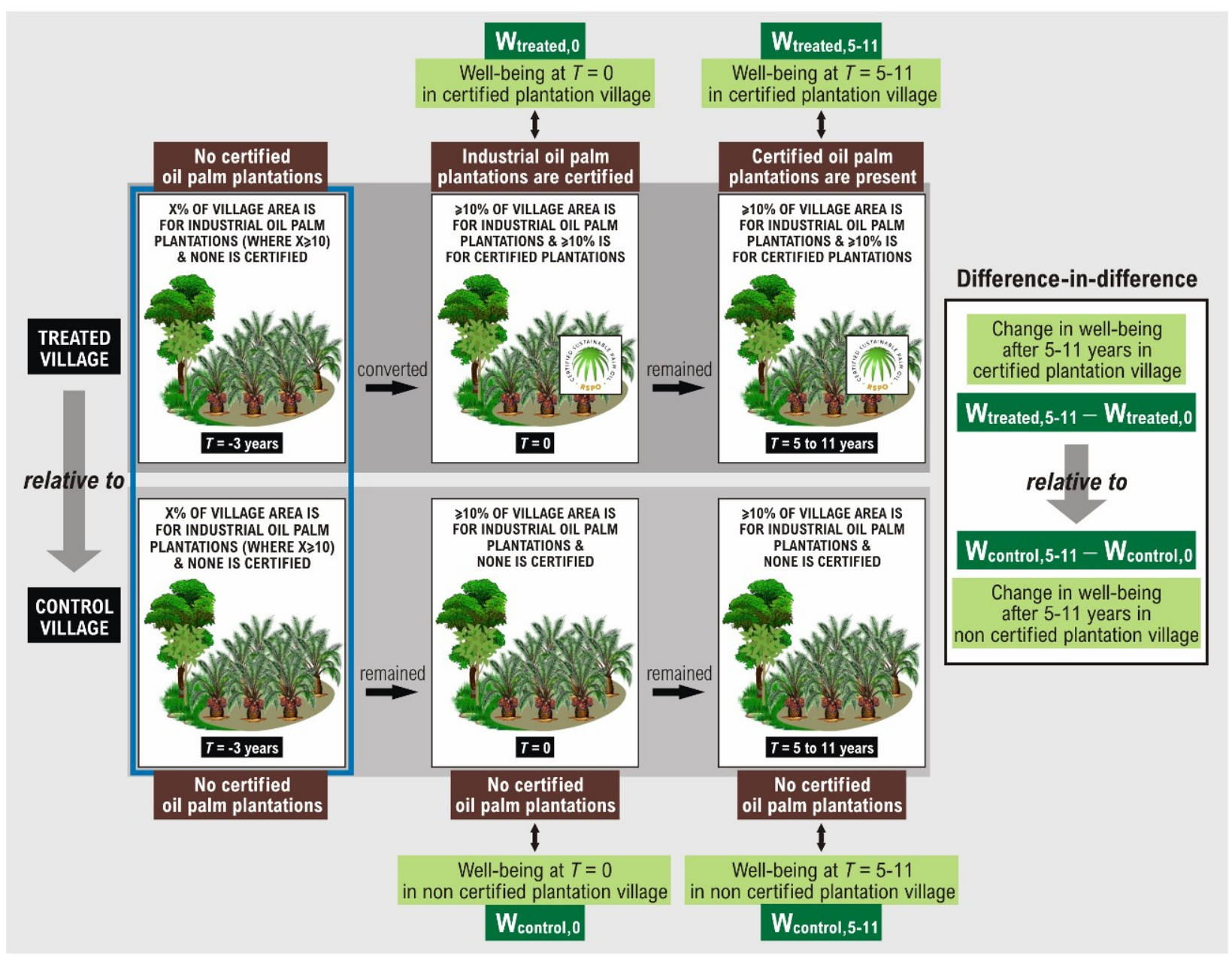

Supplementary Figure 6. Diagram representing the treated and control unit for analysing oil palm certification impacts. Diagram illustrating the selection of treated and control (counterfactual) villages for analysing the impact of RSPO certification on the well-being of oil palm villages (analysis B). The units receiving treatment were oil palm villages (i.e. villages with $\geq 10 \%$ of the land areas allocated to industrial oil palm plantations) where $\geq 10 \%$ of the land area were assigned to certified plantations over the full analysis periods, but no certified plantations were detected within the previous three years. The $10 \%$ threshold for certification was based on the median proportion of village land area allocated to certified plantations across Sumatra and Kalimantan (excluding Papua because certified plantations are rarely found in this island) (Supplementary Figure $5 d)$. As the unit for counterfactual or control, we used oil palm villages with the same proportion of their areas allocated to industrial oil palm plantations as that in the treated villages and where none of the plantations were certified over the analysis period, nor in the previous three years. For example, to assess the impact of certification on the change in village well-being between the 2011 and 2018 census (i.e. 7 years after receiving certification), the units receiving treatment were oil palm villages where $\geq 10 \%$ of the land area assigned to certified plantations between 2011 and 2018, but no certified plantation was detected in 2008, and the control units were oil palm villages with the same proportion of oil palm plantations as that in the treated villages but without any plantation being between 2008 and 2018. The number of villages in the treated and control unit analyses $A$ and $B$ varied depending on the timeframe of analysis. 

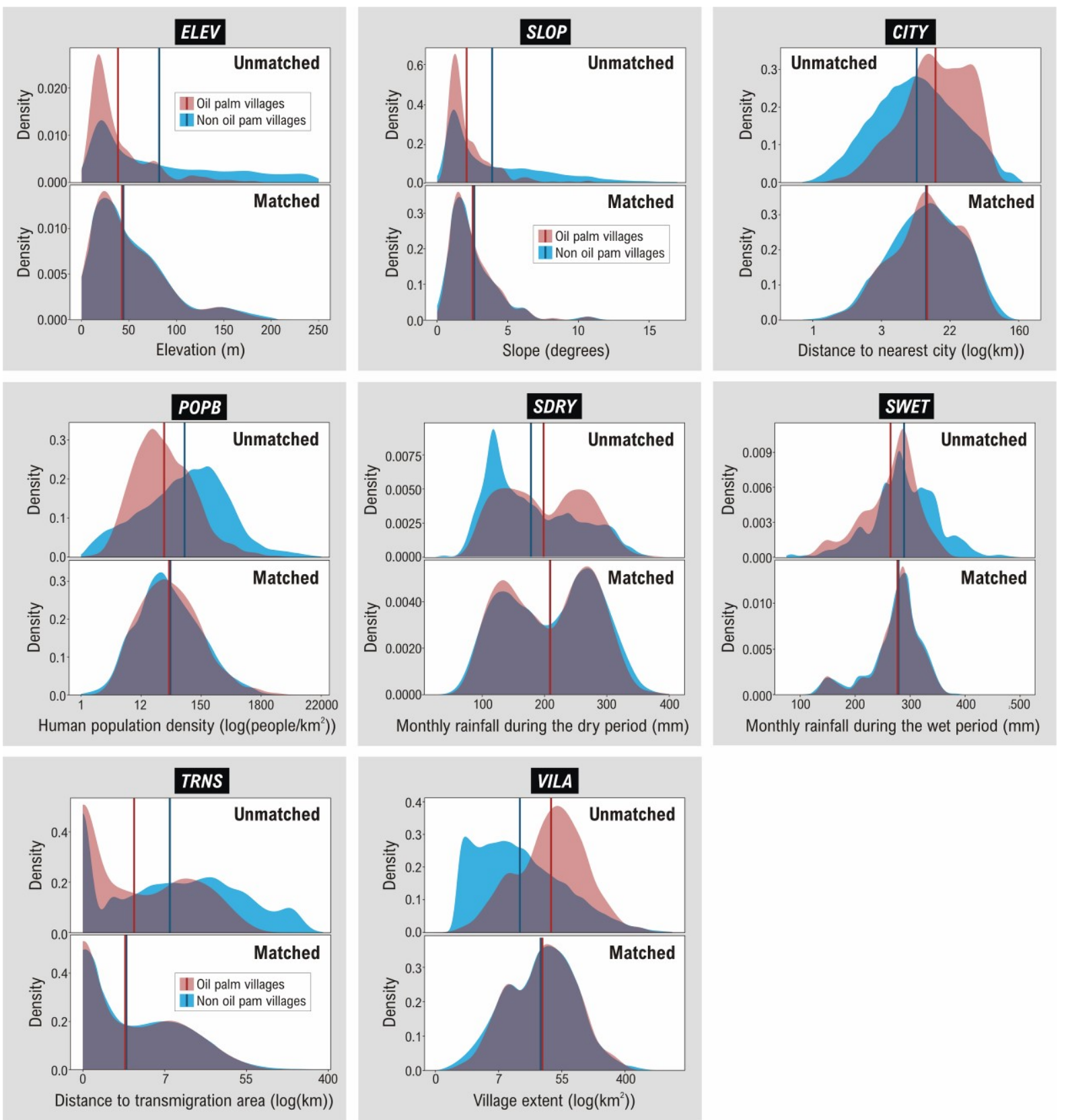

Monthly rainfall during the dry period $(\mathrm{mm})$

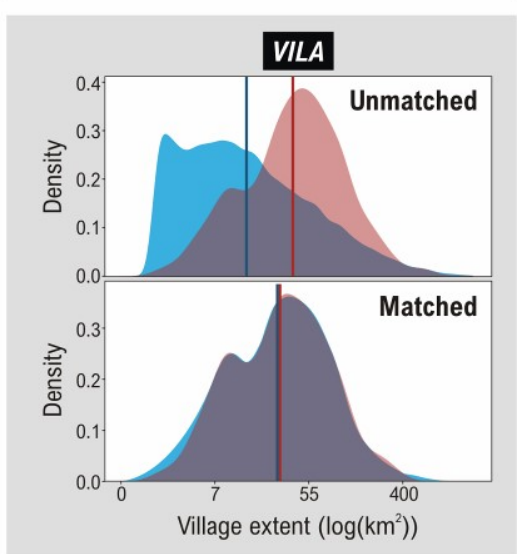

Supplementary Figure 7. Distribution of variables before and after matching for analysing the impact of industrial oil palm plantations. Improvement in the extent of overlapping areas of continuous variables ELEV (elevation), SLOP (slope), CITY (distance to nearest city), POPB (human population density), SDRY (long-term mean monthly rainfall during the dry period), SWET (long-term mean monthly rainfall during the wet period), TRNS (distance to transmigration areas), and VILA (the extent of villages), between villages with and without industrial oil palm plantation development in the matched dataset compared to the original (unmatched) dataset, aggregated across 11 time periods and three islands (Sumatra, Kalimantan and Papua). See Supplementary Table 2 for description of each variable. Detailed covariate balance diagnostics is provided in Supplementary Table 4. 

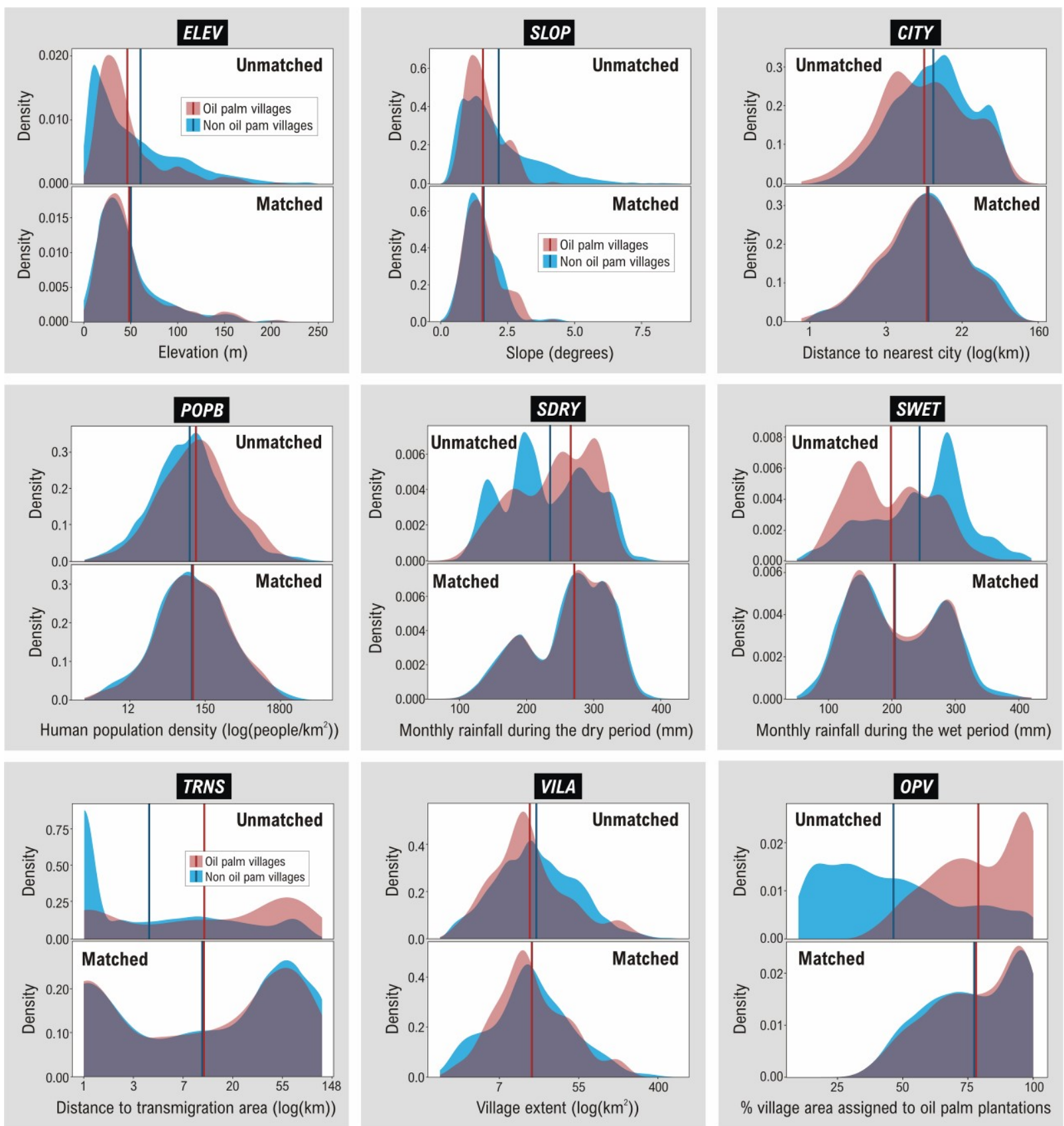

Supplementary Figure 8. Distribution of variables before and after matching for the RSPO certification impact evaluation. Improvement in the extent of overlapping areas of continuous variables ELEV (elevation), SLOP (slope), CITY (distance to nearest city), POPB (human population density), SDRY (long-term mean monthly rainfall during the dry period), SWET (long-term mean monthly rainfall during the wet period), TRNS (distance to transmigration areas), VILA (the extent of villages), and OPV (proportion village land area allocated to industrial oil palm plantations) between villages with RSPO-certified industrial oil palm plantations and those without certification in the matched dataset compared to the original (unmatched) dataset, aggregated across 3 time periods and two islands (Sumatra and Kalimantan). See Supplementary Table 2 for description of each variable. Detailed covariate balance diagnostics is provided in Supplementary Table 5. 

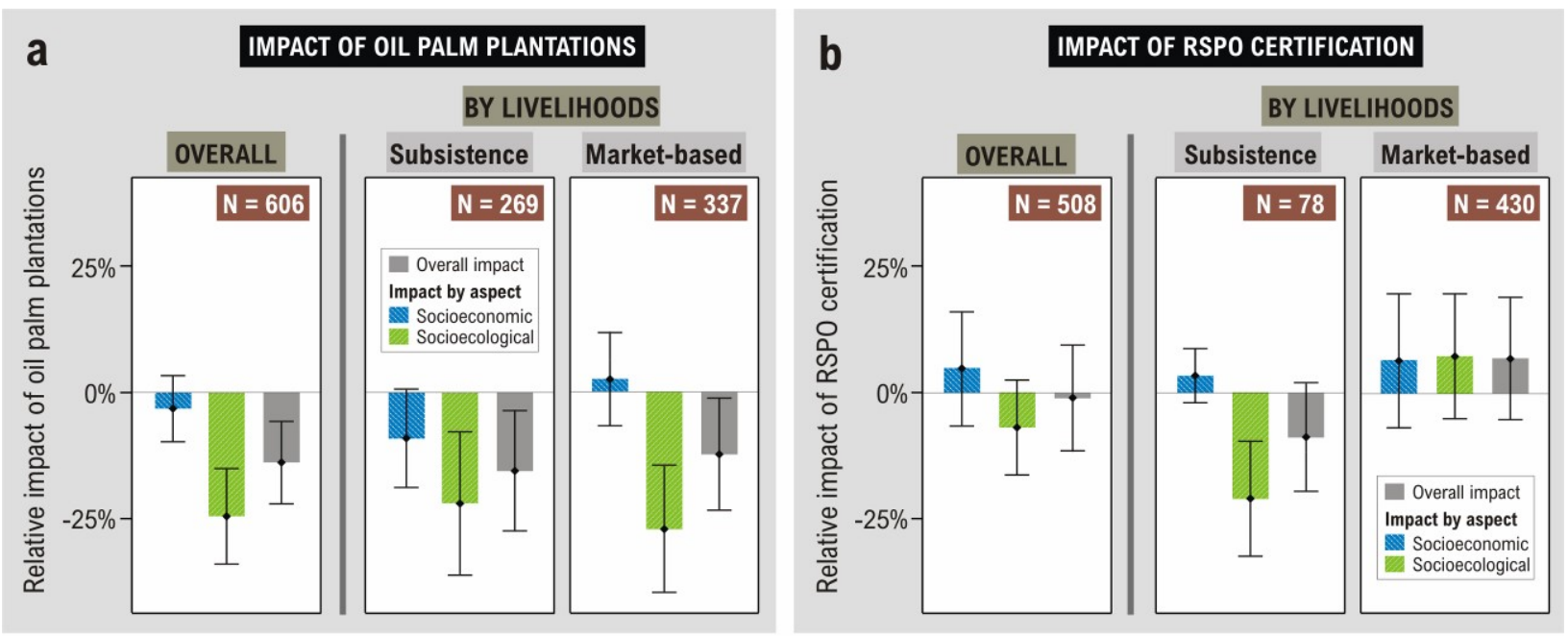

Supplementary Figure 9. Impact of oil palm plantation development and certification on village well-being obtained from alternative propensity score matching approach. (a) Impact of oil palm plantations on villagelevel well-being, evaluated by comparing the change in well-being indicators in villages with oil palm after 5-11 years of oil palm development against the change in well-being in villages without oil palm across Sumatra, Kalimantan and Papua. (b) Impact of RSPO certification on village-level well-being, evaluated by comparing the change in well-being indicators in villages with certified plantation after 5-11 years of certification against the change in well-being in villages with non-certified oil palm plantations across Sumatra and Kalimantan. In both analyses comparisons are made between village types with similar baseline characteristics appropriate to the datasets analysed. $\mathrm{N}$ represents the number of villages assessed in each panel, which are slightly different than those assessed in the main approach due to different propensity score generation. Error bars represent $95 \%$ confidence intervals. 

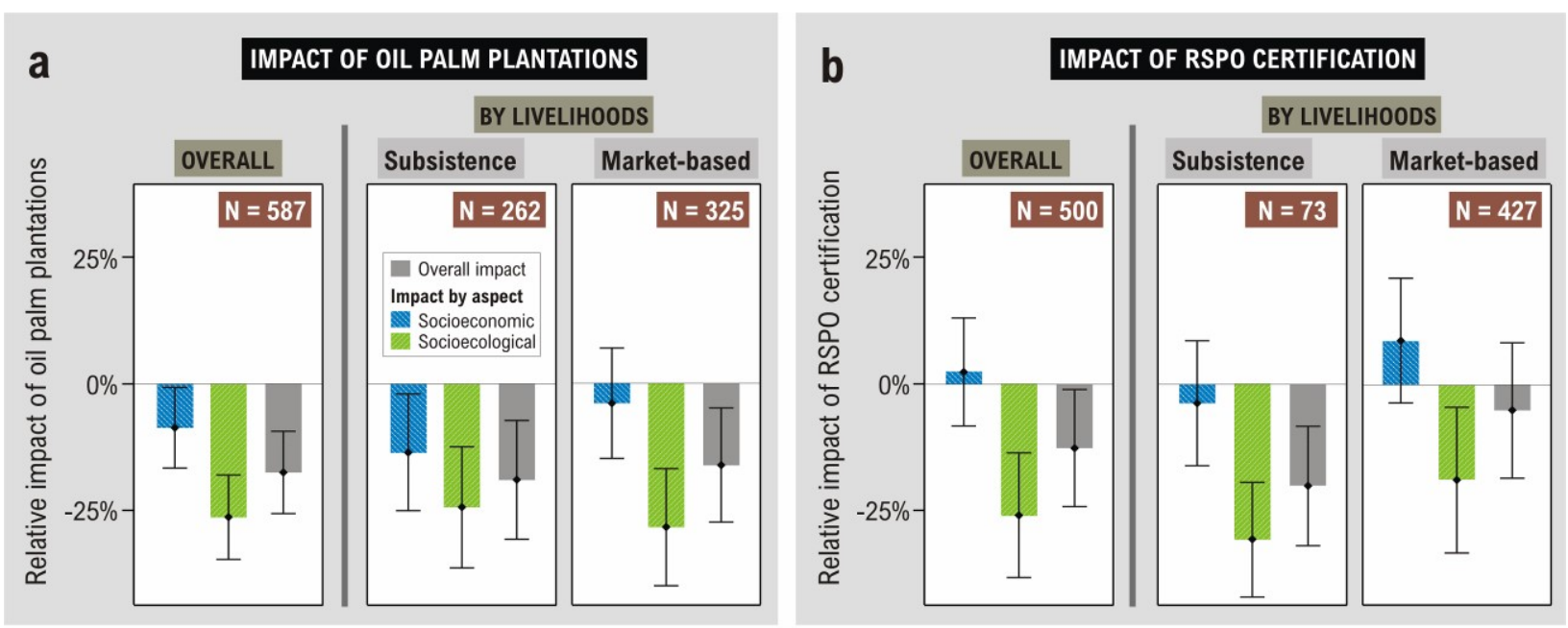

Supplementary Figure 10. Impact of oil palm plantation development and certification on village wellbeing obtained from alternative classification of well-being indicators. (a) Impact of oil palm plantations on village-level well-being, evaluated by comparing the change in well-being indicators in villages with oil palm after 5-11 years of oil palm development against the change in well-being in villages without oil palm across Sumatra, Kalimantan and Papua. (b) Impact of RSPO certification on village-level well-being, evaluated by comparing the change in well-being indicators in villages with certified plantation after 5-11 years of certification against the change in well-being in villages with non-certified oil palm plantations across Sumatra and Kalimantan. In both analyses comparisons are made between village types with similar baseline characteristics appropriate to the datasets analysed. $\mathrm{N}$ represents the number of villages assessed in each panel, which are the same as those assessed in the main approach. Error bars represent $95 \%$ confidence intervals.
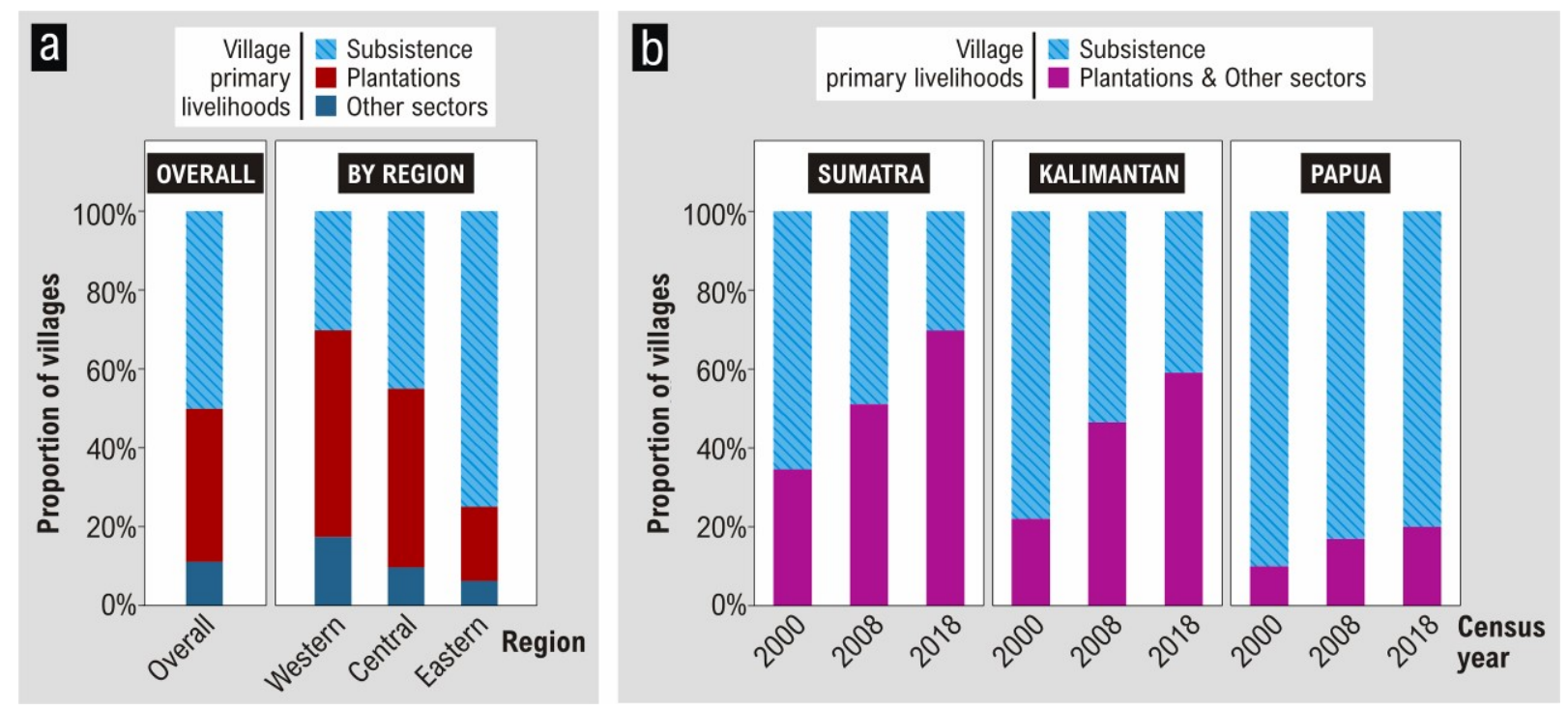

Supplementary Figure 11. Village primary livelihoods across Indonesian Outer Islands. (a) Village primary livelihood based on PODES 2018 census overall across Indonesian Outer Islands (i.e. islands outside Java and Bali) and by region (i.e. Western region: Sumatra; Central region: Kalimantan and Sulawesi; Eastern region: Nusa Tenggara, Maluku, and Papua). (b) The change village primary livelihoods between 2000 and 2018 in Sumatra, Kalimantan, and Papua. 


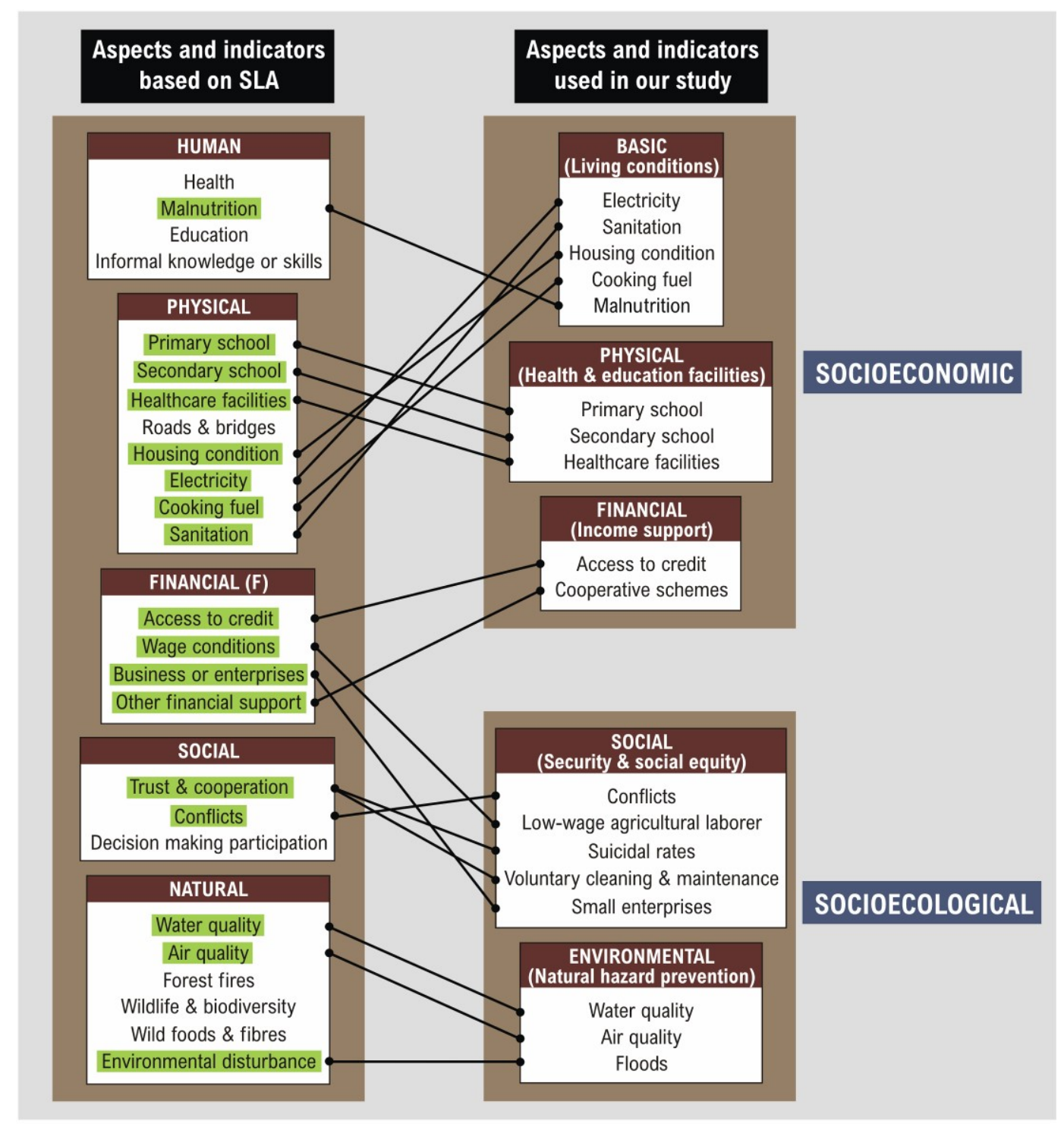

Supplementary Figure 12. Categorization of well-being indicators used in this study relative to the SLA framework. A diagram representing indicators of well-being used in our study compared to those defined in the Sustainable Livelihood Approach (SLA). 

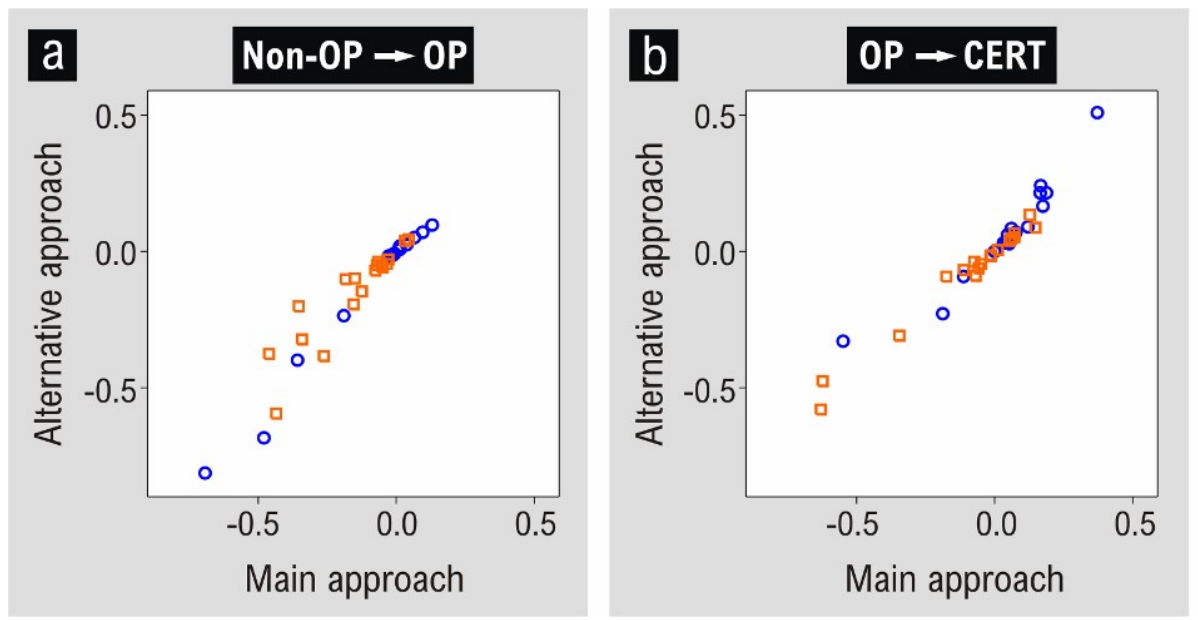

Village primary livelihoods

o Subsistence

प Market-based

Supplementary Figure 13. Agreement between the impact estimates generated from alternative propensity score matching method and our main approach. The relationship between the estimated effects of oil palm plantation development (analysis A) or RSPO certification (analysis B) on individual well-being indicator in subsistence and market-based villages obtained from the alternative method versus those obtained from the main approach. 


\section{Supplementary References}

1. Wharton, J.R. (2017) Subsistence Agriculture and Economic Development. Routledge.

2. Cramb, R.A., Colfer, C.J.P., Dressler, W., Laungaramsri, P., Le, Q.T. et al. (2009) Swidden transformations and rural livelihoods in Southeast Asia. Human Ecology 37, 323-346.

3. Li, P., Feng, Z., Jiang, L., Liao, C. \& Zhang, J. (2014) A review of swidden agriculture in Southeast Asia. Remote Sensing 6, 1654-1683.

4. Hausner, V.H., Fauchald, P., Tveraa, T., Pedersen, E., Jernsletten, J.L. et al. (2011) The ghost of development past: the impact of economic security policies on Saami pastoral ecosystems. Ecology and Society 16, 4.

5. Fall, J.A., Braem, N.S., Brown, C.L., Hutchinson-Scarbrough, L.B., Koster, D.S. et al. (2013) Continuity and change in subsistence harvests in five Bering Sea communities: Akutan, Emmonak, Savoonga, St. Paul, and Togiak. Deep Sea Research Part II: Topical Studies in Oceanography 94, $274-291$.

6. Mulyoutami, E., Rismawan, R. \& Joshi, L. (2009) Local knowledge and management of simpukng (forest gardens) among the Dayak people in East Kalimantan, Indonesia. Forest Ecology and Management 257, 2054-2061.

7. Takakura, H. (2012) The shift from herding to hunting among the Siberian Evenki: indigenous knowledge and subsistence change in Northwestern Yakutia. Asian Ethnology 71, 31-47.

8. Busilacchi, S., Russ, G.R., Williams, A.J., Sutton, S.G. \& Begg, G.A. (2013) The role of subsistence fishing in the hybrid economy of an indigenous community. Marine Policy 37, 183-191.

9. Fox, J., Fujita, Y., Ngidang, D., Peluso, N., Potter, L. et al. (2009) Policies, political-economy, and swidden in Southeast Asia. Human Ecology 37, 305-322.

10. Mertz, O., Padoch, C., Fox, J., Cramb, R.A., Leisz, S.J. et al. (2009) Swidden change in Southeast Asia: understanding causes and consequences. Human Ecology 37, 259-264.

11. Broadbent, N.D. (2013) Lapps and Labyrinths: Saami Prehistory, Colonization, and Cultural Resilience. Smithsonian Institution.

12. Orta-Martínez, M. \& Finer, M. (2010) Oil frontiers and indigenous resistance in the Peruvian Amazon. Ecological Economics 70, 207-218.

13. Hodge, R.A. (2014) Mining company performance and community conflict: moving beyond a seeming paradox. Journal of Cleaner Production 84, 27-33.

14. Pagiola, S. (2008) Payments for environmental services in Costa Rica. Ecological Economics 65, 712-724.

15. Baynes, J., Herbohn, J., Smith, C., Fisher, R. \& Bray, D. (2015) Key factors which influence the success of community forestry in developing countries. Global Environmental Change 35, 226-238.

16. Karunakar, P. (2011) Threat of globalization to indigenous peoples' culture and identities in India. Fourth World Journal 10, 153-166.

17. Ginting, L. \& Pye, O. (2013) Resisting agribusiness development: The Merauke Integrated Food and Energy Estate in West Papua, Indonesia. Austrian Journal of South-East Asian Studies 6, 160-182.

18. Colchester, M. (2016) Do commodity certification systems uphold indigenous peoples' rights? Lessons from the Roundtable on Sustainable Palm Oil and Forest Stewardship Council. Policy Matters 21, 150-165.

19. Bai, X., Van Der Leeuw, S., O'Brien, K., Berkhout, F., Biermann, F. et al. (2016) Plausible and desirable futures in the Anthropocene: a new research agenda. Global Environmental Change 39, 351-362. 
20. Foley, D. \& O'connor, A.J. (2013) Social capital and the networking practices of indigenous entrepreneurs. Journal of Small Business Management 51, 276-296.

21. Beaudoin, J.M., Bouthillier, L., Bulkan, J., Nelson, H., Trosper, R. et al. (2016) What does "First Nation deep roots in the forests" mean? Identification of principles and objectives for promoting forest-based development. Canadian Journal of Forest Research 46, 508-519.

22. Cristancho, S. \& Vining, J. (2009) Perceived intergenerational differences in the transmission of traditional ecological knowledge (TEK) in two indigenous groups from Colombia and Guatemala. Culture \& Psychology 15, 229-254.

23. Duncan, C.R. (2007) Mixed outcomes: The impact of regional autonomy and decentralization on indigenous ethnic minorities in Indonesia. Development and Change 38, 711-733.

24. Breidlid, A. (2013) Education, Indigenous Knowledges, and Development in the Global South: Contesting Knowledges for a Sustainable Future. Routledge.

25. Chan, K.M., Goldstein, J., Satterfield, T., Hannahs, N., Kikiloi, K. et al. (2011) Cultural services and nonuse values. In: Natural Capital: Theory and Practice of Mapping Ecosystem Services, pp. 206-228.

26. Throsby, D. \& Petetskaya, E. (2016) Sustainability concepts in Indigenous and non-Indigenous cultures. International Journal of Cultural Property 23, 119-140.

27. Cuni-Sanchez, A., Imani, G., Bulonvu, F., Batumike, R., Baruka, G. et al. (2019) Social Perceptions of Forest Ecosystem Services in the Democratic Republic of Congo. Human Ecology 47, 839-853.

28. Ochoa-García, H. \& Rist, S. (2018) Water justice and integrated water resources management: Constitutionality processes favoring sustainable water governance in Mexico. Human Ecology 46, 51-64.

29. Aryal, S., Cockfield, G. \& Maraseni, T.N. (2014) Vulnerability of Himalayan transhumant communities to climate change. Climatic Change 125, 193-208.

30. Savo, V., Lepofsky, D., Benner, J.P., Kohfeld, K.E., Bailey, J. et al. (2016) Observations of climate change among subsistence-oriented communities around the world. Nature Climate Change 6, 462-473.

31. Kusiluka, M.M., Kongela, S., Kusiluka, M.A., Karimuribo, E.D. \& Kusiluka, L.J. (2011) The negative impact of land acquisition on indigenous communities' livelihood and environment in Tanzania. Habitat International 35, 66-73.

32. Hadiprayitno, I.I. (2017) Who owns the right to food? Interlegality and competing interests in agricultural modernisation in Papua, Indonesia. Third World Quarterly 38, 97-116.

33. Bureau of Statistic (BPS) Indonesia (2019) Village Potential Statistics (PODES) 2000, 2003, 2005, 2008, 2014, and 2018. Jakarta, Indonesia.

34. Berenschot, W. \& Mulder, P. (2019) Explaining regional variation in local governance: Clientelism and state-dependency in Indonesia. World Development 122, 233-244.

35. Rahma, H., Fauzi, A., Juanda, B. \& Widjojanto, B. (2019) Development of a composite measure of regional sustainable development in Indonesia. Sustainability 11, 5861.

36. Kurniawan, H., de Groot, H.L. \& Mulder, P. (2019) Are poor provinces catching-up the rich provinces in Indonesia? Regional Science Policy \& Practice 11, 89-108.

37. Santika, T., Wilson, K.A., Budiharta, S., Law, E.A., Poh, T.M. et al. (2019a) Does oil palm agriculture help alleviate poverty? A multidimensional counterfactual assessment of oil palm development in Indonesia. World Development 120, 105-117.

38. Santika, T., Wilson, K.A., Meijaard, E., Budiharta, S., Law, E.A. et al. (2019b) Changing landscapes, livelihoods and village welfare in the context of oil palm development. Land Use Policy 87, 104073. 
39. Bergamini, N., Blasiak, R., Eyzaguirre, P., Ichikawa, K., Mijatovic, D. et al. (2013) Indicators of resilience in socio-ecological production landscapes (SEPLs). United Nations University Institute of Advanced Studies (UNU-IAS).

40. Dale, V.H., Efroymson, R.A., Kline, K.L., Langholtz, M.H., Leiby, P.N. et al. (2013) Indicators for assessing socioeconomic sustainability of bioenergy systems: a short list of practical measures. Ecological Indicators 26, 87-102.

41. Miteva, D.A., Loucks, C.J. \& Pattanayak, S.K. (2015) Social and environmental impacts of forest management certification in Indonesia. PLoS One 10, e0129675.

42. Jagger, P. \& Rana, P. (2017) Using publicly available social and spatial data to evaluate progress on REDD+ social safeguards in Indonesia. Environmental Science \& Policy 76, 59-69.

43. Hosseinpoor, A.R., Nambiar, D., Suparmi, E.A. \& Kusumawardani, N. (2018) Data source mapping: an essential step for health inequality monitoring. Global Health Action 11, 13-19.

44. Lee, J.S.H., Miteva, D.A., Carlson, K.M., Heilmayr, R. \& Saif, O. (2020) Does the oil palm certification create trade-offs between environment and development in Indonesia? SocArXiv. DOI: 10.31219/osf.io/zrwpd.

45. Scoones, I. (1998) Sustainable Rural Livelihoods: A Framework for Analysis. IDS Working Paper 72. Sussex: Brighton Institute of Development Studies, University of Sussex.

46. Alkire, S., Chatterjee, M., Conconi, A., Seth, S., \& Vaz, A. (2014) Global Multidimensional Poverty Index. 2014 OPHI Briefing 21. Oxford: University of Oxford.

47. Gönner, C., Haug, M., Cahyat, A., Wollenberg, E., DeJong, W. et al. (2007) Capturing nested spheres of poverty a model for multidimensional povery analysis and monitoring. CIFOR Occasional Paper No. 46. Bogor, Indonesia: Center for International Forestry Research.

48. Obidzinski, K., Andriani, R., Komarudin, H. \& Andrianto, A. (2012) Environmental and social impacts of oil palm plantations and their implications for biofuel production in Indonesia. Ecology and Society 17, 25.

49. Sinaga, H. (2013) Indonesian oil palm plantations: Decent work deficit despite employment growth. In: The Food Crisis: Implications for Labor (eds. C. Scherrer \& D. Saha), pp. 99-126. Rainer Hampp Verlag.

50. Booth, A. (2012) The performance of the Indonesian agricultural sector: twelve questions and some tentative answers. In: Land, Livelihood, The Economy and the Environment in Indonesia: Essays in Honour of Joan Hardjono (eds. A. Booth, C. Manning \& Thee Kian Wie), pp. 51-84. Jakarta: Yayasan Pustaka Obor Indonesia.

51. Van Vliet, N., Mertz, O., Heinimann, A., Langanke, T., Pascual, U. et al. (2012) Trends, drivers and impacts of changes in swidden cultivation in tropical forest-agriculture frontiers: a global assessment. Global Environmental Change 22, 418-429.

52. Bureau of Statistic (BPS) Indonesia (2018) Gini Ratio by Province 2002- 2018. Jakarta: Bureau of Statistics Indonesia.

53. Pambudhi, F., Belcher, B., Levang, P. \& Dewi, S. (2004) Rattan (Calamus spp.) gardens of Kalimantan: resilience and evolution in a managed non-timber forest product system. In: Forest Products, Livelihoods and Conservation: Case Studies of Non-Timber Forest Product Systems (eds. K. Kuster \& Belcher), pp. 337-354. CIFOR.

54. Dewi, S., Belcher, B. \& Puntodewo, A. (2005) Village economic opportunity, forest dependence, and rural livelihoods in East Kalimantan, Indonesia. World Development 33, 1419-1434.

55. Klasen, S., Meyer, K.M., Dislich, C., Euler, M., Faust, H. et al. (2016) Economic and ecological trade-offs of agricultural specialization at different spatial scales. Ecological Economics 122, 111-120. 
56. Liu, Y. \& Xu, Y. (2016) A geographic identification of multidimensional poverty in rural China under the framework of sustainable livelihoods analysis. Applied Geography 73, 62-76.

57. Oberlack, C., Tejada, L., Messerli, P., Rist, S. \& Giger, M. (2016) Sustainable livelihoods in the global land rush? Archetypes of livelihood vulnerability and sustainability potentials. Global Environmental Change 41, 153-171.

58. Colombo, E., Romeo, F., Mattarolo, L., Barbieri, J. \& Morazzo, M. (2018) An impact evaluation framework based on sustainable livelihoods for energy development projects: an application to Ethiopia. Energy Research \& Social Science 39, 78-92.

59. Zhang, C., Fang, Y., Chen, X. \& Congshan, T. (2019) Bibliometric analysis of trends in global sustainable livelihood research. Sustainability 11, 1150.

60. Bureau of Statistic (BPS) Indonesia (2014) Digital Map of Local Statistical Area 2014. Jakarta, Indonesia

61. Ministry of Environment and Forestry Indonesia (MEF) (2018) Peta Penutupan Lahan (PPL) 1990-2017. Jakarta, Indonesia.

62. Gaveau, D.L.A. \& Salim, A. (2019) Atlas of Deforestation and Industrial Plantations in Borneo. Center for International Forestry Research (CIFOR). URL: www.cifor.org/map/atlas

63. Carlson, K.M., Heilmayr, R., Gibbs, H.K., Noojipady, P., Burns, D.N. et al. (2018) Effect of oil palm sustainability certification on deforestation and fire in Indonesia. Proceedings of the National Academy of Sciences 115, 121-126.

64. Margono, B.A., Potapov, P.V., Turubanova, S., Stolle, F. \& Hansen, M.C. (2014) Primary forest cover loss in Indonesia over 2000-2012. Nature Climate Change 4, 730.

65. Hansen, M.C., Potapov, P.V., Moore, R., Hancher, M., Turubanova, S. et al. (2013) High-resolution global maps of 21st-century forest cover change. Science $342,850-853$.

66. Descals, A., Szantoi, Z., Meijaard, E., Sutikno, H., Rindanata, G. \& Wich, S. (2019) Oil palm (Elaeis guineensis) mapping with details: Smallholder versus industrial plantations and their extent in Riau, Sumatra. Remote Sensing 11, 2590.

67. Indonesian Sustainable Palm Oil (ISPO) (2014) Table of Plantations Companies Receiving the ISPO Certification by January 2014. ISPO Jakarta.

68. Hidayat, N.K., Offermans, A. \& Glasbergen, P. (2018) Sustainable palm oil as a public responsibility? On the governance capacity of Indonesian Standard for Sustainable Palm Oil (ISPO). Agriculture and Human Values 35, 223-242.

69. Astari, A.J. \& Lovett, J.C. (2019) Does the rise of transnational governance 'hollow-out' the state? Discourse analysis of the mandatory Indonesian sustainable palm oil policy. World Development 117, 112.

70. Ridgeway, G. (2019) Generalized Boosted Models: A guide to the gbm package.

71. Dehejia, R.H. \& Wahba, S. (2002) Propensity score-matching methods for nonexperimental causal studies. Review of Economics and Statistics 84, 151-161.

72. Austin, P.C. (2011) Optimal caliper widths for propensity- score matching when estimating differences in means and differences in proportions in observational studies. Pharmaceutical Statistics 10, 150-161.

73. Sekhon, J.S. (2015) Multivariate and Propensity Score Matching With Balance Optimization. R Package Version 4.9-2.

74. Brueckner, J.K. (2013) Slums in developing countries: New evidence for Indonesia. Journal of Housing Economics 22, 278-290. 
75. Shibata, T., Wilson, J.L., Watson, L.M., Nikitin, I.V., La Ane, R. et al. (2015) Life in a landfill slum, children's health, and the Millennium Development Goals. Science of the Total Environment 536, 408-418.

76. Kusharjanto, H. \& Kim, D. (2011) Infrastructure and human development: the case of Java, Indonesia. Journal of the Asia Pacific Economy 16, 111-124.

77. Skoufias, E. \& Olivieri, S. (2013) Sources of spatial welfare disparities in Indonesia: Household endowments or returns? Journal of Asian Economics 29, 62-79.

78. Andadari, R.K., Mulder, P. \& Rietveld, P. (2014) Energy poverty reduction by fuel switching: Impact evaluation of the LPG conversion program in Indonesia. Energy Policy 66, 436-449.

79. Sambodo, M.T. \& Novandra, R. (2019) The state of energy poverty in Indonesia and its impact on welfare. Energy Policy 132, 113-121.

80. Isunju, J.B., Schwartz, K., Schouten, M.A., Johnson, W.P. \& van Dijk, M.P. (2011) Socio-economic aspects of improved sanitation in slums: a review. Public Health 125, 368-376.

81. De Silva, I. \& Sumarto, S. (2018) Child malnutrition in Indonesia: Can education, sanitation and healthcare augment the role of income? Journal of International Development 30, 837-864.

82. Gillespie, S., Haddad, L., Mannar, V., Menon, P., Nisbett, N. et al. (2013) The politics of reducing malnutrition: building commitment and accelerating progress. The Lancet 382, 552-569.

83. Sumarto, S., Suryahadi, A. \& Widyanti, W. (2005) Assessing the impact of Indonesian social safety net programmes on household welfare and poverty dynamics. The European Journal of Development Research 17, 155-177.

84. Agus, Y. \& Horiuchi, S. (2012) Factors influencing the use of antenatal care in rural West Sumatra, Indonesia. BMC Pregnancy and Childbirth 12, 9.

85. Balisacan, A.M., Pernia, E.M. \& Asra, A. (2003) Revisiting growth and poverty reduction in Indonesia: what do subnational data show? Bulletin of Indonesian Economic Studies 39, 329-351.

86. Vuri, D. (2010) The effect of availability of school and distance to school on children's time allocation in Ghana. Labour 24, 46-75.

87. Dang, H.A.H. \& Rogers, F.H. (2016) The decision to invest in child quality over quantity: Household size and household investment in education in Vietnam. The World Bank Economic Review 30, 104-142.

88. Meemken, E.M., Spielman, D.J. \& Qaim, M. (2017) Trading off nutrition and education? A panel data analysis of the dissimilar welfare effects of Organic and Fairtrade standards. Food Policy 71, 74-85.

89. Rist, L., Feintrenie, L. \& Levang, P. (2010) The livelihood impacts of oil palm: smallholders in Indonesia. Biodiversity and Conservation 19, 1009-1024.

90. Takahashi, K., Higashikata, T. \& Tsukada, K. (2010) The short- term poverty impact of small- scale, collateral- free microcredit in Indonesia: A matching estimator approach. The Developing Economies 48, 128-155.

91. Suneetha, M.S., Rahajoe, J.S., Shoyama, K., Lu, X., Thapa, S. et al. (2011) An indicator-based integrated assessment of ecosystem change and human-well-being: selected case studies from Indonesia, China and Japan. Ecological Economics 70, 2124-2136.

92. Prabowo, D., Maryudi, A. \& Imron, M.A. (2017) Conversion of forests into oil palm plantations in West Kalimantan, Indonesia: Insights from actors' power and its dynamics. Forest Policy and Economics 78, 3239.

93. Dhiaulhaq, A., McCarthy, J.F. \& Yasmi, Y. (2018) Resolving industrial plantation conflicts in Indonesia: Can mediation deliver? Forest Policy and Economics 91, 64-72. 
94. McCarthy, J.F. (2010) Processes of inclusion and adverse incorporation: oil palm and agrarian change in Sumatra, Indonesia. The Journal of Peasant Studies 37, 821-850.

95. Susanti, A. \& Maryudi, A. (2016) Development narratives, notions of forest crisis, and boom of oil palm plantations in Indonesia. Forest Policy and Economics 73, 130-139.

96. Rodriguez, E. (2012) Firm and group dynamics in the small and medium enterprise. Small Firm Dynamism in East Asia 18, 141-161.

97. Idris, S. \& Primiana, I. (2015) Effect of competitive strategy and partnership strategy for small industry performance. International Journal of Economics, Commerce and Management 3, 1-18.

98. Kennedy, J. \& King, L. (2014) The political economy of farmers' suicides in India: indebted cash-crop farmers with marginal landholdings explain state-level variation in suicide rates. Globalization and Health $10,16$.

99. Merriott, D. (2016) Factors associated with the farmer suicide crisis in India. Journal of Epidemiology and Global Health 6, 217-227.

100. Sholihah, A.B. \&Athas, S.I.A. (2018) Analysis of social sustainability models: Toward more sustainable Indonesian cities. Advanced Science Letters 24, 9219-9222.

101. Tucunan, K.P. \& Medha, A.N. (2018) Social sustainability indicators in kampung; dialogue between Ibn Khaldun's Tamadun concepts and sustainable developments approaches. IOP Conference Series: Earth and Environmental Science 202, 012073.

102. Pawitan, H. \& Haryani, G.S. (2011) Water resources, sustainability and societal livelihoods in Indonesia. Ecohydrology \& Hydrobiology 11, 231-243.

103. Ebenstein, A. (2012) The consequences of industrialization: evidence from water pollution and digestive cancers in China. Review of Economics and Statistics 94, 186-201.

104. Sheldon, T.L. \& Sankaran, C. (2017) The impact of Indonesian forest fires on Singaporean pollution and health. American Economic Review 107, 526-29.

105. Zhang, X., Zhang, X. \& Chen, X. (2017) Happiness in the air: How does a dirty sky affect mental health and subjective well-being? Journal of Environmental Economics and Management 85, 81-94.

106. Van Voorst, R. (2014) The right to aid: perceptions and practices of justice in a flood-hazard context in Jakarta, Indonesia. The Asia Pacific Journal of Anthropology 15, 339-356.

107. Güneralp, B., Güneralp, I. \& Liu, Y. (2015) Changing global patterns of urban exposure to flood and drought hazards. Global Environmental Change 31, 217-225.

108. Ministry of Environment and Forestry Indonesia (MEF) (2010) Peta Kawasan Hutan. Jakarta, Indonesia.

109. Jarvis, A., Reuter, H.I., Nelson, A. \& Guevara, E. (2008) Hole-filled SRTM for the Globe Version 4.

110. Geospatial Information Agency (BIG) (2016) Peta Propinsi Kalimantan Barat, Kalimantan Selatan, Kalimantan Tengah, Kalimantan Timur, dan Kalimantan Utara. Jakarta, Indonesia.

111. Fick, S.E. \& Hijmans, R.J. (2017) WorldClim 2: new 1-km spatial resolution climate surfaces for global land areas. International Journal of Climatology 37, 4302-4315.

112. Ministry of Environment and Forestry Indonesia (MEF) (2017) Peta Kesatuan Hidrologi Gambut. Jakarta. 